\author{
Universidade de São Paulo \\ Escola de Engenharia de São Carlos \\ Departamento de Engenharia Elétrica
}

\title{
RECONFIGURAÇÃO ÓTIMA DE SISTEMAS DE DISTRIBUIÇÃO DE ENERGIA ELÉTRICA BASEADO NO COMPORTAMENTO DE COLÔNIAS DE FORMIGAS
}

\author{
Fernando Silva Pereira
}

Tese apresentada à Escola de Engenharia de São Carlos da Universidade de São Paulo, como parte dos requisitos para obtenção do título de Doutor em Engenharia Elétrica.

Área de concentração: Sistemas elétricos de potência

Orientador: Prof. Dr. Geraldo Roberto Martins da Costa

São Carlos

2010 
Candidato(a): Engenheiro FERNANDO SILVA PEREIRA.

Tese defendida e julgada em 26/02/2010 perante a Comissão Julgadora:

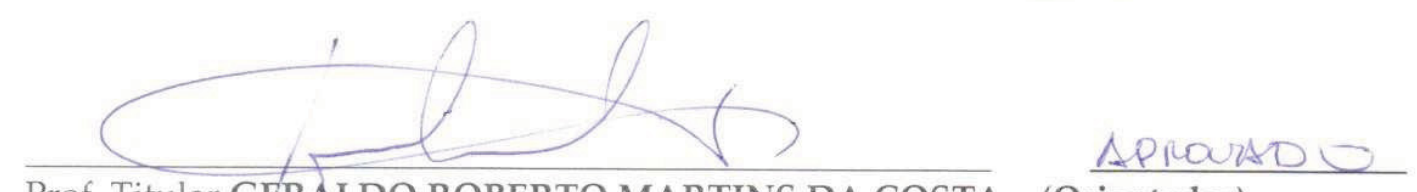

Prof. Titular GERALDO ROBERTO MARTINS DA COSTA - (Orientador)

(Escola de Engemharia de São Carlos/USP)

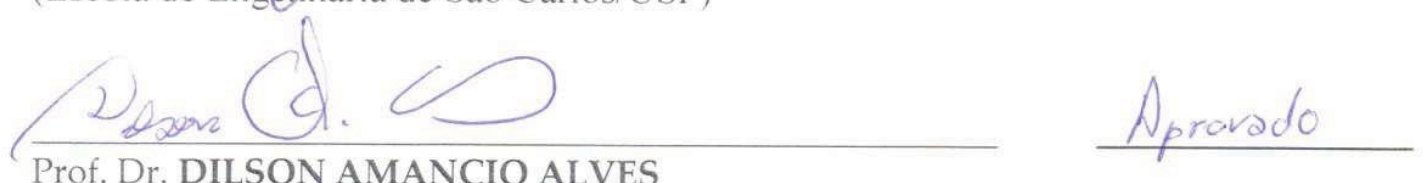

(Universidade Estadual Paulista "Julio de Mesquita Filho"/UNESP/Campus de Ilha Solteira)

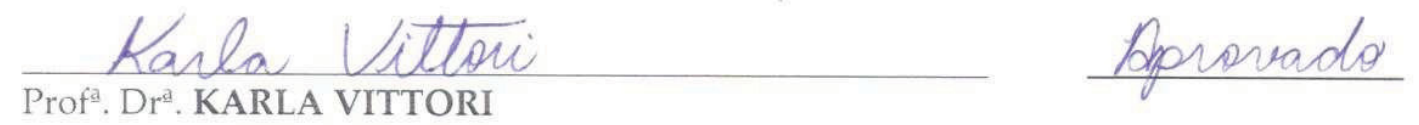

(Faculdade de Tecnologia SENAI CIMATEC)

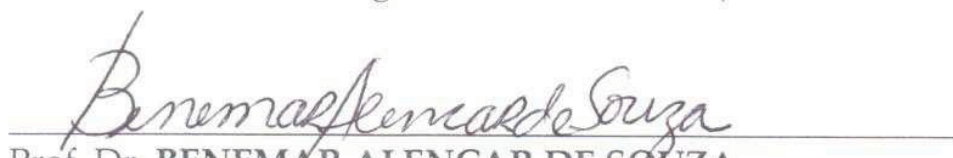

Aprovado

Prof. Dr. BENEMAR ALENCAR DE SOUZA

(Universidade Federal de Campina Grande/UFCG)

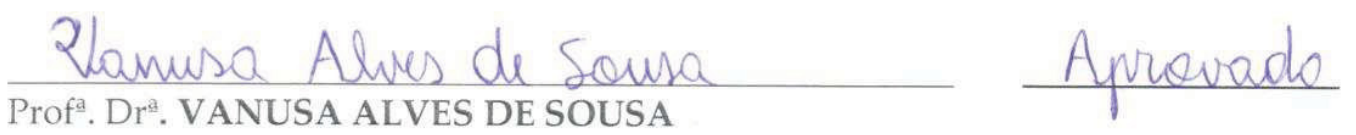

(Universidade Federal de São Carlos/UFSCar)

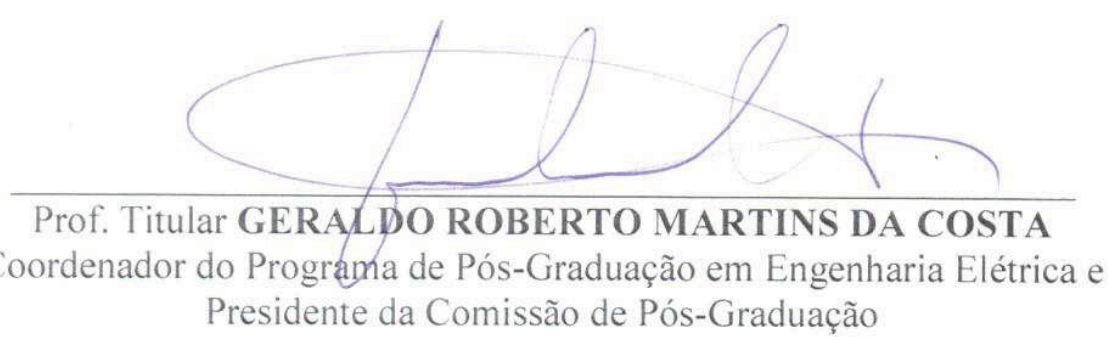


À minha família. 


\section{AGRADECIMENTOS}

Ao professor Dr. Geraldo Roberto Martins da Costa, por todo apoio e orientação no desenvolvimento deste trabalho.

Aos meus pais Braz e Severina, e meus irmãos André, Lívia, Marcelo e Natália por existirem.

Aos amigos do LASEE, Cristiane, Vanusa, Guilherme, Aline, Scheila e Eduardo pelo companheirismo e convívio nesses anos de doutorado.

À Karla, pela ajuda e sugestões desde o início deste trabalho.

A todos os amigos que fiz durante este período que estive na EESC.

Às melhores funcionárias do Departamento de Engenharia Elétrica, Jussara e Marisa.

À CNPq - Conselho Nacional de Desenvolvimento Científico e Tecnológico pela bolsa de estudo concedida. 
"Eficiência é fazer as coisas de maneira correta; eficácia são as coisas certas. $O$ resultado depende de fazer certo as coisas certas."

Peter Ferdinand Drucker 


\section{RESUMO}

PEREIRA, F. S. Reconfiguração ótima de sistemas de distribuição de energia elétrica baseado no comportamento de colônias de formigas. 2010. $105 \mathrm{f}$. Tese (Doutorado) Escola de Engenharia de São Carlos, Universidade de São Paulo, São Carlos, 2010.

O objetivo deste trabalho é apresentar uma nova abordagem para obtenção de configurações para sistemas de distribuição de energia elétrica com o intuito de minimizar o valor de perdas ativas sem violar as restrições operacionais. Para isso, considera-se que os sistemas de distribuição estão operando em regime permanente e que suas fases estão equilibradas e simétricas, podendo o sistema ser representado por um diagrama unifilar. A reconfiguração é feita de forma a redistribuir os fluxos de corrente nas linhas, transferindo cargas entre os alimentadores e melhorando o perfil de tensão ao longo do sistema. O problema de reconfiguração do sistema pode ser formulado como um problema de programação não-linear inteiro misto. Devido à explosão combinatorial inerente a este tipo de problema, a resolução do mesmo por técnicas de otimização clássicas torna-se pouco atraente, dando espaço para técnicas heurísticas e metaheurísticas. Essas outras, mesmo não garantindo o ótimo global, são capazes de encontrar boas soluções em um espaço de tempo relativamente curto. Para a resolução do problema de reconfiguração, utilizou-se uma nova metodologia baseada no comportamento de colônias de formigas em busca de alimento na natureza. Nesta, formigas artificiais (agentes) exploram o meio ambiente (sistema de distribuição) e trocam informações para tentar encontrar a topologia que apresente os menores valores de perdas ativas. Para o cálculo das perdas, este trabalho também apresenta uma nova abordagem para resolução do problema de fluxo de potência (FP) em sistemas de distribuição radial. O fluxo de potência é uma ferramenta básica utilizada pelos centros de controle para determinar os estados e condições operacionais desses sistemas de potência. Basicamente, as metodologias empregadas para o cálculo do fluxo de potência são baseadas nos métodos clássicos de Newton ou Gauss. Mas em sistemas de distribuição de energia, devido a particularidades inerentes a estes, como a alta relação entre resistência e reatância das linhas $(r / x)$ e a operação radial, estes métodos apresentam problemas de convergência e se tornam ineficientes na maioria das vezes. A abordagem consiste na associação dos métodos da função penalidade e 
de Newton. O mal-condicionamento da matriz Jacobiana de Newton é resolvido pela associação com o método da função penalidade. São apresentados testes realizados em sistemas de 5 barras, 16 barras, 33 barras, 69 barras e 136 barras para avaliar a potencialidade das técnicas propostas. Os resultados são considerados bons ou muito bons quando comparado com as técnicas existentes atualmente.

Palavras chaves: Algoritmo de colônias de formigas. Fluxo de potência ótimo. Metaheurística. Minimização de perdas. Sistemas de distribuição de energia elétrica. Reconfiguração. 


\section{ABSTRACT}

PEREIRA, F. S. Optimal reconfiguration of the electric power distribution systems using a modified ant colony system algorithm. 2009. $105 \mathrm{f}$. Tese (Doutorado) - Escola de Engenharia de São Carlos, Universidade de São Paulo, São Carlos, 2009.

The objective of this work is to present a novel methodology for obtaining new configurations of the distribution system in order to minimize the active power losses without violating operational constraints. For this, it is considered that any distribution system is operating in a steady state and that it is balanced, therefore it can be represented by a one-line diagram. The reconfiguration is done in order to redistribute de current flows on the distribution power lines, transferring loads among the feeders and improving the voltage profile along the system. Such problem can be formulated as a mixed integer nonlinear programming problem. Due to its inherent combinatorial characteristic and since its solution by classic optimization techniques is not appealing, heuristic and metaheuristic techniques are thus better suited for its solution. Although these latter do not guarantee a global optimum, they are able to find good solutions in a relatively short time. The solution of the reconfiguration problem in this approach makes use of a novel methodology based on ant colony behavior, when these search for victuals in nature. In this technique, the artificial ants (agents) explore the environment (distribution system) and exchange information among them in order to find the topology that provides the smallest active losses. For the active losses calculation, this work also presents a novel approach for the solution of the power flow problem for radial distribution systems. The solution of the power flow problem is used by system operators in order to determine the state and operational conditions of power systems. Basically, the most common techniques used in the power flow solution are based on either Newton's or Gauss' approaches. However, due to particular characteristics of distribution systems such as the high ratio of $r / x$ and the radial topology, these methods present convergence problems and are not efficient in most of the cases. Thus, this novel technique consists in associating Newton's and the penalty function approaches. The matter of the ill-conditioned Jacobian matrix in Newton's method is overcome with the penalty function method. Some tests performed in different systems are then presented in order to assess the effectiveness of both proposed techniques. 
Keywords: Active loss minimization. Ant colony optimization. Electrical distribution systems. Metaheuristic. Optimal power flow. Reconfiguration. 
1 INTRODUÇÃ O

1.1 Reconfiguração de sistemas de distribuição..................................................................... 7

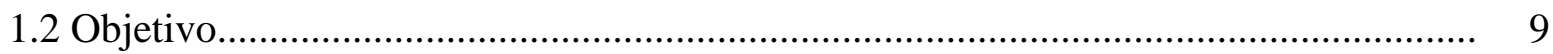

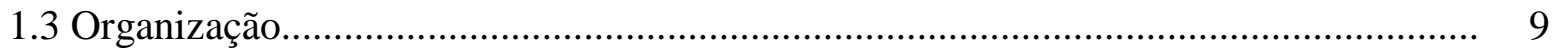

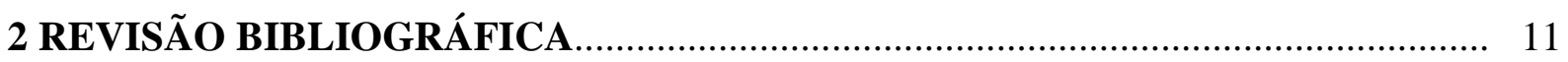

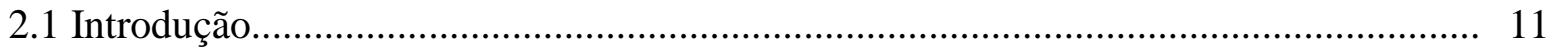

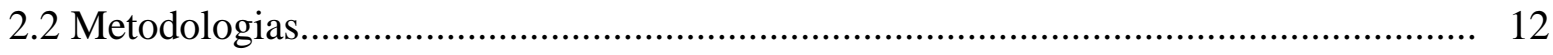

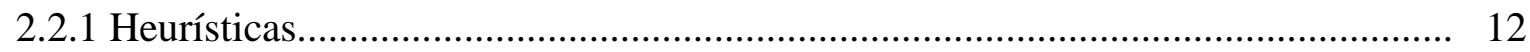

2.2.2 Inteligência Artificial.................................................................................. 15

2.2.2.1 Redes neurais artificiais............................................................................ 15

2.2.2.2 Computação evolucionária............................................................................ 16

2.2.3 Otimização Clássica....................................................................................... 17

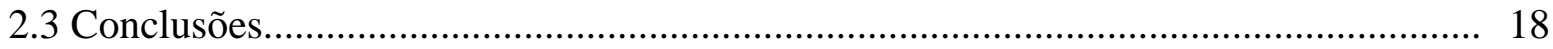

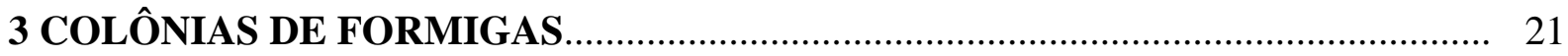

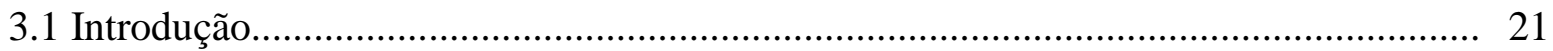

3.2 Otimização baseada no comportamento de colônias de formigas............................... 22

3.3 ACO aplicado ao problema do caixeiro viajante.................................................... 25

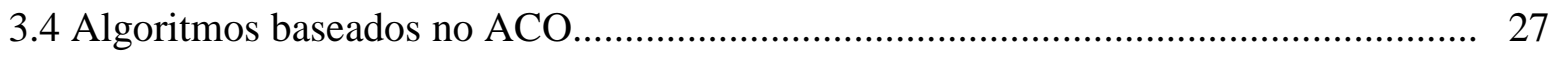

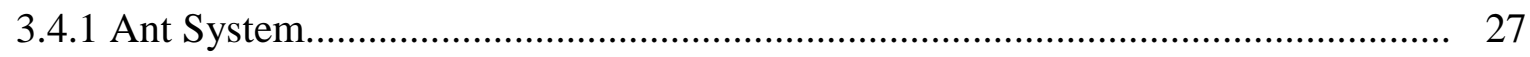

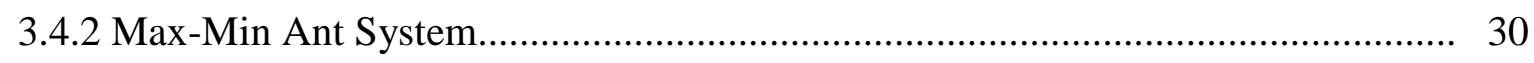

3.4.3 Ant Colony System................................................................................ 31

3.5 ACO aplicado ao problema de reconfiguração..................................................... 32

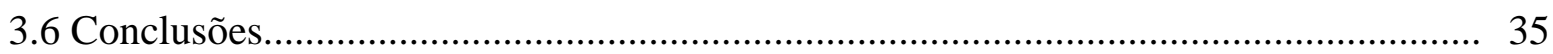

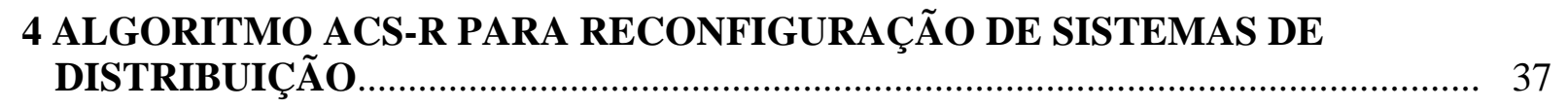

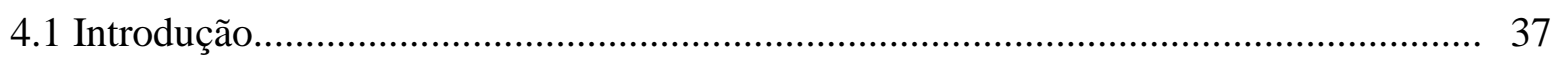

4.2 Reconfiguração de sistemas de distribuição por ACS............................................... 38

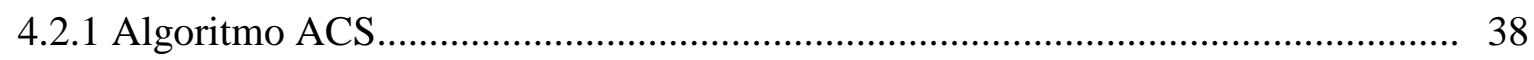

4.2.2 Exemplo 1: Sistema de 5 barras - ACS............................................................. 42

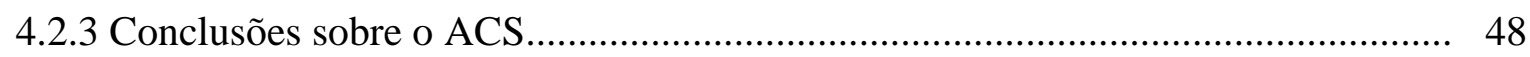




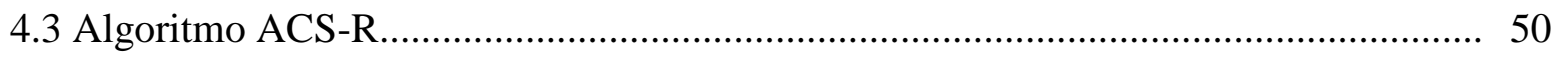

4.3.1 Exemplo 2: Sistema de 5 barras - ACS-R......................................................... 51

4.3.2 Exemplo 3: ACS-R - Variando o número de agentes........................................... 54

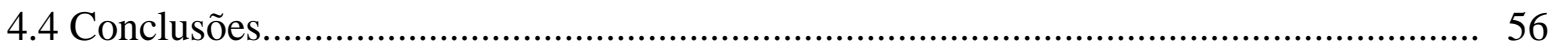

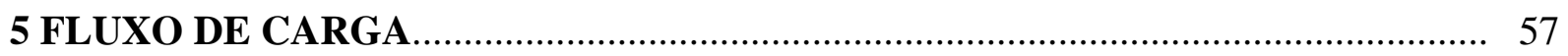

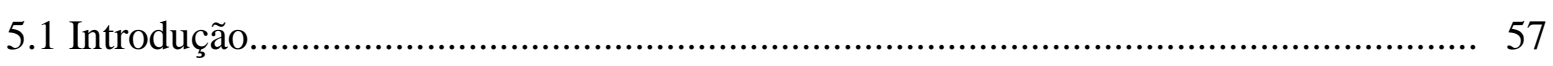

5.2 Método da Função Penalidade-Newton.................................................................. 59

5.3 Método da Função Penalidade-Newton (FPN) aplicado ao fluxo de potência radial... 61

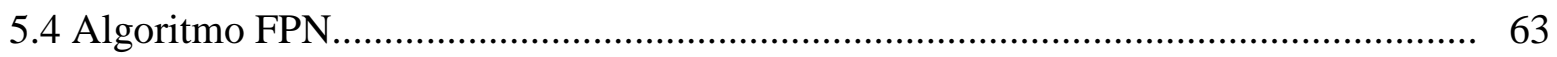

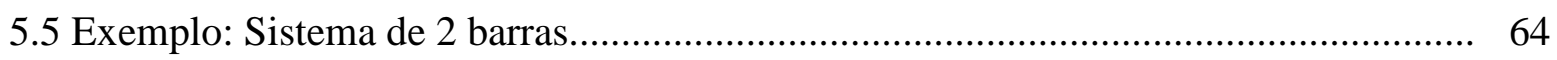

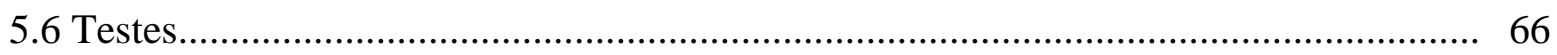

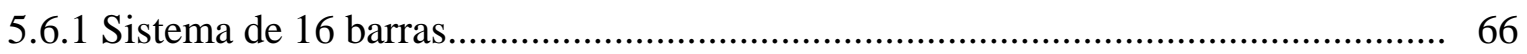

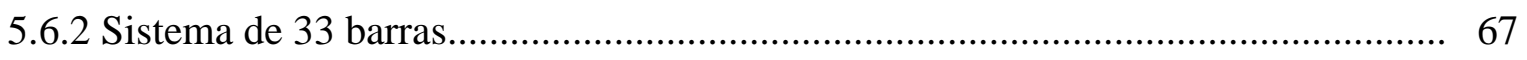

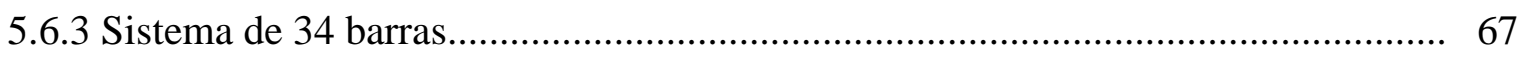

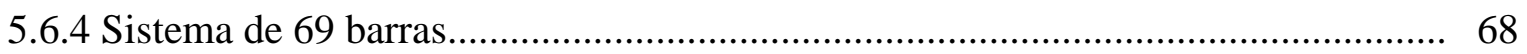

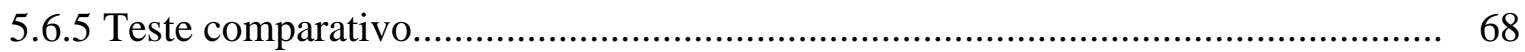

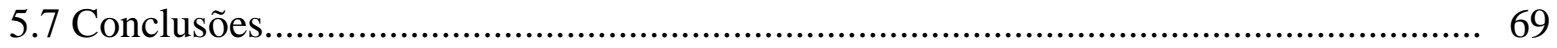

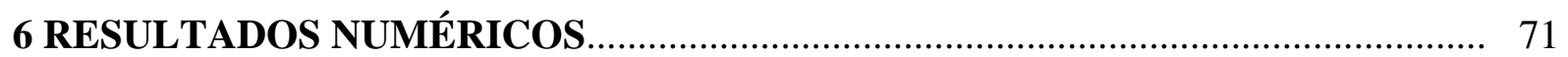

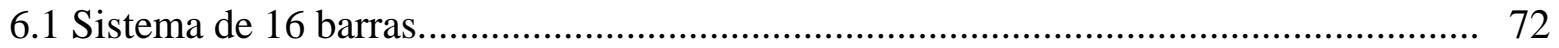

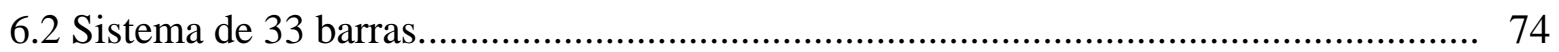

6.2.1 Sistema de 33 barras - Teste 1..................................................................... 75

6.2.2 Sistema de 33 barras - Teste 2 ...................................................................... 76

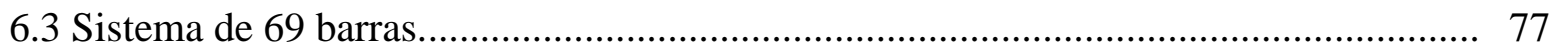

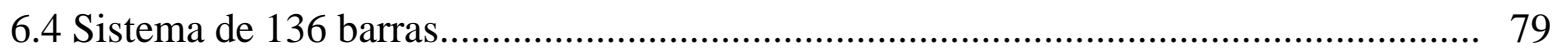

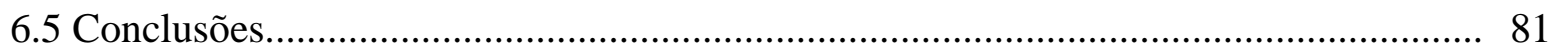

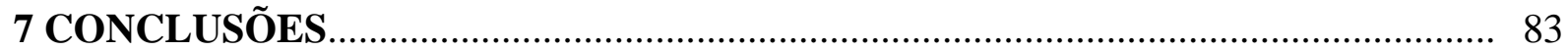

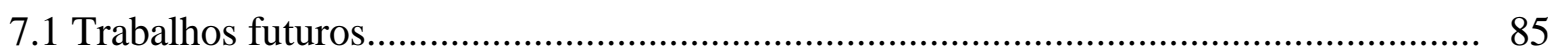

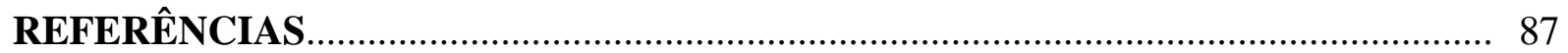

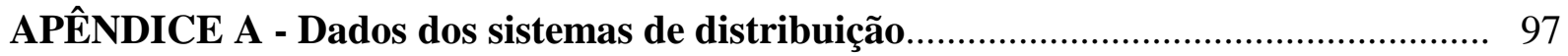




\section{CAPÍTULO 1}

\section{INTRODUÇÃO}

Os sistemas de distribuição de energia elétrica devem operar de forma confiável e econômica, respeitando tanto as restrições de carga como as restrições operacionais (CAVELLUCI, 1998). O primeiro tipo de restrição está relacionado com o suprimento da demanda total dos consumidores alimentados pelo sistema, enquanto que o segundo estabelece os limites de tensão e corrente para garantir que as linhas e os equipamentos instalados operem de forma segura e eficiente.

Uma vez que o sistema está operando em regime permanente, é desejável aumentar sua eficiência e diminuir seu custo operacional. Uma das formas de se obter este resultado é através da operação do sistema no estado de mínimas perdas. Neste estado o sistema de distribuição apresenta um melhor perfil de tensão ao longo dos alimentadores, caracterizada por uma melhor distribuição do fluxo de potência nas linhas, o que influencia diretamente no aumento da vida útil dos equipamentos instalados na rede (CAVELLUCI, 1998).

Algumas técnicas utilizadas na redução das perdas do sistema são as seguintes: (i) o aumento do nível de tensão da rede; (ii) o recondutoramento; (iii) a instalação de capacitores e (iv) a reconfiguração da rede de distribuição primária. Dentre estas técnicas, a reconfiguração é a mais atrativa para a empresa distribuidora de energia elétrica, pois permite a utilização de recursos já existentes no sistema. Assim, o custo de implantação é mínimo, o que evita novos investimentos.

\subsection{RECONFIGURAÇÃO DE SISTEMAS DE DISTRIBUIÇÃO}

A reconfiguração de sistemas de distribuição de energia elétrica consiste na abertura e fechamento de chaves de interconexão, alterando a topologia da rede, o que permite a transferência de cargas de um alimentador fortemente carregado para outro, relativamente menos carregado (CASTRO JR; WATANABE, 1990). O problema consiste em encontrar 
uma configuração que apresente o menor valor de perdas ativas, respeitando sempre as seguintes restrições: (i) níveis de tensão das linhas; (ii) capacidade de fluxo das linhas; (iii) potência nominal dos transformadores e (iv) radialidade do sistema. Os sistemas malhados não são recomendáveis em redes de distribuição de energia, porque exigem uma quantidade maior de dispositivos de segurança do que os sistemas radiais, tornando difícil a proteção e, conseqüentemente, sua operação.

O problema de reconfiguração, geralmente, é um problema combinatorial, não linear, multi-objetivo e sujeito às restrições operacionais e de cargas. O tamanho do problema está intimamente relacionado ao número de chaves envolvidas na busca de uma configuração ótima. Dado um sistema com $C$ chaves, existirão $2^{C}$ possíveis configurações correspondendo às posições aberta e fechada de todas estas chaves. Algumas destas configurações não são permitidas, ou porque levam a um sistema desconectado com várias ilhas ou a sistemas não radiais. Outras ainda não são factíveis, por violarem as restrições operacionais e de carga do problema (DELBEM, 2002).

O presente trabalho apresenta um método para reconfiguração de sistemas de distribuição a partir de um algoritmo de otimização baseado no comportamento de colônias de formigas (Ant Colony Optimization - ACO), proposto por Dorigo e colaboradores (DORIGO; MANIEZZO; COLORNI, 1996; DORIGO; DI CARO, 1999; DORIGO; DI CARO; GAMBARDELLA, 1999; DORIGO; BIRATTARI; STÜTZLE, 2006). No método ACO, um conjunto de formigas artificiais (agentes) cooperam entre si a fim de encontrar soluções “ótimas" para problemas de otimização discretos e complexos. Estes agentes utilizam um mecanismo de comunicação indireta e possuem somente informação local sobre o ambiente. A maioria das características do método ACO advém do comportamento de formigas na natureza em busca de alimento.

Conforme o algoritmo ACO é executado, várias soluções (topologias) são encontradas, podendo essas serem melhores ou piores que soluções previamente encontradas. Para saber se uma topologia é melhor que outra, se faz necessário o cálculo da função objetivo do problema, ou seja, das perdas ativas de cada topologia. Este cálculo é feito através de uma ferramenta matemática denominada fluxo de potência radial (F.P.R.), que calcula de forma iterativa os estados (tensão e ângulos das barras) do sistema de distribuição (MONTICELLI, 1983). Uma vez conhecidos os estados do sistema, é possível então determinar as perdas ativas para o mesmo. Assim, com uma comparação direta, uma topologia que apresente um valor de perdas ativas menor que outra previamente calculada, e que mantém a operacionalidade do sistema é considerada a melhor. 
Como parte desta pesquisa, uma nova abordagem para resolução do problema de fluxo de potência em sistemas de distribuição radiais também é proposta. A abordagem consiste na associação dos métodos da função penalidade (BAZARAA; SHETY, 1979) e de Newton para resolver o fluxo de carga. O mal-condicionamento da matriz Jacobiana de Newton é contornado pela associação com o método da função penalidade.

\subsection{OBJETIVO}

Este trabalho tem por finalidade apresentar uma nova abordagem para a resolução do problema de reconfiguração de sistemas de distribuição de energia elétrica para a redução de perdas ativas através do método ACO. Para isso, foi feita uma adequação deste método ao problema de reconfiguração, modificando a forma como os agentes procuram pela solução ótima. Isto tornou o método mais generalizado e permitiu que o algoritmo trabalhasse em um espaço mais abrangente de soluções factíveis.

\subsection{ORGANIZAÇÃO}

No capítulo 2, encontra-se uma revisão bibliográfica dos principais métodos utilizados na reconfiguração de sistemas de distribuição. O método ACO e alguns dos algoritmos mais conhecidos baseados na sua estrutura, bem como alguns trabalhos que utilizaram algoritmos ACO para resolver o problema de reconfiguração, são apresentados no capítulo 3. No capítulo 4, o método proposto é apresentado, juntamente com um exemplo didático para demonstrar o seu funcionamento. Para o cálculo das perdas, uma breve descrição do fluxo de carga é apresentada no capítulo 5. Testes realizados com o método proposto - que utilizam sistemas conhecidos da literatura - figuram no capítulo 6. Por fim, o capítulo 7 traz as conclusões e propostas de trabalhos futuros. 


\section{CAPÍTULO 2}

\section{REVISÃO BIBLIOGRÁFICA}

\subsection{INTRODUÇÃO}

$\mathrm{Na}$ maior parte do século passado, o planejamento e a operação da geração e da transmissão de energia elétrica apresentaram muitos desafios para os engenheiros e pesquisadores. Com o aumento do número de usinas e os milhares de quilômetros de distância das linhas de transmissão - formando redes interligadas - a operação dos sistemas exigiu o desenvolvimento de novas técnicas de análise e operação. O sistema de distribuição, entretanto, recebeu pouca atenção e continuou a entregar potência com pouca ou nenhuma análise (LORENZETI, 2004).

Nas últimas décadas, porém, as redes de distribuição vêm sendo submetidas a um aumento contínuo de carga, fazendo com que o sistema de distribuição opere próximo de sua capacidade máxima. O sobrecarregamento do sistema pode ocasionar problemas como a diminuição da vida útil de equipamentos e a saída de linhas, devido ao acionamento de dispositivos de segurança, o que acarreta prejuízos financeiros para concessionárias e usuários. É neste contexto que a reconfiguração de sistemas de distribuição, visando à minimização das perdas ativas no sistema, pode ser uma importante ferramenta para diminuir este carregamento e melhorar o perfil de tensão da rede através da melhor distribuição da carga entre os alimentadores (CAVELLUCI, 1998).

Apesar de ter sido proposta pela primeira vez há mais de 30 anos, a reconfiguração de redes de distribuição de energia elétrica para a redução de perdas ativas só recebeu a devida atenção a partir do final da década de 1980. Desde então, várias técnicas têm sido propostas ao longo dos anos. Sua natureza combinatória é responsável pelo crescimento exponencial do custo computacional em função do número de chaves manobráveis existentes no sistema.

Dado um sistema com $C$ chaves, existirão $2^{C}$ possíveis configurações correspondendo às posições aberta e fechada de todas estas chaves. Dessa forma, faz-se necessária uma grande 
quantidade de cálculos, que demandam um tempo relativamente alto para encontrar uma solução factível.

As abordagens para resolver problemas de reconfiguração em sistemas de distribuição de energia elétrica diferem entre si em relação ao tipo de estratégia utilizada na solução do problema (SARFI et. al., 1994). Estas, de forma geral, podem ser dividas em três classes: (i) algoritmos de otimização (WAGNER et. al., 1991; ABU, A., 1996; LAI E MA, 1997); (ii) heurísticas (CIVANLAR et. al., 1988; BARAN; WU, 1989a; JASMON; LEE, 1991; HSU et. al., 1992; KASHEM et. al., 2000) e (iii) técnicas de Inteligência Artificial ou Metaheurísticas (NARA et. al., 1992; NARA 1995; LIN et. al., 2000, MENDONZA et. al., 2006).

Este capítulo apresenta algumas das principais técnicas utilizadas para a reconfiguração de redes de distribuição encontradas na literatura.

\subsection{METODOLOGIAS}

\subsubsection{Heurísticas}

Em problemas de reconfiguração, em que a complexidade da solução é uma função exponencial do número de chaves, o elevado número de variáveis pode levar a uma explosão combinatorial, dificultando a utilização de programação matemática para redes de distribuição de grande porte.

Neste cenário, surgem as técnicas heurísticas - conjuntos de regras e métodos que conduzem à resolução relativamente rápida de problemas, mas não asseguram que esta seja a melhor (SARFI et al., 1994). Com isso, obtêm-se ganhos em termos da eficiência computacional em detrimento da precisão das respostas encontradas.

O primeiro trabalho na área de reconfiguração de redes de distribuição de energia elétrica para a redução de perdas foi apresentado pelos pesquisadores franceses Merlin e Back $^{1}$ (1975 apud BUENO, 2005). Estes utilizaram dois métodos para resolver o problema: um heurístico e um exato. O método heurístico consistia em fechar todas as chaves abertas -

\footnotetext{
${ }^{1}$ MERLIN, A.; BACK, H. Search for a minimal-loss operation spanning tree configuration in a urban power distribution system. Proceedings of $5^{\text {th }}$ Power System Computation Conference - PSCC, Cambridge, UK, 1975, v.1, p. 1-18.
} 
impetrando um sistema malhado - e, em seguida, calcular o fluxo de carga para este sistema. $\mathrm{O}$ arco com menor fluxo era aberto e um novo fluxo de carga era executado. Este processo era repetido até que uma solução radial fosse encontrada e recebeu o nome de "abertura seqüencial de chaves" (BUENO, 2005). Partindo de uma configuração malhada, tinha a vantagem de que a solução encontrada fosse independente do estado de operação inicial do sistema.

Um método heurístico conhecido como "troca de ramos" (branch-exchange) foi proposto em 1988 (CIVANLAR et al., 1988), o qual iniciava a partir de uma configuração radial do sistema de distribuição. Esta configuração inicial era alterada através do fechamento de uma chave e a abertura de outra, de forma a manter a estrutura radial do sistema. Analisando as tensões terminais da chave escolhida para ser fechada, é possível estimar a variação da perda total do sistema devido à transferência de carga de um circuito para outro. Esta análise foi utilizada para evitar um número excessivo de operações de abertura e fechamento de chaves. Para demonstrar o funcionamento do método, os autores o aplicaram a dois sistemas fictícios: um sistema de 12 barras e outro de 16 barras. Este último ficou muito conhecido na literatura especializada, sendo utilizado por muitos outros autores nos anos seguintes. Apesar de encontrar a resposta, considerada pelos autores como a que apresentou o menor valor de perdas, o resultado obtido pelos autores para o sistema de 16 barras não representava a solução ótima global (GOMES et al., 2005).

Em 1989, Shirmohammadi e Hong (1989) modificaram o método heurístico de Merlin e Back (1975) incluindo na formulação do problema, os limites de tensão nos barramentos e de corrente nas linhas. Outra modificação foi em relação ao fluxo de carga, o qual considerava as energias reativas, o que não acontecia anteriormente. No mesmo ano, Baran e Wu (1989a) aperfeiçoaram o método de Cinvalar et al. (1988), propondo uma heurística mais elaborada e novas aproximações para o cálculo do fluxo de carga para redes radiais. Os autores utilizaram um sistema de 33 barras que, assim como o sistema de 16 barras de Civanlar et al. (1988), ficou muito conhecido e foi utilizado por muitos outros autores em diversas metodologias para reconfiguração. O resultado obtido pelos autores, apesar de ser considerado bom, não representava a melhor solução possível para o sistema (GOMES et al., 2005).

Borozan et al. (1995) apresentaram um método baseado no modelo de Merlin e Back (1975). Os autores propuseram um fluxo de carga específico para sistemas fracamente malhados, o que aumenta a eficiência do método em termos de tempo de processamento, 
sendo mais rápidos quando comparados aos do método apresentado por Shirmohammadi e Hong (1989). Os autores realizaram testes considerando diversos carregamentos para os sistemas de 16 barras de Civanlar et al. (1988), 33 barras de Baran e Wu (1989a) e 69 barras apresentado em Chiang e Jean Jumeau (1990). Os valores das perdas encontrados nos testes foram os mesmos quando comparados com os obtidos por Shirmohammadi e Hong (1989), e menores ou muito próximos quando comparados com Baran e Wu (1989a) e Chiang e Jean Jumeau (1990), respectivamente.

Em 1999, McDermott et al. (1999) apresentaram um método heurístico construtivo para a reconfiguração de redes que, ao contrário do que propunham Merlin e Back (1975), inicia com todas as chaves do sistema abertas e, à medida que o algoritmo avança, estas vão sendo fechadas até que um sistema radial seja encontrado. Uma fórmula aproximada ajuda na escolha das chaves a serem fechadas, verificando o incremento das perdas totais no sistema após o fechamento de cada uma. Após a escolha definitiva das chaves, executa-se um fluxo de carga para verificar o incremento exato das perdas. Testes foram realizados em sistemas como o de 10 barras de Glamocanin (1990), os de 12 barras e 16 barras de Civanlar et al. (1988) e 33 barras de Baran e Wu (1989a). Segundo os autores, em todos os testes, foram encontradas as melhores soluções possíveis.

Os métodos de abertura seqüencial de chaves e de troca de ramos são muito conhecidos na literatura especializada. Vários pesquisadores desenvolveram, a partir deles, diferentes métodos: alguns com pequenas modificações; outros, híbridos, que se associavam a outras abordagens. Como exemplo, Gomes et al. (2005) apresentaram um método para aplicação em grandes sistemas de distribuição que consistia em duas etapas. A primeira delas é feita com todas as chaves manobráveis do sistema inicialmente fechadas. A partir de um critério de abertura baseado no aumento da perda total do sistema, estas chaves são sucessivamente abertas de maneira a eliminar os laços (malhas). A segunda etapa é um refinamento da primeira através da metodologia de troca de ramos. Os autores realizaram três testes com o sistema de 33 barras de Baran e Wu (1989a). Em todos os testes, os resultados foram comparados com um método de força bruta (o qual garante encontrar a melhor topologia para o sistema), com o método de McDermott et al. (1999), com o de Shirmohammadi e Hong (1989) e com o de Goswami e Basu (1992). Os resultados obtidos em todos os testes foram ótimos ou próximos do ótimo global.

No ano seguinte, Salume et al. (2006) aplicaram o mesmo método de Gomes et al. (2005) aos sistemas de 33 barras de Baran e Wu (1989a) e de 69 barras de Chiang e Jean 
Jumeau (1990). Os sistemas foram considerados como sendo trifásicos e desequilibrados e em todos os testes, segundo os autores, os resultados obtidos foram ótimos.

\subsubsection{Inteligência Artificial}

A Inteligência Artificial ou metaheurística busca, através de técnicas inspiradas na natureza, o desenvolvimento de sistemas inteligentes que imitem aspectos do comportamento dos seres vivos (PACHECO, 1999), tais como: aprendizado, percepção, raciocínio (redes neurais artificiais - KIM et al., 1993; HAYASHI et al., 1996; SALAZAR et al., 2006), evolução e adaptação (computação evolucionária - NARA et al., 1992; QUEIROZ et al., 2006; AMASIFEN, 2003). Estes métodos são apresentados a seguir.

\subsubsection{Redes Neurais Artificiais}

Em 1993, foi apresentado um método baseado em técnicas de Redes Neurais Artificiais do tipo Perceptron Multicamadas (KIM et al., 1993) com o objetivo de propor uma solução para o problema de reconfiguração. Para treinar a rede neural, os autores utilizaram um conjunto de boas configurações para diferentes valores de carregamento e, com o intuito de diminuir o esforço computacional, a rede de distribuição foi dividida em zonas de carga. Isto exigiu a utilização de dois grupos de redes neurais: o primeiro identifica o perfil de carga; o segundo gera as topologias baseado nas saídas obtidas pelo anterior. Para os testes, foi utilizado o sistema de 16 barras de Civanlar et al. (1988) e os resultados obtidos em cada perfil de carga foram considerados muito próximos dos ótimos.

Em 1996, Hayashi et al. (1996) apresentaram um método baseado em redes neurais do tipo Hopfield, com a capacidade de evitar mínimos locais. A este foram associados conhecimentos técnicos sobre a rede para que, mesmo após alguma falta, uma topologia gerada pela rede neural continuasse segura e podendo operar dentro dos limites. Testes foram realizados em dois sistemas de distribuição do Japão, e apesar de os autores não informarem os dados destes sistemas, segundos os mesmos, o método foi capaz de encontrar soluções ótimas para vários cenários de operações. 
Assim como Kim et al. (1993), Salazar et al. (2006) apresentaram uma rede neural do tipo Perceptron Multicamadas para resolver o problema de reconfiguração. Para reduzir o tamanho do conjunto de teste, foi utilizada uma técnica matemática de classificação de padrões capaz de identificar as melhores topologias para o treinamento da rede, o que possibilitou determinar boas topologias com baixo custo computacional, utilizando uma única rede neural. Testes foram realizados em dois sistemas de distribuição, sendo um o de 14 barras do IEEE e o outro de 136 barras do sistema de distribuição da cidade de Três Lagoas MS e, segundo os autores, apresentaram desempenho igual, ou melhor, a outros métodos que utilizam redes neurais.

\subsubsection{Computação Evolucionária}

Esta área de pesquisa é inspirada no princípio Darwiniano da evolução das espécies. Seguindo esta linha, para o problema de reconfiguração de redes de distribuição, são utilizados os algoritmos genéticos (AG) (NARA et al., 1992, QUEIROZ et al., 2006) e os algoritmos evolutivos (AE) (AMASIFEN, 2003).

O AG baseia-se nos processos genéticos dos organismos biológicos, em que seus cromossomos são representados por cadeias de bits e caracteres. Estes cromossomos, ao longo de várias gerações, vão sofrendo processos de cruzamento e mutação, também chamados operadores genéticos, na forma similar aos problemas naturais, e evoluem de acordo com os princípios de seleção natural e sobrevivência dos mais aptos.

Em 1992, surgiu o primeiro método baseado em algoritmos genéticos (NARA et al., 1992) aplicado na reconfiguração de redes de distribuição. Os autores codificaram os genes (indivíduos) através de uma representação binária baseada nos estados das chaves do sistema (o número 1 indica a chave fechada e o número zero indica a chave aberta). Testes foram realizados em dois sistemas de distribuição de médio porte (106 chaves manobráveis) e grande porte (1692 chaves manobráveis) e foram feitas comparações com a metodologia de Aoki et al. (1990), onde os resultados mostraram que o método baseado em algoritmos genéticos obteve o melhor desempenho. Porém, este método tinha como limitação a geração de indivíduos inválidos quando seus pais eram submetidos aos operadores genéticos e, conseqüentemente, tinham que ser descartados. 
Para contornar esta limitação, Queiroz et al. (2006) adotaram uma representação dos indivíduos através de cadeias de grafos que não permitem esta infactibilidade durante o processo de geração. Também adotaram uma taxa de mutação variável ao longo da execução do método, o que melhora sua convergência. Testes foram realizados em 5 sistemas de distribuição que equivalem a redes de cidades brasileiras [os dados sobre estes sistemas não foram mencionados]. O método proposto foi comparado com outros dois algoritmos genéticos (Algoritmo Genético Simples - AGS e Algoritmo Genético Híbrido - AGH), sendo que seu desempenho foi melhor em todos os testes.

O AE tem como conceito básico de simulação a evolução dos indivíduos mais adaptados ao ambiente (problema). Amasifen et al. (2004) apresentaram um método baseado em algoritmo evolutivo para resolver o problema de reconfiguração de redes sob diferentes condições de carregamento. Os indivíduos são simbolizados por vetores decimais que representam somente as chaves abertas necessárias para manter o sistema radial. Para reduzir o esforço computacional na geração da população inicial e melhorar o desempenho do processo, o autor desenvolveu uma metodologia capaz de identificar redes radiais. Foi utilizado um sistema de distribuição real de 215 barras considerando que todas as linhas têm uma chave de manobra. Ao todo, foram realizadas cinco simulações para quatro situações diferentes, sendo que o método foi capaz de encontrar boas soluções em todos os casos.

\subsubsection{Otimização Clássica}

Técnicas de programação matemática não são aconselhadas para resolver problemas de reconfiguração devido à explosão combinatorial a que estes estão sujeitos. Assim, existem poucos exemplos na literatura que utilizam estas abordagens (SARFI et al., 1994).

Merlin e Back (1975 apud SARFI et al., 1994) apresentaram um método viável apenas em redes de pequeno porte, que utilizava a técnica de programação inteira "branch-andbound" para encontrar a configuração ótima de mínimas perdas.

Glamocanin (1990) concebeu o problema de reconfiguração como um problema de transporte com custos quadráticos. O método proposto necessitou de uma topologia radial inicial, obtida através da linearização das perdas, a partir da qual se utilizou o método Simplex para problemas quadráticos, a fim de melhorar a solução. Segundo o autor, o método foi capaz de encontrar a solução ótima do problema para um sistema de teste de 10 barras. 
Abur (1996a, 1996b) apresentou um método baseado em um algoritmo de programação linear modificado, capaz de encontrar a melhor topologia para um sistema de pequeno porte. Essa modificação garantiu que a topologia encontrada no final da execução fosse radial. A função objetivo do problema era minimizar o valor da soma de todos os fluxos nas linhas ativas, levando em consideração somente as restrições de capacidade das linhas e não as de tensão nas barras. Testes foram realizados em sistemas de 16 barras (Abur, 1996a) e 10 barras (Abur, 1996b). Para os mesmos, o autor considerou duas situações: em uma impôs limites de corrente nas linhas e na outra não. O método foi capaz de encontrar a melhor solução, segundo o autor, para ambos os casos.

\subsection{CONCLUSÕES}

Neste capítulo, foram apresentadas algumas metodologias aplicadas na solução do problema de reconfiguração de redes de distribuição para a minimização de perdas, que diferem entre si em relação ao tipo de estratégia utilizada.

Alguns métodos, em sua formulação, consideram o sistema equilibrado e apenas aplicam a reconfiguração para diminuir as perdas para um determinado perfil de carga. Outros consideram demandas variáveis ou sistemas desequilibrados, fazendo uso da representação trifásica do sistema e de curvas de carga ao longo do período estudado. Por falta de informações detalhadas a respeito de testes e resultados (tempo de processamento, hardware, interface de desenvolvimento, sistema operacional, etc.) a comparação direta entre metodologias diferentes torna-se difícil de ser realizada.

A formulação matemática do problema e o modo como os métodos obtém novas topologias podem gerar espaços de busca diferentes de um método para outro, afetando suas respostas. Um determinado método, adequado a um sistema de distribuição, pode não ter o mesmo desempenho em outros sistemas. E quando aplicados ao mesmo problema, métodos diferentes têm grandes chances de encontrarem respostas diferentes, ainda que sejam próximas.

Novas técnicas vêm surgindo todos os anos, atestando a dificuldade de resolver o problema de reconfiguração, e de forma geral, podem ser dividas em três classes: (i) algoritmos de otimização; (ii) heurísticas e (iii) técnicas de inteligência Artificial. 
Com o objetivo de reduzir o espaço de busca e o tempo de processamento, têm sido utilizadas, gradativamente, técnicas heurísticas e de Inteligência Artificial que apresentam um esforço computacional relativamente pequeno quando comparado aos métodos de otimização clássica, e proporcionam resultados satisfatórios quando aplicados em sistemas de grande porte, mesmo que não garantam a solução ótima do sistema.

Como contribuição a este grande conjunto de métodos, propõe-se uma metodologia metaheurística baseada em comportamento de colônias de formigas (Ant Colony Optimization - ACO) para a resolução do problema de reconfiguração do sistema com o intuito de minimizar as perdas ativas.

No capítulo a seguir, são descritos os princípios do método de otimização baseado em colônias de formigas e de alguns algoritmos baseados na sua estrutura. Apresentam-se também alguns trabalhos que utilizaram o ACO para a reconfiguração de redes de distribuição. 


\section{CAPÍTULO 3}

\section{COLÔNIA DE FORMIGAS}

\subsection{INTRODUÇÃO}

Durante anos, os insetos que vivem em colônias têm fascinado pesquisadores ao redor do mundo. Como a colônia se organiza? Como se dá a comunicação entre os indivíduos? Como estes indivíduos conseguem executar tarefas complexas? Como é feita a divisão de tarefas dentro da colônia? Estas são questões que ainda são investigadas. A colônia parece ser governada por uma inteligência muito maior do que a esperada para os simples indivíduos e cada um deles parece ter consciência de suas obrigações dentro da colônia (BONABEAU; DORIGO; THERAULAZ, 1999).

Com o avanço nas pesquisas, o comportamento social destes insetos acabou por inspirar o que foi chamado de inteligência de enxame (Swarm Intelligence), uma abordagem relativamente nova para resolver problemas de otimização discretos e complexos. As formigas, em particular, inspiraram alguns métodos e técnicas, dentre os quais o mais estudado e de mais sucesso é o baseado no comportamento de colônias de formigas (Ant Colony Optimization - ACO) (BONABEAU; DORIGO; THERAULAZ, 1999; DORIGO; DI CARO, 1999; DORIGO; DI CARO; GAMBARDELLA, 1999; DORIGO; STÜTZLE, 2004; DORIGO; BIRATTARI; STÜTZLE, 2006).

Neste capítulo, é realizada uma breve introdução ao ACO e a alguns algoritmos de otimização baseados na sua estrutura. São apresentadas também algumas pesquisas que utilizaram o ACO para a reconfiguração de redes de distribuição. 


\subsection{OTIMIZAÇÃO BASEAdA NO COMPORTAMENTO DE COLÔNIAS DE FORMIGAS}

Quando uma formiga se movimenta por um ambiente e descobre uma fonte de alimento, ela deposita uma substância no solo denominada feromônio (HÖLLDOBLER; WILSON, 1990). Esta substância atrai outras formigas do ninho para a coleta do alimento encontrado, as quais seguem a trilha construída e reforçam o feromônio sobre ela. Se existirem várias trilhas de feromônio conduzindo a uma dada fonte, as formigas selecionam a trilha a ser percorrida de forma probabilística, baseadas na concentração de feromônio sobre os caminhos existentes. A figura 3.1 (DORIGO; GAMBARDELLA, 1997) representa a movimentação de formigas sob caminhos diferentes ao longo do tempo. Na figura, nota-se como a quantidade de feromônio (representada por linhas tracejadas) sobre os caminhos aumenta conforme as formigas se deslocam (desde (a) até (d)).

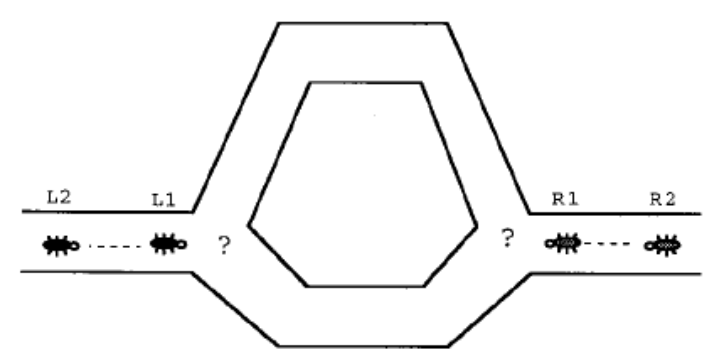

(a)

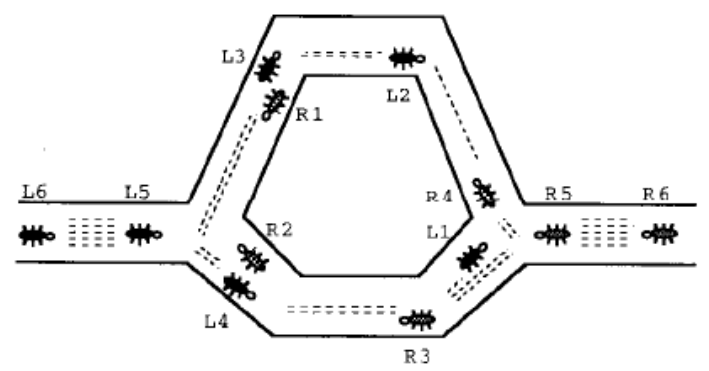

(c)

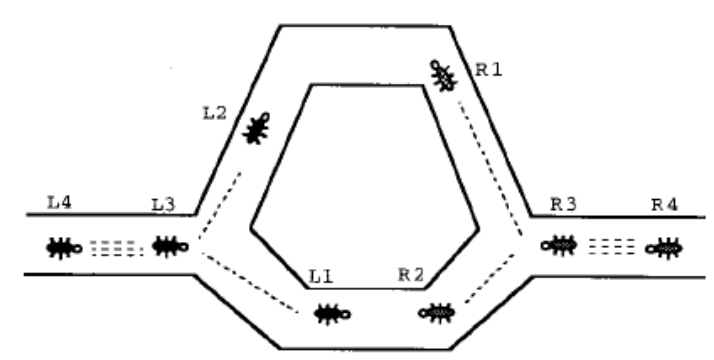

(b)

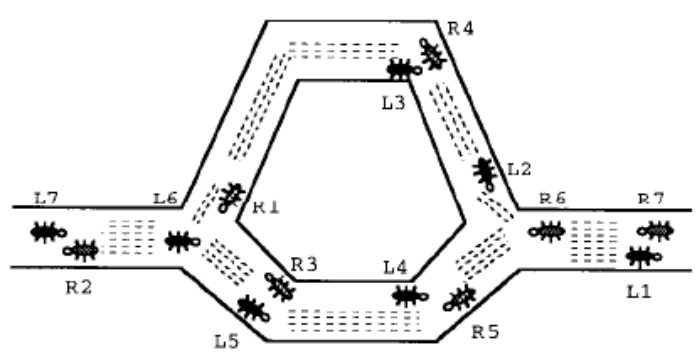

(d)

Figura 3.1 - Comportamento de formigas sob caminhos de comprimentos diferentes.

As formigas que percorrem a menor trilha até a fonte de alimento retornam ao ninho antes daquelas que escolheram trilhas maiores. Portanto, a trilha menor possuirá uma concentração maior de feromônio que as demais e, consequientemente, atrairá um número maior de formigas. Deste modo, as formigas são capazes de selecionar o menor caminho para 
uma determinada fonte de alimento de forma cooperativa. Foi o estudo deste comportamento que inspirou o desenvolvimento do método ACO (DORIGO; BIRATTARI; STÜTZLE, 2006).

O ACO foi proposto no início da década de 1990 por DORIGO ${ }^{1}$ (1992 apud DORIGO; MANIEZZO; COLORNI, 1996; GAMBARDELLA; DORIGO, 1996; DORIGO; GAMBARDELLA, 1997; BONABEAU; DORIGO; THERAULAZ, 1999; DORIGO; DI CARO, 1999; DORIGO; DI CARO; GAMBARDELLA, 1999; BLUM; DORIGO, 2004; DORIGO; BIRATTARI; STÜTZLE, 2006) e, desde então, tem sido aplicado a diferentes problemas de otimização (VITTORI, 2005):

[...] algoritmos baseados em formigas foram inicialmente aplicados ao problema do caixeiro viajante (DORIGO; GAMBARDELLA, 1997; DORIGO et al., 1991). Resultados encorajadores obtidos na resolução deste problema promoveram a aplicação desses algoritmos a diferentes problemas, como: (i) coloração de grafos (graph coloring) (WAGNER et al., 2000); (ii) roteamento de veículos (DORIGO et al., 1999); (iii) roteamento em redes de telecomunicações (BONABEAU et al., 1998; DI CARO e DORIGO, 1998; SCHOONDERWOERD et al., 1996, 1997; SIM e SUN, 2003); (iv) data mining (PARPINELLI et al., 2002) e (v) reconstrução filogenética (PERRETTO e LOPES, 2004).

Em sistemas elétricos, pode-se citar algumas de suas aplicações: (i) alocação de capacitores (CHIOU; CHANG; SU, 2004); (ii) alocação de chaves de manobras (TENG; LIU, 2002; BARROS; MELO, 2006); (iii) alocação de unidades geradoras (SISHAJ; PADHY; ANAND, 2006a, 2006b); (iv) despacho econômico (HOU et al., 2002; SUM-IM, 2004); (v) fluxo de carga (VLACHOGIANNIS; HATZIARGYRIOU; LEE, 2005); (vi) planejamento de circuitos primários (GOMEZ et al., 2004; IPPOLITO; SANSEVERINO; VUINOVICH, 2004) e (vii) reconfiguração (CARPANETO; CHICCO, 2004; DANIEL; KHAN; RAVICHANDRAN, 2005; SU; CHANG; CHIOU, 2005; KHOA; BINH, 2006; GHORBANI; HOSSEINIAN; VAHIDI, 2008, ZHIJIAN HU et al. 2008; CHANG, 2008; BENEMAR et al. 2009).

No método ACO, formigas artificiais (chamadas de agentes) cooperam entre si para encontrar soluções "ótimas" para problemas de otimização discretos e complexos (DORIGO; BIRATTARI; STÜTZLE, 2006).

\footnotetext{
${ }^{1}$ DORIGO, M. Optimization, learning and natural algorithms (in Italian), Ph.D. dissertation, DEI, Politecnico di Milano, Italy, 1992.
} 
As características das formigas no meio ambiente incorporadas aos agentes do método ACO compreendem: i) a comunicação indireta entre os indivíduos sobre as ações realizadas; ii) o acesso à informação local e iii) a decisão probabilística sobre a ação a ser efetuada. No método ACO, o problema é representado por um conjunto de pontos (chamados de estados) por onde os agentes se movimentam (VITTORI, 2005).

Alguns mecanismos extras ao comportamento de colônias de formigas na natureza também foram anexados ao ACO - como a consideração de estados discretos do meio e de diferentes momentos de depósito de feromônio - para a obtenção de respostas satisfatórias. As principais características do ACO são (BONABEAU; DORIGO; THERAULAZ, 1999):

a) colônia de agentes cooperativos: os agentes cooperam entre si para a obtenção de uma boa solução para o problema, através do compartilhamento da informação por eles coletada em seu deslocamento sobre o meio;

b) movimentos locais: os agentes se movem entre estados adjacentes do ambiente buscando os menores caminhos;

c) trilhas de feromônio: enquanto as formigas reais modificam o meio depositando feromônio sobre ele, os agentes mudam uma informação numérica sobre as condições do ambiente, a qual é armazenada em cada estado visitado;

d) política probabilística: os agentes selecionam suas ações de forma probabilística, baseados na informação local sobre o ambiente;

e) mundo discreto: o movimento dos agentes se caracteriza por transições entre estados discretos;

f) estado interno: os agentes possuem capacidade de memória relacionada com as ações passadas;

g) depósito de feromônio: a quantidade de feromônio depositado pode ocorrer em função da qualidade da solução obtida, e o momento em que este depósito ocorre é dependente do problema;

h) capacidades extras: os agentes podem utilizar outros mecanismos, como otimização local, consideração de ações passadas ou estados futuros.

Para entender o funcionamento do método ACO, a seguir é apresentado o primeiro problema ao qual foi aplicado um algoritmo de formigas.

As características de $a$ à $e$ foram extraídas do comportamento das formigas na natureza e as de $f$ à $h$ foram inseridas para a melhoria do desempenho do método (BONABEAU; DORIGO; THERAULAZ, 1999). 


\subsection{ACO APLICADO AO PROBLEMA DO CAIXEIRO VIAJANTE}

Um aspecto importante no comportamento forrageiro das colônias de formigas na natureza é que, uma vez encontrado o menor caminho entre dois pontos (ninho e fonte de alimento), este é mantido pela colônia, desde que o ambiente não seja modificado. Por esta razão, o problema do caixeiro viajante (Traveling Salesman Problem - TSP) foi a primeira aplicação para um algoritmo baseado no comportamento de formigas (BONABEAU; DORIGO; THERAULAZ, 1999).

No TSP, um conjunto de $C$ cidades é dado e a distância $d$ entre elas é conhecida. O objetivo é encontrar a menor rota que conecta este conjunto de cidades, passando por cada uma delas uma única vez. A figura 3.2 mostra um exemplo de uma solução do TSP para um conjunto qualquer de cidades do estado de São Pauloº ${ }^{2}$

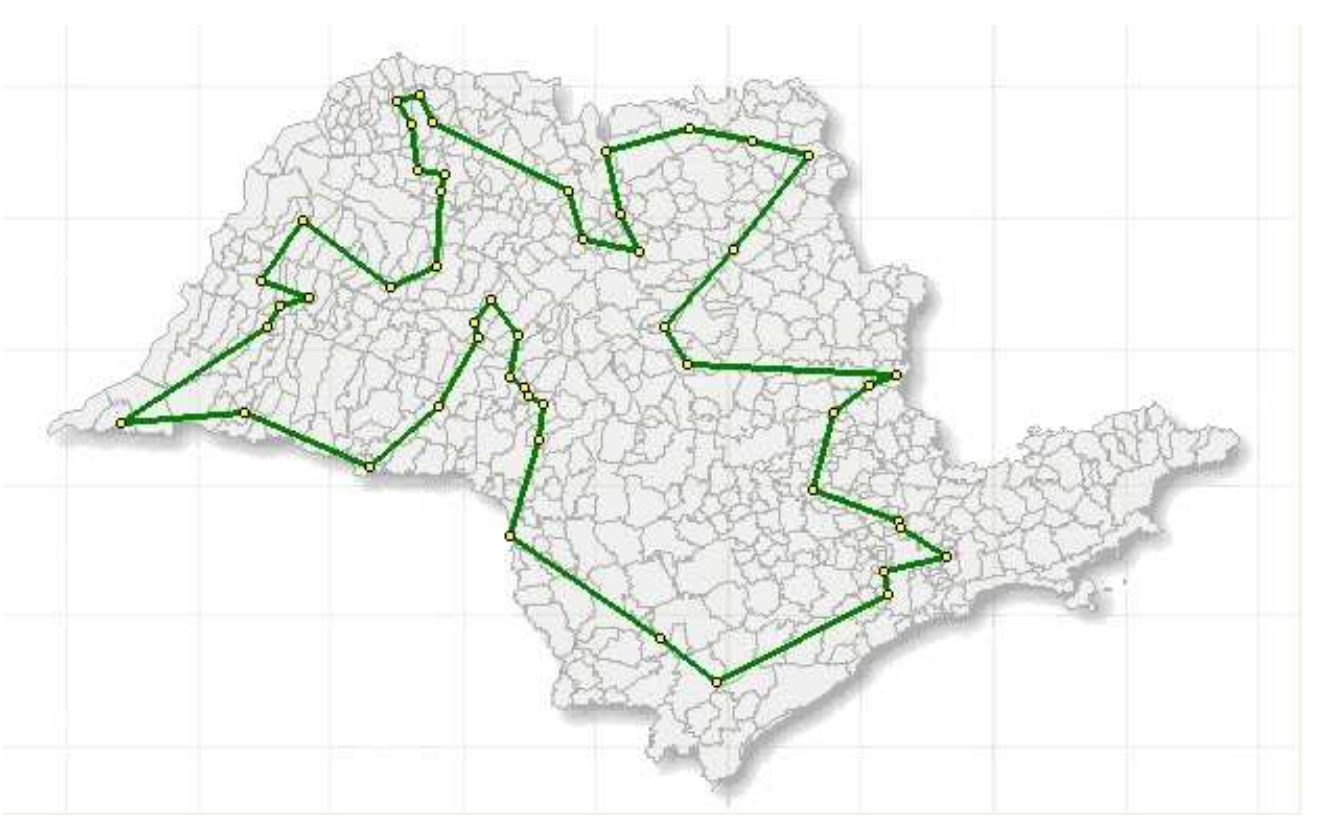

Figura 3.2 - Rota interligando algumas cidades de São Paulo (sem repetição).

Para resolver este problema, o ACO faz uma simulação com um número de agentes se deslocando de uma cidade para outra através dos caminhos que as interligam. A cada

\footnotetext{
2 Miyazawa, F. K. Otimização combinatória. Disponível em: < http://www.ic.unicamp.br/ fkm/problems/combopt.html > Acesso em: 22 set. 2009.
} 
caminho, é associado um valor de feromônio virtual que pode ser lido e modificado pelos agentes. O ACO é um algoritmo iterativo, e a cada iteração, um número $N_{a}$ fixo de agentes é considerado. Assim, cada agente constrói uma rota a partir do seu deslocamento entre as cidades, até que todas sejam visitadas. A este processo é dado o nome de ciclo.

A cada início de ciclo, os agentes são distribuídos aleatoriamente, um a um, sobre as cidades contidas em $C$. A partir de então, cria-se, para cada agente $k$, uma lista individual $L_{k}$ das cidades a serem visitadas. A transição de uma cidade para outra leva em consideração três aspectos (BONABEAU; DORIGO; THERAULAZ, 1999):

a) se uma cidade já foi ou não visitada: conforme o agente move-se de uma cidade para outra, as cidades visitadas são retiradas da sua lista; isto evita que o agente passe por uma cidade mais de uma vez.

b) distância entre cidades: baseado apenas na informação local, o inverso da distância entre as cidades é utilizado como uma heurística para guiar os agentes durante o processo de construção da rota. Esta informação é estática e não sofre mudanças durante a resolução do problema.

c) quantidade de feromônio virtual: conforme os agentes se movimentam de uma cidade para outra, eles modificam a quantidade de feromônio virtual sobre os caminhos que percorrem. Diferente da distância, o feromônio sofre mudanças durante a solução do problema para refletir a experiência adquirida pelos agentes durante o processo de construção da rota.

O primeiro algoritmo baseado no ACO é conhecido como Sistema de Formigas (Ant System - AS) e foi proposto no início da década de 90 (BONABEAU; DORIGO; THERAULAZ, 1999; DORIGO; STÜTZLE, 2004; DORIGO; BIRATTARI; STÜTZLE, 2006). Este algoritmo é descrito na próxima seção.

Ao longo dos anos, vários outros algoritmos baseados no ACO foram propostos, dentre os quais o MAX-MIN Ant System (MMAS) e o Ant Colony System (ACS) merecem destaque, pois são considerados como as variantes do Ant System de maior sucesso (DORIGO; BIRATTARI; STÜTZLE, 2006). A seguir, são apresentadas as principais características destes três algoritmos aplicados ao TSP. 


\subsection{ALGORITMOS BASEADOS NO ACO}

\subsubsection{Ant System}

O Ant System (AS) foi o primeiro algoritmo proposto na literatura. Sua principal característica é a atualização (incremento) do feromônio ao final de cada ciclo somente para os agentes que conseguiram construir uma solução completa, ou seja, uma rota interligando todas as cidades no TSP (DORIGO; BIRATTARI; STÜTZLE, 2006).

$\mathrm{Na}$ construção da rota, a probabilidade de um agente $k$ que se encontra em uma cidade $i$ visitar uma cidade $j$ é dada pela regra de transição a seguir:

$$
P_{i j}^{k}=\left\{\begin{array}{cr}
\frac{\left[\tau_{i j}\right]^{\alpha} \cdot\left[\eta_{i j}\right]^{\beta}}{\sum_{u \in M_{k}}\left[\tau_{i u}\right]^{\alpha} \cdot\left[\eta_{i u}\right]^{\beta}} & \text { se } j \in M_{k} \\
0 & \text { caso contrário }
\end{array}\right.
$$

onde $P_{i j}^{k}$ é a probabilidade do agente $k$ visitar a cidade $j$ a partir da cidade $i$; $\tau_{i j}$ é o feromônio sobre a conexão (ij); $\eta_{i j}$ é o inverso da distância entre as cidades $i$ e $j ; M_{k}$ é o conjunto de cidades vizinhas de $i$ que não foram visitadas pelo agente $k ; \alpha$ e $\beta$ são os pesos atribuídos ao feromônio e ao inverso da distância, respectivamente. Estes pesos indicam a importância que é dada ao feromônio e à distância entre as cidades na escolha dos agentes.

Analisando a regra de transição, verifica-se que, fazendo-se a escolha para o valor de $\alpha=0$, consideram-se apenas as distâncias entre as cidades. Desta forma, quanto mais perto estiver uma cidade da outra, maior a probabilidade de ser escolhida pelo agente. Esta escolha poderia proporcionar soluções de baixa qualidade. Por outro lado, fazendo-se $\beta=0$, leva-se em conta apenas a concentração de feromônio, o que poderia causar uma convergência prematura do método. Em ambos os casos, as rotas encontradas pelos agentes podem não ser ótimas (BONABEAU; DORIGO; THERAULAZ, 1999).

É importante notar que, apesar da equação (3.1) permanecer constante durante todo o processo de execução do AS, o valor da probabilidade $P_{i j}^{k}$ - para dois agentes que se 
encontram na mesma cidade - pode ser diferente, uma vez que a probabilidade é função dos caminhos percorridos por cada um dos agentes naquele determinado instante.

Após os agentes completarem um ciclo, as rotas interligando todas as cidades terão o feromônio atualizado sobre os seus caminhos de acordo com a equação (3.2), também conhecida como atualização global:

$$
\tau(i, j)=(1-\rho) \cdot \tau(i, j)+\sum_{k=1}^{N_{a}} \Delta \tau_{i j}^{k}
$$

sendo $\rho \in(0,1]$ a taxa de evaporação do feromônio, $N_{a}$ o número de agentes, e $\Delta \tau_{i j}^{k}$ a quantidade de feromônio deixada pelo agente $k$ no percurso entre as cidades $i$ e $j$.

$$
\Delta \tau_{i j}^{k}=\left\{\begin{array}{c}
Q / D_{k} \text { se o agente } k \text { utilizou a conexão }(i, j) \text { na sua rota } \\
0 \quad \text { caso contrário }
\end{array}\right.
$$

Na equação (3.3), $Q$ é um parâmetro definido pelo usuário e $D_{k}$ é o comprimento da rota construída pelo agente $k$. O valor de $Q$ é definido empiricamente de acordo com as características do problema, podendo ser um valor previamente conhecido de uma rota inicial, ou a rota de menor comprimento encontrada até o momento para este problema (BONABEAU; DORIGO; THERAULAZ, 1999).

Ao observar a equação (3.2), vê-se que, mesmo que uma conexão $(i, j)$ não seja percorrido por um agente $k$, o valor do feromônio sobre este decai devido a taxa de evaporação $(\rho)$. A taxa de evaporação do feromônio deve ser aplicada para todas as conexões $(i, j)$ que interligam as cidades do problema. Isto é feito para evitar que algumas destas conexões possuam uma quantidade de feromônio muito superior às demais e provoquem a estagnação dos agentes sobre estas, podendo levar a uma convergência prematura do algoritmo para um mínimo local (BONABEAU; DORIGO; THERAULAZ, 1999).

Após cada ciclo, as rotas encontradas pelos agentes são comparadas entre si. A que possuir o menor comprimento é armazenada e comparada com a menor rota encontrada, desde o início do algoritmo até o presente. Se o valor do comprimento da menor rota encontrada no ciclo atual for maior que o valor da menor rota encontrada nos ciclos anteriores, a rota atual é descartada, pois isto significa que os agentes não conseguiram encontrar uma solução melhor 
que a dos ciclos anteriores. Porém, se for menor, a rota é armazenada para a comparação com outras rotas nos ciclos futuros. Após um dado número de ciclos, determina-se a menor rota encontrada pelos agentes.

De uma forma simplificada, o algoritmo AS-TSP pode ser descrito através dos seguintes passos:

a) Passo 1: Dado um conjunto de cidades $C$, definir o número de agentes $N_{a}$, o número de ciclos $N_{c}$, a quantidade de feromônio inicial $\tau_{0}$, o valor do parâmetro $Q$ e dos parâmetros $\alpha$ e $\beta$ para todos os caminhos que interligam as cidades;

b) Passo 2: Distribuir os $N_{a}$ agentes, aleatoriamente, sobre as cidades. Para cada agente $k$, escolher a próxima cidade $j$ a ser visitada aplicando a equação (3.1) até que todas as cidades sejam visitadas;

c) Passo 3: Analisar as rotas construídas ao final de cada ciclo e armazenar a de menor comprimento. Se houve melhora na solução, armazenar a menor rota para comparações futuras; se não, descartá-la;

d) Passo 4: Atualizar o feromônio sobre todos os caminhos, segundo a equação (3.2);

e) Passo 5: Se o número total de ciclos $N_{c}$ foi alcançado, fim; se não, voltar para o passo 2.

O número de agentes $N_{a}$, constante durante todo o processo, é um importante parâmetro para o sucesso do método. Utilizar um número muito grande de agentes pode, rapidamente, reforçar caminhos sub-ótimos e levar o algoritmo a convergir prematuramente para soluções ruins. Um número muito pequeno de agentes pode fazer com que o conhecimento sobre as ações passadas não tenha eficácia, pois a taxa de evaporação do feromônio (apesar de necessária) poderia apagar totalmente estas informações. Bonabeau, Dorigo e Theraulaz (1999) sugerem que o número de agentes para se resolver o TSP seja igual ao número de cidades.

Ainda segundo Bonabeau, Dorigo e Theraulaz (1999), quando aplicado a problemas relativamente pequenos (30 cidades), o AS-TSP foi capaz de encontrar soluções melhores que as soluções encontradas por outros métodos. Mas ao ser aplicado a sistemas grandes (de 50 a 70 cidades), mesmo tendo convergido para boas soluções rapidamente, este nunca foi capaz de encontrar as melhores rotas. 


\subsubsection{MAX-MIN Ant System}

O algoritmo MAX-MIN Ant System (MMAS) foi proposto para ter um desempenho melhor que o do algoritmo AS. Diferente do AS, no MMAS a atualização global do feromônio, que agora possui limites superiores e inferiores de valor, ocorre somente para a melhor rota encontrada por ciclo. A atualização do feromônio é feita seguinte forma:

$$
\tau_{i j}=\left[(1-\rho) \cdot \tau_{i j}+\Delta \tau_{i j}^{b e s t}\right]_{\tau_{\min }}^{\tau_{\max }}
$$

onde $\tau_{\min }$ e $\tau_{\max }$ são os limites mínimo e máximo do feromônio e o operador $[x]_{b}^{a}$ é definido como:

$$
[x]_{b}^{a}= \begin{cases}a & \text { se } x>a \\ b & \text { se } x<b \\ x & \text { caso contrário }\end{cases}
$$

e $\Delta \tau_{i j}^{\text {best }}$ é:

$$
\Delta \tau_{i j}^{\text {best }}=\left\{\begin{array}{cl}
1 / D_{b e s t} & \text { se }(i, j) \text { pertence a menor rota } \\
0 & \text { caso contrário. }
\end{array}\right.
$$

onde $D_{\text {best }}$ é o comprimento da melhor rota, que pode ser a menor rota encontrada no ciclo atual ou a menor rota encontrada deste o início do algoritmo. 


\subsubsection{Ant Colony System}

Também desenvolvido para ter um desempenho melhor que o AS, o Ant Colony System (ACS) apresenta como principal modificação a introdução da atualização local do feromônio (BONABEAU; DORIGO; THERAULAZ, 1999; DORIGO; BIRATTARI; STÜTZLE, 2006). Esta atualização é feita sempre ao final de cada transição do agente $k$ de uma cidade $i$ para a cidade $j$ e somente na conexão $(i, j)$ que interliga essas duas cidades. Esta atualização local é dada pela equação (3.7):

$$
\tau_{i j}=(1-\rho) \cdot \tau_{i j}+\rho \cdot \tau_{0}
$$

onde $\tau_{0}$ é o valor inicial do feromônio na linha $(i, j)$.

Segundo Bonabeau, Dorigo e Theraulaz (1999), a atualização local do feromônio faz com que o valor do feromônio sobre a conexão $(i, j)$ escolhido diminua. Com isso, os agentes encorajam os agentes subseqüentes a escolherem outros caminhos, produzindo assim, soluções diferentes. Isto torna pouco provável que vários agentes produzam soluções idênticas durante um ciclo.

A atualização global do feromônio é ligeiramente similar à da MMAS, onde apenas o feromônio sobre os caminhos pertencentes à melhor rota é atualizado:

$$
\tau_{i j}= \begin{cases}(1-\rho) \cdot \tau_{i j}+\rho \cdot \Delta \tau_{i j} & \text { se } i j \text { pertence a melhor rota } \\ \tau_{i j} & \text { caso contrário. }\end{cases}
$$

Como no MMAS $\Delta \tau_{i j}=1 / D_{\text {best }}$, onde $D_{\text {best }}$ é o comprimento da melhor rota, que pode ser a melhor rota encontrada no ciclo atual ou a melhor rota encontrada deste o início das iterações do algoritmo.

Outra importante diferença entre o ACS e o AS é a regra de decisão. No ACS, esta foi modificada para diversificar a exploração de caminhos. Assim, um agente $k$ em uma cidade $i$ move-se para a cidade $j$ segundo a seguinte regra: 


$$
j=\left\{\begin{array}{lr}
\max \left\{\left[\tau_{i u}\right] \cdot\left[\eta_{i u}\right]^{\beta} \rightarrow u \in J_{i}^{k}\right\} & \text { se } q \leq q_{0} \\
J & \text { se } q>q_{0}
\end{array}\right.
$$

onde $q$ é uma variável uniformemente distribuída sobre [0,1], $q_{0}$ é um parâmetro ajustável $\left(0 \leq q_{0} \leq 1\right)$, e $J \in J_{i}^{k}$ é uma cidade aleatoriamente escolhida de acordo com a probabilidade

$$
p_{i J}^{k}=\frac{\left[\tau_{\mathrm{iJ}}\right] \cdot\left[\eta_{\mathrm{iJ}}\right]^{\beta}}{\sum_{l \in J_{i}^{k}}\left[\tau_{\mathrm{IJ}}\right] \cdot\left[\eta_{\mathrm{IJ}}\right]^{\beta}}
$$

Nota-se que, quando $q>q_{0}$, a regra de transição é muito parecida com a do AS, favorecendo a exploração dos caminhos pelos agentes. Quando $q \leq q_{0}$, o algoritmo tira proveito do conhecimento sobre o problema, isto é, o conhecimento sobre as distâncias entre as cidades e aquele armazenado na forma de feromônio adquirido pelos agentes ao longo da execução do algoritmo. Reduzir a exploração através do ajuste de $q_{0}$ permite ao algoritmo se concentrar nas melhores soluções ao invés de explorar o espaço de soluções constantemente.

Testes realizados com o ACS-TSP em problemas de vários tamanhos (43, 48, 50, 70, 75, 100, 170, 198, 318, 532 e 783 cidades) e comparado com outros algoritmos (Recozimento Simulado (Simulated Annealing), Algoritmo de Rede Elástica (Elastic Net Algorithm) e Mapas Auto-Organizados (Self-organizing Maps)) mostraram que o mesmo obteve os melhores resultados na maioria dos casos (Dorigo e Gambardella, 1997).

\subsection{ACO APLICADO AO PROBLEMA DE RECONFIGURAÇÃO}

Para aplicar o método ACO a algum problema de otimização combinatorial, é necessário que o problema possa ser descrito por um conjunto de pontos adjacentes por onde os agentes possam se movimentar. No caso da reconfiguração de sistemas de distribuição, estes pontos representam as barras do sistema, e as arestas que interligam estes pontos são as linhas de distribuição. Com base nisso, a seguir são apresentados alguns trabalhos que utilizaram o método ACO para resolver o problema de reconfiguração. 
Em 2004, Carpaneto e Chicco (2004) apresentaram um método de reconfiguração baseado na estrutura do AS. O método utiliza um procedimento construtivo durante o ciclo, que intrinsecamente garante que as topologias encontradas durante todo o processo são radiais. No início de cada ciclo, os agentes são colocados na(s) barra(s) de subestação(ões) dos sistemas. A evaporação do feromônio ocorre para todas as linhas do sistema ao final de cada ciclo. No entanto, o incremento é utilizado para reforçar o feromônio sobre as linhas da melhor topologia encontrada no ciclo se, e somente se, o valor das perdas ativas desta for menor que o valor de perdas ativas da melhor topologia encontrada nos ciclos anteriores. $\mathrm{O}$ algoritmo foi aplicado a dois sistemas de distribuição de 33 e 44 barras e seus resultados foram comparados com outros três métodos, sendo eles Melhoramento Iterativo (Iterative Improvement), Recozimento Simulado e Busca Tabu (Tabu Search). Segundos os autores, todos os métodos encontraram a mesma resposta, mas o AS teve um desempenho melhor.

No ano seguinte, Su et al. (2005) utilizaram o algoritmo ACS para reconfiguração de sistemas de distribuição. Junto com o feromônio, os autores utilizaram o tamanho das linhas como heurística para guiar a busca dos agentes. O método foi aplicado a dois sistemas de distribuição de 33 e 94 barras e seu desempenho foi comparado com o de dois métodos, um baseado em Algoritmos Genéticos e outro em Recozimento Simulado. Segundo os autores, o método baseado no ACS produziu as melhores respostas e em menor tempo.

Ainda em 2005, Charles, Khan e Ravichandran (2005) apresentaram um trabalho onde também utilizaram o algoritmo ACS para a reconfiguração. Os autores utilizaram na regra de transição o inverso das perdas nas linhas como heurística de busca. O cálculo destas perdas é realizado para todas as linhas do sistema no início de cada ciclo. O método foi aplicado a um sistema de transmissão de 14 barras e, segundo os autores, foi encontrada a topologia que apresenta o menor valor de perdas ativas.

Ahuja e Pahwa (2005) utilizaram uma nova estrutura para utilização do AS no problema de reconfiguração, denominada Estrutura de Hiper-cubo (Hyper-cube Framework). Esta nova estrutura, apresentada em Blum e Dorigo (2004), além de melhorar a qualidade das soluções encontradas durante o processo de busca, tornou o algoritmo mais robusto. Três anos depois, Carpaneto e Chicco (2008) associaram o algoritmo Hyper-cube framework-ACO com a técnica branch-exchange apresentada por Cinvalar et al. (1988), para obter respostas melhores e mais rápidas. Ambos os métodos foram testados em um sistema de 33 barras e comparados com outros métodos conhecidos da literatura. Em Ahuja e Pahwa (2005), os autores não conseguiram encontrar a topologia que representa o menor valor de perdas ativas 
(GOMES et al., 2005), enquanto que em Carpaneto e Chicco (2008) os autores encontraram a topologia que representa este valor ótimo global.

Em 2006, Khoa e Binh (2006) apresentaram um algoritmo ACS híbrido para melhorar o desempenho do ACS. Neste algoritmo, os agentes fazem uso de duas regras de transição combinadas: (1) a regra de transição clássica, mas sendo função apenas da quantidade de feromônio das linhas e (2) uma regra baseada na lógica fuzzy, que atribui valores a cada chave do sistema de acordo com uma função trapezoidal, indicando o grau de pertinência que cada uma tem na escolha dos agentes. Esta função, baseada no conhecimento dos operadores de sistemas de distribuição, parte do seguinte princípio: chaves próximas das subestações têm pouca probabilidade de serem escolhidas pelos agentes, enquanto que as chaves mais distantes têm maior probabilidade. Foram feitas comparações com três métodos baseados no ACS clássico, Algoritmos Genéticos e Recozimento Simulado. Todos obtiveram as mesmas respostas (ótimos locais) para os testes, sendo que o ACS híbrido foi o mais rápido.

Ahuja et al. (2007) propuseram um método híbrido combinando os conceitos de Sistemas Imunológicos Artificiais (Artificial Immune System) e ACO. O algoritmo AIS gera uma população de soluções candidatas, chamadas de anticorpos, enquanto o ACO reforça, através do feromônio, as melhores soluções, guiando o processo de geração de topologias para soluções ainda melhores. Utilizando-se de uma tabela de feromônio nas linhas, criada durante o processo de reconfiguração, o método foi aplicado ao problema de restabelecimento de energia, ou seja, a reconfiguração do sistema de distribuição após uma contingência, gerando boas configurações de forma rápida e eficaz.

Em 2008, Ghorbani et al. (2008) propuseram uma nova estratégia de seleção de chaves para minimizar as perdas de um sistema de distribuição utilizando o ACS. Nesta estratégia, os agentes trabalham o número mínimo de chaves que devem ficar abertas para que o sistema de distribuição seja radial. Desta forma, o espaço de busca é diminuído, fazendo com que a geração de novas topologias para o sistema seja mais rápida. O método foi aplicado em três sistemas de distribuição de 16, 33 e 69 barras, obtendo boas soluções.

Hu et al. (2008) introduziram modificações nas regras de transição e atualização de feromônio do algoritmo ACS, baseadas nas características estruturais do sistema, simplificando e diminuindo o espaço de busca por configurações ótimas, evitando mínimos locais. O método foi aplicado a um sistema de 69 barras e comparado com o ACS básico, obtendo soluções melhores e em um número menor de ciclos.

Chang (2008) propôs o algoritmo ACS para resolver os problemas de reconfiguração e alocação de capacitores simultaneamente. Para isto, o espaço de busca foi composto por 
pontos que representam tanto as barras do sistema como os bancos de capacitores relativos a cada barra. A primeira parte da busca é feita para a escolha do banco de capacitores que deve ser adicionado a cada barra. Esta busca é baseada na concentração de feromônio de cada banco de capacitores e no custo de implantação deste banco. A segunda parte é feita para escolher quais chaves devem ser abertas para formar uma topologia radial, baseadas na concentração de feromônio de cada chave e no inverso do comprimento da linha que esta chave está alocada. O método foi aplicado a dois sistemas de distribuição de 16 e 94 barras e comparado com os métodos de Algoritmos Genéticos e Recozimento Simulado, obtendo um melhor desempenho que estes dois métodos.

\subsection{CONCLUSÕES}

Neste Capítulo, foram introduzidos os conceitos básicos da estrutura do ACO, bem como sua primeira aplicação a um problema de otimização combinatorial e alguns de seus principais algoritmos. Em relação aos algoritmos, segundo Bonabeau et al. (1999), o algoritmo ACS é o que apresenta o melhor desempenho comparado ao AS e ao MMAS, pois introduziu a atualização local do feromônio, tornando pouco provável que vários agentes produzam soluções idênticas durante um ciclo. Ele também modificou a política de transição, possibilitando ao algoritmo se concentrar nas melhores soluções, ao invés de somente explorar o espaço de soluções constantemente.

Foram citadas algumas das aplicações do ACO que podem sem encontradas na literatura, sendo uma delas a reconfiguração de sistemas de distribuição. Para esta, foram apresentados alguns trabalhos que utilizaram o método ACO e, na maioria das vezes, o algoritmo ACS. Para melhorar o desempenho, alguns autores introduziram modificações, seja ela na transição dos agentes, na atualização do feromômio, seja associando o ACO a outros métodos heurísticos. Todos os algoritmos obtiveram boas soluções e melhor desempenho quando comparados a outras metodologias, como Algoritmos Genéticos, Recozimento Simulado e Busca Tabu.

Como proposta deste trabalho, no próximo capítulo será apresentado um novo algoritmo baseado na estrutura do ACO para resolver o problema de reconfiguração de sistemas de distribuição de energia elétrica para a minimização de perdas ativas. O algoritmo tem como principal característica a geração somente de topologias radiais, o que dispensa um 
procedimento à parte para verificação da restrição de radialidade. Esta característica limita o espaço de soluções à somente o conjunto de todas as topologias radiais conexas, evitando topologias com laços ou com barras isoladas, aumentando assim, a possibilidade de encontrar soluções ótimas. 


\section{CAPÍTULO 4}

\section{ALGORITMO ACS-R PARA RECONFIGURAÇÃO DE SISTEMAS DE DISTRIBUIÇÃO}

\subsection{INTRODUÇÃO}

Os sistemas de distribuição são projetados de tal forma que, em casos de contingências ou manutenção, é possível isolar determinadas partes do sistema enquanto são aplicadas as medidas necessárias para restaurar o fornecimento de energia, atendendo todas as cargas ou o maior número de usuários possível. Isto é feito através de chaves de manobras colocadas em pontos estratégicos do sistema. Em regime permanente, estas chaves podem ser utilizadas para transferir cargas entre os alimentadores, melhorando o perfil de tensão e diminuindo o carregamento das linhas. A este processo é dado o nome de reconfiguração de sistemas de distribuição (RSD). Neste trabalho, o problema de RSD foi proposto e formulado como um problema de otimização não linear, sendo o objetivo minimizar as perdas ativas do sistema de distribuição de energia e satisfazer a um conjunto de restrições de carga e operacionais, como fluxos nas linhas, limites de tensão e a radialidade do sistema. Esta formulação pode ser expressa como:

$$
\operatorname{Minimizar} f(x)=\sum_{j=1}^{N_{R}} R_{j} I_{j}^{2}
$$

Sujeito às seguintes restrições:

a) Limite de magnitude das tensões nodais:

$$
V_{\min } \leq V_{i} \leq V_{\max } ; \quad \forall i, i \in N_{b}
$$

b) Limite de magnitude das correntes nos ramos:

$$
\left|I_{j}\right| \leq I_{j \max } ; \quad \forall j, j \in N_{R}
$$

c) Radialidade. 
onde $V_{i}$ é a magnitude de tensão da barra $i, V_{\min }$ e $V_{\max }$ são os limites mínimo e máximo da tensão respectivamente; $\left|I_{j}\right|$ e $I_{j \max }$ são a magnitude da corrente e o limite máximo da corrente no ramo $j$ respectivamente, $R_{j}$ é a resistência do ramo $j$ e $N_{b}$ e $N_{R}$ são o conjunto de barras e o conjunto de ramos do sistema respectivamente e.

Para resolver este problema, é proposto um algoritmo para reconfiguração de redes baseado no comportamento coletivo de colônias de formigas. Este capítulo está dividido em duas partes. A primeira parte mostra como o algoritmo ACS clássico (BONABEAU; DORIGO; THERAULAZ, 1999; DORIGO; BIRATTARI; STÜTZLE, 2006) pode ser aplicado ao problema de reconfiguração. Baseado nos resultados desta aplicação, a segunda parte apresenta o algoritmo proposto neste trabalho.

\subsection{RECONFIGURAÇÃO DE SISTEMAS DE DISTRIBUIÇÃO POR ACS}

Observou-se no capítulo anterior que, dos três algoritmos baseados no comportamento de colônias de formigas, o algoritmo ACS é o mais utilizado na reconfiguração de redes de distribuição. Para a aplicação do ACS ao problema de reconfiguração, a rede de distribuição é representada por um conjunto de pontos interligados por onde os agentes se movimentam. Os pontos, neste caso, representam as barras do sistema; e as conexões representam as linhas (ramos) que interligam estas barras.

\subsubsection{Algoritmo ACS}

O algoritmo ACS para reconfiguração de redes pode ser descrito de forma simplificada como:

a) Passo 1: Inicialmente, cada linha da rede possui a mesma concentração de feromônio $\tau_{0}$; o número de agentes $N_{a}$ é definido, juntamente com o número de ciclos $N_{c}$ e os parâmetros $\rho, \beta$ e $q_{0}$. 
b) Passo 2: Com todas as chaves do sistema fechadas, os agentes são posicionados aleatoriamente sobre as barras da rede; uma lista de barras $J_{k}$ é criada para cada agente $k$, contendo as barras a serem por eles visitadas.

c) Passo 3: Quando um agente $k$ se encontra sobre a barra $i$, ele seleciona a barra vizinha $j$ (contida em $J_{k}$ e diretamente conectada a barra $i$ ) a ser visitada, baseado na concentração de feromônio sobre a linha $(i, j)$, representada por $\tau_{i j}$ e no inverso da resistência desta linha, representado por $\eta_{i j}$. Esta seleção é feita conforme mostra a Equação 4.4.

$$
j= \begin{cases}\max _{u \in J_{i}^{k}}\left\{\left[\tau_{i u}\right] \cdot\left[\eta_{i u}\right]^{\beta}\right\} & \text { se } q \leq q_{0} \\ J & \text { se } q>q_{0}\end{cases}
$$

onde $\eta_{i u}=\left(r_{i u}\right)^{-1}$ é o inverso da resistência da linha que interliga as barras $i$ e $u ; \beta$ é o peso associado à $\eta_{i u} ; q$ é uma variável uniformemente distribuída sobre $[0,1] ; q_{0}$ é um parâmetro ajustável $\left(0 \leq q_{0} \leq 1\right) ; \quad J_{i}^{k}$ é o conjunto de barras conectadas diretamente com a barra $i$ e contidas em $J^{k} ; J \in J_{i}^{k}$ é uma barra escolhida aleatoriamente de acordo com a probabilidade

$$
p_{i J}^{k}=\frac{\left[\tau_{i J}\right] \cdot\left[\eta_{i J}\right]^{\beta}}{\sum_{l \in J_{i}^{k}}\left[\tau_{l J}\right] \cdot\left[\eta_{l J}\right]^{\beta}}
$$

Sempre que o agente $k$ se desloca, a barra escolhida é retirada de $J^{k}$, evitando que a mesma seja escolhida num passo posterior. A atualização local do feromônio é realizada na linha utilizada na transição do agente, da seguinte forma:

$$
\tau_{i j}=(1-\rho) \cdot \tau_{i j}+\rho \cdot \tau_{0}
$$

onde $\tau_{0}$ e $\tau_{i j}$ são as quantidades de feromônio inicial e sobre a linha $(i, j)$ respectivamente; $\rho \in(0,1]$ é a taxa de evaporação do feromônio.

d) Passo 4: Após um dado número de $\operatorname{passos}^{1}$ (completando um ciclo), cada agente terá percorrido um caminho completo (todas as barras terão sido visitadas, ou seja, $\left.J^{k}=\varnothing\right)$, gerando sua própria topologia. Se o agente $k$ não conseguir percorrer um

\footnotetext{
${ }^{1}$ Para qualquer sistema de distribuição, o número máximo de passos que cada agente deve dar é igual ao número mínimo de linhas necessárias para interligar todas as barras do sistema, ou seja, $\left(N_{b}-1\right)$ linhas, sendo $N_{b}$ o número de barras do sistema.
} 
caminho completo após um ciclo, sua rota é descartada e ele retorna no próximo ciclo. A seguir, estima-se o valor da função objetivo (Equação 4.1) para cada uma destas topologias, que corresponde à soma das perdas ativas em cada linha de cada alimentador da rede.

e) Passo 5: Em seguida, atualiza-se o feromônio sobre a melhor topologia (menor valor de perdas ativas) dentre as encontradas pelos agentes, da seguinte forma:

$$
\tau_{i j}=\left\{\begin{array}{cl}
(1-\rho) \cdot \tau_{i j}+\rho \cdot \Delta \tau_{i j} & \text { se }(i j) \text { pertence a melhor topologia } \\
\tau_{i j} & \text { caso contrário. }
\end{array}\right.
$$

onde $\Delta \tau_{i j}=\left(D_{b e s t}\right)^{-1}$, sendo $D_{b e s t}$ o valor das perdas ativas da melhor topologia, que pode ser a melhor topologia encontrada no ciclo atual ou a melhor topologia encontrada deste o início do algoritmo.

f) Passo 6: Se o número máximo de ciclos não for atingido, voltar ao passo 2.

g) Passo 7: Se o número máximo de ciclos for atingido, fim do algoritmo. Neste ponto, sabe-se qual é a melhor topologia encontrada pela colônia.

A seguir é apresentado o pseudocódigo do algoritmo ACS aplicado à reconfiguração de sistemas de distribuição seguido de um exemplo didático com um sistema fictício de 5 barras. 


\section{Algoritmo 4.1 Pseudocódigo ACS}

/* Inicialização*/

PARA cada linha $(i, j)$ FAZER

$\tau_{i j}(0)=\tau_{0}$

\section{FIM}

PARA $k=1$ até $N_{a}$ FAZER

Distribuir aleatoriamente os agentes sobre as barras do sistema

FIM

Seja $T^{+}$a melhor topologia encontrada no início e $P^{+}$o valor de perdas ativas desta.

/*Laço principal*/

PARA $t=1$ até $N_{c}$ FAZER

PARA $k=1$ até $N_{a}$ FAZER

Construir a topologia $T^{k}(t)$ aplicando $n-1$ vezes os seguintes passos:

Escolher a próxima barra $j, j \in J_{i}^{k}$, como segue

$$
j=\left\{\begin{array}{cc}
\arg \max _{u \in J_{i}^{k}}\left\{\left[\tau_{i u}(t)\right] \cdot\left[\eta_{i u}\right]^{\beta}\right\} & \text { se } q \leq q_{0}, \\
J & \text { se } q>q_{0}
\end{array}\right.
$$

onde $J \in J_{i}^{k}$ é escolhida de acordo com a probabilidade:

$$
p_{i j}^{k}(t)=\frac{\left[\tau_{i j}(t)\right] \cdot\left[\eta_{i j}\right]^{\beta}}{\sum_{l \in J_{i}^{k}}\left[\tau_{i l}(t)\right] \cdot\left[\eta_{i l}\right]^{\beta}},
$$

e onde $i$ é a barra atual onde se encontra o agente.

Após cada transição do agente $k$ aplicar a atualização local do feromônio:

$$
\tau_{i j}(t) \leftarrow(1-\rho) \cdot \tau_{i j}(t)+\rho \cdot \tau_{0}
$$

\section{FIM}

PARA $k=1$ até $N_{a}$ FAZER

Calcular as perdas ativas $P^{k}(t)$ produzidas pela topologia $T^{k}(t)$ encontrada pelo agente $k$

FIM

SE uma topologia com menores perdas foi encontrada ENTÃo

$$
\text { Atualizar } T^{+} \text {e } P^{+} \text {. }
$$

FIM

PARA cada linha $(i, j) \in T^{+}$FAZER

$$
\tau_{i j}(t) \leftarrow(1-\rho) \cdot \tau_{i j}(t)+\rho \cdot \Delta \tau_{i j}(t) \text { onde } \Delta \tau_{i j}(t)=1 / P^{+}
$$

FIM

\section{FIM}

Imprimir a melhor topologia $T^{+}$e seu valor de perdas ativas $P^{+}$ 


\subsubsection{Exemplo 1: Sistema de 5 barras - ACS}

A figura 4.1 representa o sistema distribuição fictício de 5 barras ao qual o ACS foi aplicado. Os dados referentes ao sistema encontram-se no apêndice A.

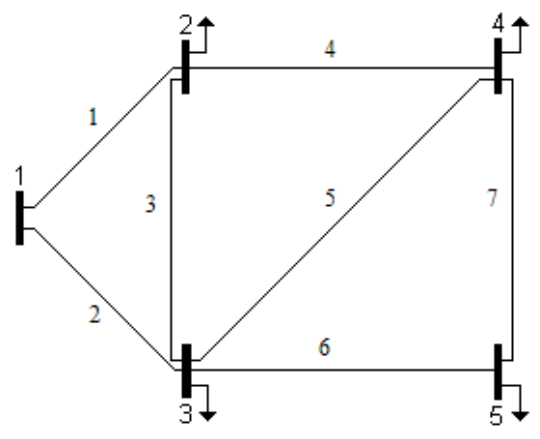

Figura 4.1 - Sistema de distribuição de 5 barras

Para este sistema de cinco barras, considera-se que a barra 1 seja a subestação e que cada linha deste sistema tem apenas uma chave manobrável. $O$ número de chaves manobráveis $n c$ é igual ao número de linhas $n l,(n c=n l=7)$. Ao todo existem 128 configurações possíveis entre factíveis e não factíveis (configurações: $2^{n c}=2^{7}=128$ ). Do ponto de vista da radialidade, existem apenas 21 configurações factíveis.

Todas as 21 topologias radiais possíveis para este sistema são mostradas a seguir com suas respectivas perdas (em p.u.):
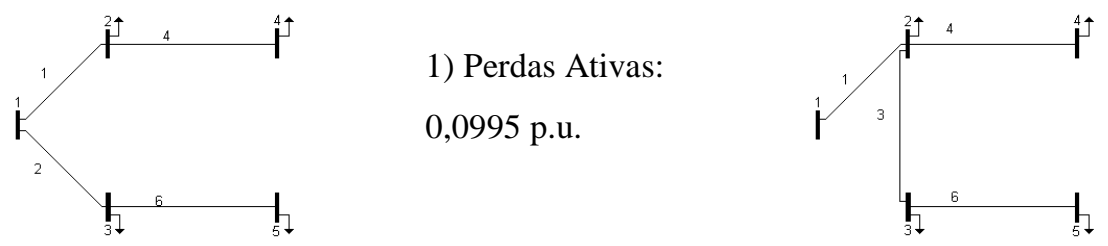

2) Perdas ativas:

1) Perdas Ativas:

0,0995 p.u.

0,1622 p.u.

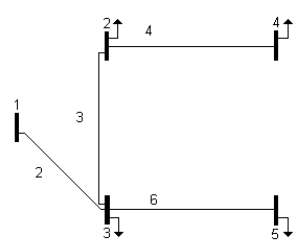

3) Perdas Ativas: 0,0537 p.u.

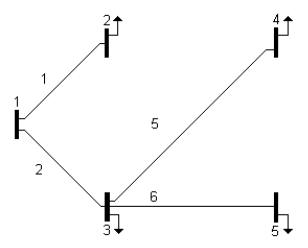

4) Perdas Ativas: 0,0362 p.u.

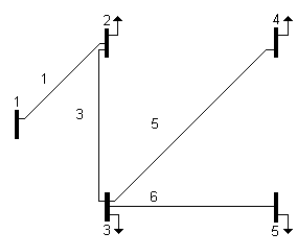

5) Perdas Ativas:

0,1492 p.u.

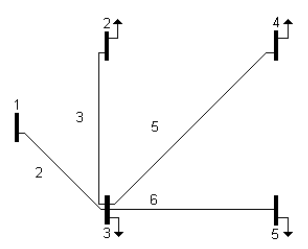

6) Perdas Ativas: 0,0370 p.u. 


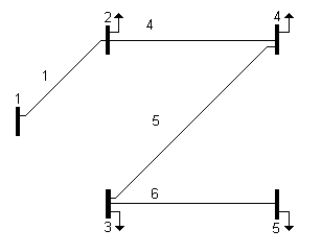

7) Perdas Ativas:

0,1931 p.u.
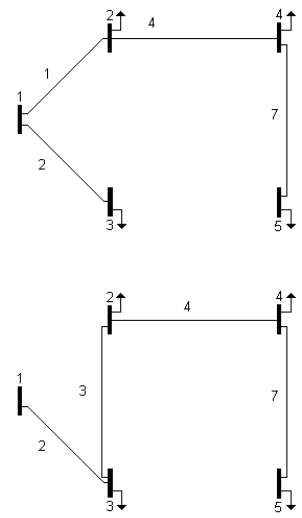

11) Perdas Ativas: 0,0739 p.u.

0,1604 p.u.
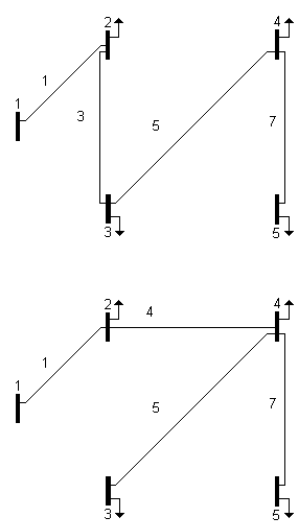

15) Perdas Ativas: 0,1929 p.u.
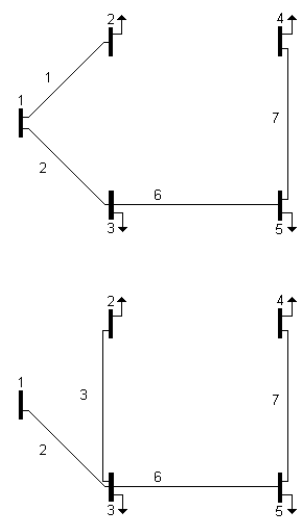

13) Perdas Ativas: 0,1516 p.u.

17) Perdas Ativas: 0,0605 p.u.

19) Perdas Ativas: 0,0616 p.u.

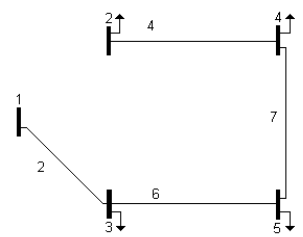

21) Perdas Ativas:

0,1414 p.u.

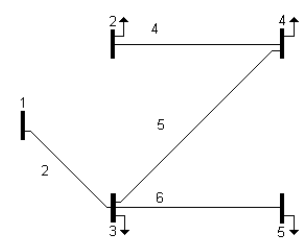

8) Perdas Ativas: 0,0564 p.u.

10) Perdas Ativas: 0,1820 p.u.

12) Perdas Ativas: 0,0383 p.u.

14) Perdas Ativas: 0,0392 p.u.

16) Perdas Ativas: 0,0599 p.u.

18) Perdas Ativas:

0,1765 p.u.

20) Perdas Ativas: 0,1958 p.u. 
Para mostrar um ciclo completo do algoritmo, considera-se que apenas um agente será utilizado para gerar uma topologia. Uma vez definidos os parâmetros do algoritmo ${ }^{2}$ (tabela 4.1), sorteia-se uma barra aleatória do sistema.

Tabela 4.1 - Valores dos parâmetros

\begin{tabular}{lr}
\hline \multicolumn{1}{c}{ Parâmetro } & Valor \\
\hline Números de agentes $\left(N_{a}\right)$ & 1 \\
Feromônio inicial $\left(\tau_{0}\right)$ & 1,0 \\
Peso $(\beta)$ & 2,0 \\
Decaimento $(\rho)$ & 0,1 \\
Parâmetro $\left(q_{0}\right)$ & 0,9 \\
\hline
\end{tabular}

Supondo que a barra 2 seja sorteada (figura 4.2), cria-se a lista de barras a serem visitadas por este agente: $J^{1}=\left[\begin{array}{llll}1 & 3 & 4 & 5\end{array}\right]$; da figura abaixo sabe-se que as barras 1,3 e 4 estão ligadas diretamente à barra 2 .

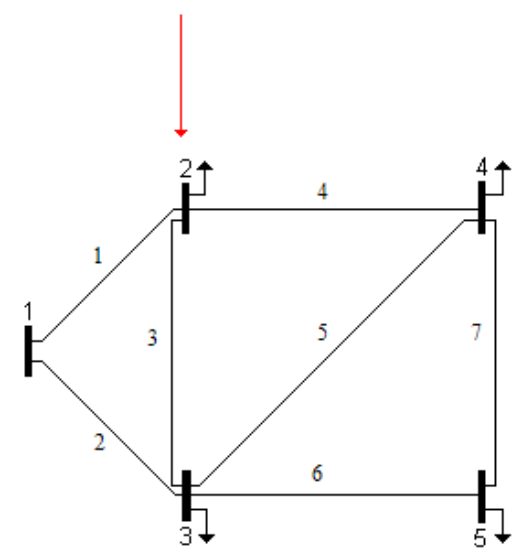

Figura 4.2 - Escolha da barra inicial (barra 2)

O próximo passo é sortear aleatoriamente a variável $q \in[0,1]$ para determinar qual a próxima barra será a escolhida. Supondo que $q=0,94 \rightarrow q>q_{0}$, passa-se da equação 4.4 para a equação 4.5 e calculam-se as probabilidades de cada barra ser visitada pelo agente, ou seja, $p_{21}$ (probabilidade de visitar a barra 1 a partir da barra 2$), p_{23}$ ( probabilidade de visitar a barra 3 a partir da barra 2) e $p_{24}$ ( probabilidade de visitar a barra 4 a partir da barra 2). Neste ponto, deve-se observar que a equação 4.5 representa a "probabilidade", e não a "certeza", de

\footnotetext{
${ }^{2}$ Para este exemplo, os valores destes parâmetros são os sugeridos por Bonabeau, Dorigo e Theraulaz (1999).
} 
escolha de um agente. Se fosse ao contrário, a barra com maior probabilidade sempre seria escolhida e esta equação perderia seu significado.

Então é feito um sorteio aleatório, agora entre as barras a serem visitadas, utilizando um gerador aleatório de números inteiros ${ }^{3}$. Supondo que a barra 1 seja a sorteada, ela é retirada de $J^{1}$ e o feromônio sobre a linha 1 que interliga as barras 2 e 1 é atualizado, segundo a equação 4.6:

$$
\left\{\begin{array}{c}
J^{1}=\left[\begin{array}{lll}
3 & 4 & 5
\end{array}\right] \\
\tau_{21}=(1-\rho) \cdot \tau_{21}+\rho \cdot \tau_{0}=(1-0,1) \cdot(1)+(0,1) \cdot(1)=1
\end{array}\right.
$$

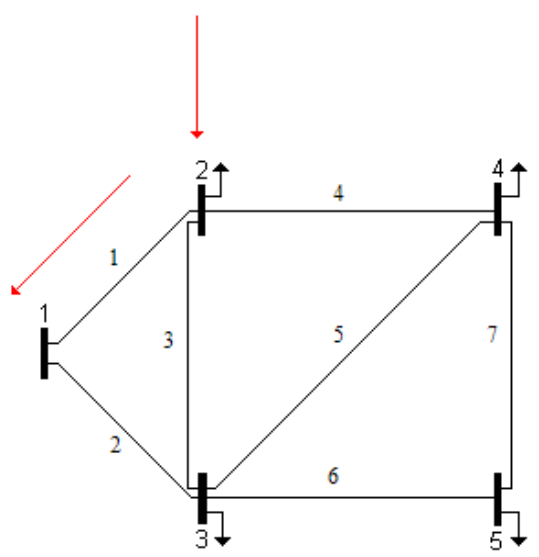

Figura 4.3 - Deslocamento do agente deste a barra 2 até a barra 1.

Agora, têm-se que a única barra da lista $J^{1}$ que está ligada à barra 1 é a barra 3 . Neste caso, não há escolha de barra a ser visitada. $\mathrm{O}$ agente passa da barra 1 direto para barra 3.

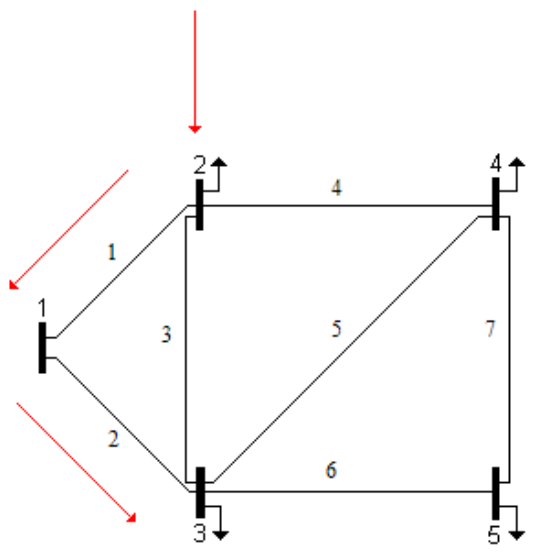

Figura 4.4 - Deslocamento do agente desde a barra 2 até a barra 3.

\footnotetext{
${ }^{3} \mathrm{O}$ algoritmo ACS foi implementado em linguagem Fortran. Para o sorteio da barra a ser visitada, foi utilizada a função random_number ( ) para gerar o número aleatório.
} 
Atualiza-se $J^{1}$ e o feromônio da linha 2 que interliga as barras 1 e 3:

$$
\left\{\begin{array}{l}
J^{1}=\left[\begin{array}{ll}
4 & 5
\end{array}\right] \vdots \\
\tau_{13}=(1-\rho) \cdot \tau_{13}+\rho \cdot \tau_{0}=(1-0,1) \cdot(1)+(0,1) \cdot(1)=1
\end{array}\right.
$$

Verifica-se que as barras 4 e 5 estão ligadas à barra 3. Sorteia-se aleatoriamente a variável $q \in[0,1]$. Supondo agora que $q \leq q_{0}$, escolhe-se a barra que tem o maior argumento na equação 4.4 , neste caso a barra 4 , como pode ser visto:

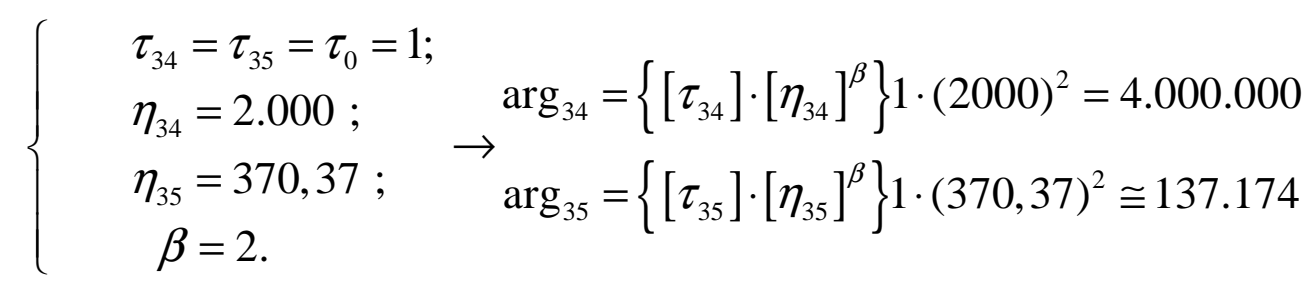

$$
\begin{aligned}
& \therefore \arg _{34}>\arg _{35}
\end{aligned}
$$

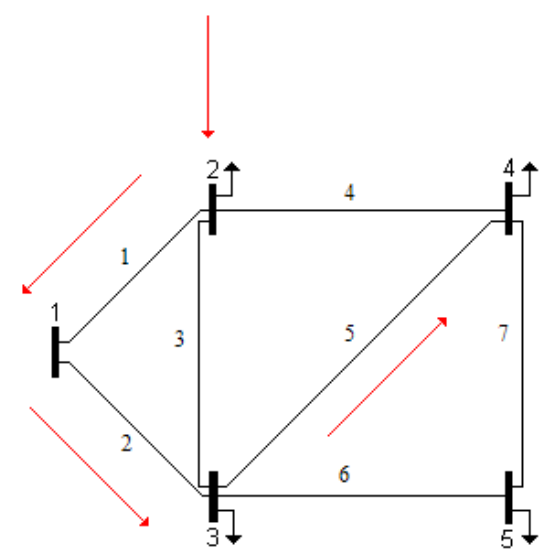

Figura 4.5: Deslocamento do agente desde a barra 2 até a barra 4.

Atualiza-se o feromônio da linha 5 que interliga as barras 3 e 4 e retira-se a barra 4 de $J^{1}$

$$
\left\{\begin{array}{c}
J^{1}=[5] \\
\tau_{34}=(1-\rho) \cdot \tau_{34}+\rho \cdot \tau_{0}=(1-0,1) \cdot(1)+(0,1) \cdot(1)=1
\end{array}\right.
$$

Neste ponto, restou apenas a barra 5 a ser escolhida e, como ela está ligada diretamente com a barra 4, o agente passa através da linha 7 para a barra 5 finalizando o ciclo ( $J^{1}$ está vazia). Atualiza-se o feromônio sobre a linha 7 que interliga as barras 4 e 5:

$$
\left\{\begin{aligned}
J^{1} & =[\varnothing] \\
\tau_{45} & =(1-\rho) \cdot \tau_{45}+\rho \cdot \tau_{0}=(1-0,1) \cdot(1)+(0,1) \cdot(1)=1
\end{aligned}\right.
$$


A topologia encontrada refere-se à topologia de número 12, dentre as 21 topologias possíveis mostradas anteriormente. Neste momento, executa-se o fluxo de carga e calcula-se a função objetivo através da equação 4.1, determinando o valor das perdas para esta topologia (perdas iguais a 0,0383 p.u.). Faz-se a atualização global do feromônio sobre as linhas 1 (que interliga as barras 2 e 1), 2 (que interliga as barras 1 e 3), 5 (que interliga as barras 3 e 4) e 7 (que interliga as barras 4 e 5).

$$
\left\{\begin{array} { c } 
{ \Delta _ { i j } = \frac { 1 } { 0 , 0 3 8 3 } = 2 6 , 1 } \\
{ \tau _ { i j } = ( 1 - \rho ) \cdot \tau _ { i j } + \rho \cdot \Delta \tau _ { i j } }
\end{array} \rightarrow \left\{\begin{array}{l}
\tau_{21}=(1-0,1) \cdot 1+0,1 \cdot 26,1=3,5 \\
\tau_{13}=(1-0,1) \cdot 1+0,1 \cdot 26,1=3,5 \\
\tau_{34}=(1-0,1) \cdot 1+0,1 \cdot 26,1=3,5 \\
\tau_{45}=(1-0,1) \cdot 1+0,1 \cdot 26,1=3,5
\end{array}\right.\right.
$$

O resumo dos passos executados pelo agente e a topologia resultante podem ser vistos na figura 4.6 a seguir:

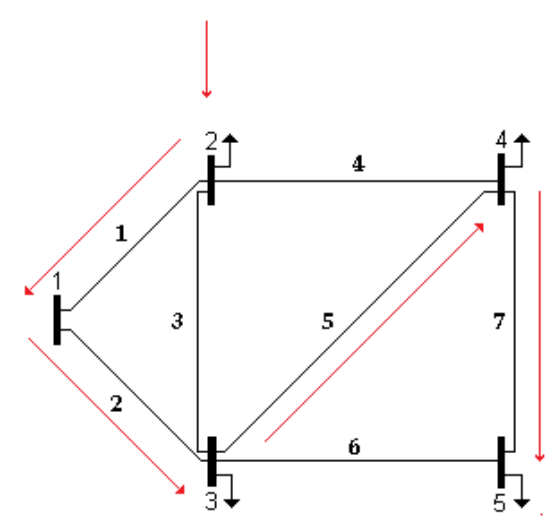

(a)

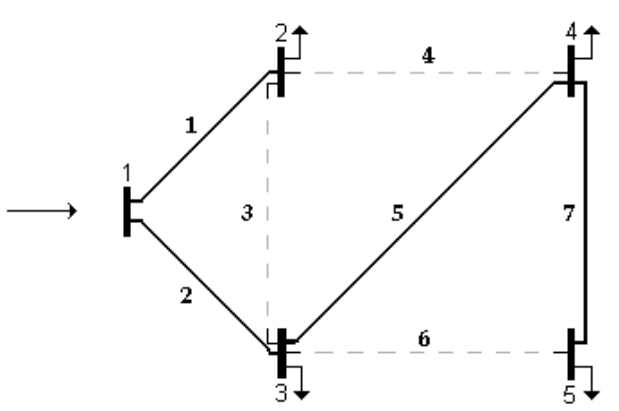

(b)

Figura 4.6: Ciclo de geração de topologia: (a) passos do agente; (b) topologia resultante.

O mesmo agente saindo da barra 2, em ciclos futuros, também poderia encontrar outras opções de topologia, como as topologias 17 e 21 a seguir: 


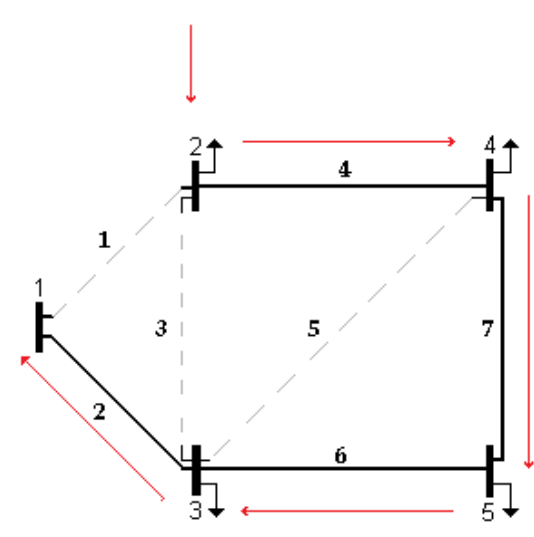

(a)

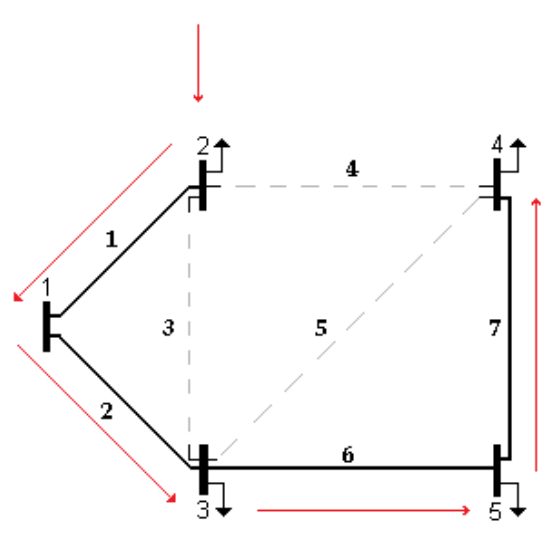

(b)

Figura 4.3: Topologias: (a) topologia 21; (b) topologia 17

\subsubsection{Conclusões sobre o ACS}

Ao retirar a barra visitada pelo agente $k$ de $J^{k}$, evita-se que este passe duas vezes por esta mesma barra. Esta característica traz implicitamente um benefício para o problema de reconfiguração: não existe a possibilidade de se encontrar uma topologia com laços. Isto torna desnecessária uma rotina para verificar a radialidade das topologias geradas, pois toda a topologia encontrada pelos agentes será radial.

Por outro lado, esta característica também traz um inconveniente: como cada agente constrói sua própria topologia, apenas são encontradas topologias que podem ser representadas por uma linha interligando todas as barras do sistema. Para este sistema de 5 barras, nas topologias que podem ser encontradas pelos agentes, cada barra está ligada no máximo a outras duas barras, o que corresponde a 10 topologias (topologias 1, 7, 9, 11, 12, 13, 17, 18, 20 e 21). Desta forma, o algoritmo não explora todo o espaço de busca do problema, podendo nunca encontrar a topologia que apresente o menor valor de perdas ativas ${ }^{4}$.

Outro problema decorrente desta característica é o isolamento do agente em uma parte do sistema, não gerando nenhuma topologia no ciclo em algumas situações, como mostram as topologias incompletas a seguir:

\footnotetext{
${ }^{4}$ Por se tratar de uma metaheurística, o método ACO não garante que a melhor solução para um problema de otimização seja encontrada.
} 


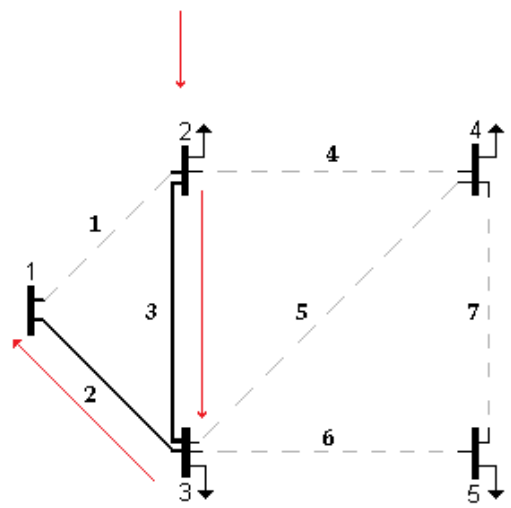

(a)

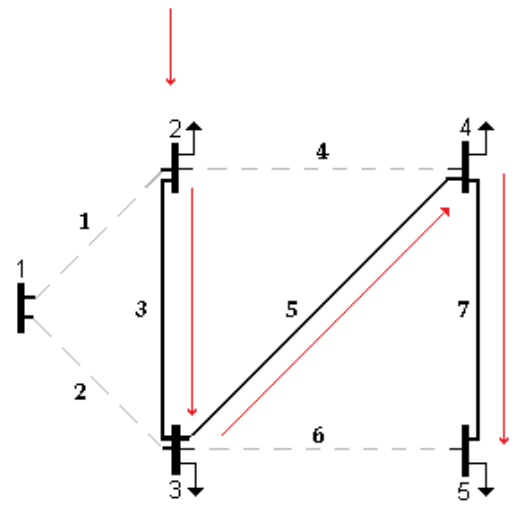

(b)

Figura 4.4: Topologias geradas por ciclos incompletos

Na figura 4.4(a), ao se movimentar da barra 3 para a barra 1, o agente $k$ não possui mais nenhuma opção na lista de barras a serem visitadas $J^{k}$ para deslocamento, pois as barras 2 e 3 já foram visitadas e as barras 4 e 5 não estão conectadas diretamente à barra 1 . O mesmo ocorre com o agente ao chegar à barra 5 na figura 4.4(b). Esta barra só tem ligação direta com as barras 3 e 4, deixando a barra 1 isolada.

O ciclo incompleto do agente, além de não gerar uma topologia, tira o sentido da atualização local de feromônio. Nestes casos, fazer a atualização local de feromônio após cada passo do agente e, depois, descartar a topologia incompleta, poderia diminuir a quantidade de feromônio sobre estas linhas de forma acelerada fazendo com que os agentes evitassem essas linhas em ciclos futuros e o algoritmo poderia convergir prematuramente para um ótimo local. Então, atualizar o feromônio sobre estas linhas só faz sentido se o agente consegue gerar uma topologia completa com as mesmas.

Para se ter uma estimativa de quantas topologias incompletas são geradas durante a execução do ACS, o algoritmo foi executado 10 vezes com este sistema, sendo o número de ciclos igual a 100 e o número de agentes igual a 5, utilizando os mesmos parâmetros da tabela 4.1. Os resultados mostram uma média de $40 \%$ de topologias incompletas, sendo que em alguns ciclos seguidos, os todos os agentes não encontraram nenhuma topologia. Em termos de processamento, significa que uma parte do esforço computacional é desperdiçada com más escolhas feitas pelos agentes. 


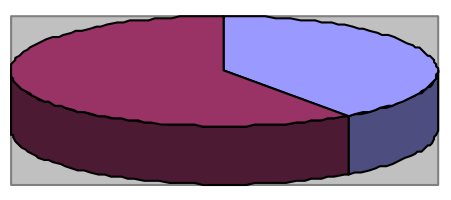

$\square$ Topologias

Incompletas: $40 \%$

$\square$ Topologias

Completas: $60 \%$

Figura 4.5: Média das Topologias Incompletas x Topologias Completas no ACS

Outro problema que pode limitar o desempenho do algoritmo é a necessidade de executar um fluxo de carga para cada topologia encontrada por cada agente. Assim, quanto maior o número de agentes maior a quantidade de fluxos de carga executados. Para este exemplo, em uma execução do algoritmo, se todos os agentes $\left(N_{a}=5\right)$ encontrassem uma topologia em todos os ciclos $\left(N_{c}=100\right)$, o fluxo de carga seria executado 500 vezes $\left(N_{a} \cdot N_{c}=(100) \cdot(5)=500\right)$. Para um sistema de pequeno porte, este problema poderia até ser desprezado, mas ao se trabalhar com sistemas de maior porte, com um número maior de agentes, o desempenho do algoritmo pode ser diretamente afetado.

Para evitar topologias incompletas, aumentar o espaço de busca de soluções e manter a característica do método ACS de gerar apenas configurações radiais, é proposta uma modificação na forma como os agentes constroem suas topologias. Esta proposta será chamada de ACS para Reconfiguração (ACS-R) de agora em diante, sendo descrita a seguir.

\subsection{ALGORITMO ACS-R}

Para superar as limitações do algoritmo ACS e melhor adaptá-lo ao problema de reconfiguração de sistemas de distribuição, é necessário que cada agente, ao invés de construir sua própria topologia, trabalhe em conjunto com os outros agentes na construção de uma única topologia por ciclo. Apesar de esta característica limitar à apenas 1 o número de topologias geradas por ciclo, ela pode, como será demonstrado, aumentar o espaço de busca, aumentando assim a probabilidade dos agentes encontrarem a topologia que apresente o menor valor de perdas ativas. Além disso, apenas um fluxo de carga é executado por ciclo independente do número de agentes utilizados. 
O algoritmo ACS-R é similar ao ACS. Sua principal modificação está na lista de barras a serem visitadas pelos agentes. No ACS, cada agente $k$ possui sua própria lista $T^{k}$, a qual é atualizada após cada transição individual feita pelo mesmo. Já no ACS-R, todos os agentes compartilham uma mesma lista $J$, atualizada após todos os agentes realizarem uma transição.

Para evitar topologias com laços, a transição dos agentes deve respeitar os seguintes critérios: um agente $k_{1}$, localizado em uma barra $i$, no tempo $t$, só pode visitar uma barra $j$, no tempo $t+1$, se: i) a barra $j$ não foi visitada por nenhum agente, ou se ii) a barra $j$ já foi visitada por um agente $k_{2}$, mas ambos os agentes $k_{1}$ e $k_{2}$ estavam na barra $i$ no tempo $t$.

No ACS-R, a regra de transição, bem como as atualizações local e global de feromônio são as mesmas utilizadas pelo algoritmo ACS. A cada início de um novo ciclo, é sorteada aleatoriamente uma única barra onde todos os agentes são colocados. A Figura 4.6 mostra um exemplo do método ACS-R aplicado ao sistema de 5 barras:

\subsubsection{Exemplo 2: Sistema de 5 barras - ACS-R}

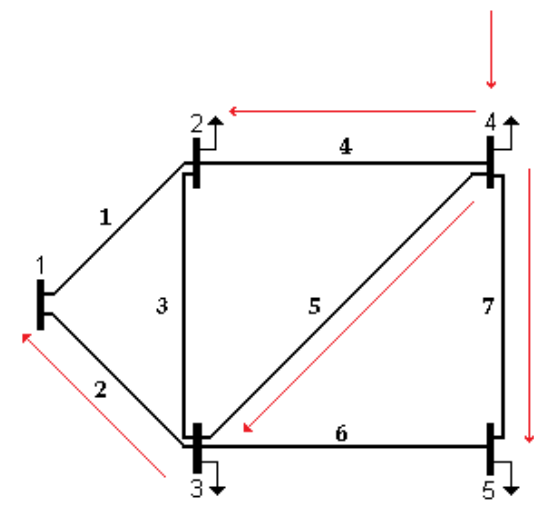

(a)

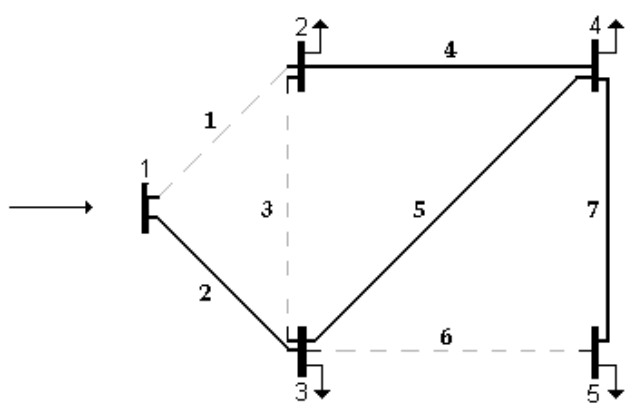

(b)

Figura 4.6: Transição dos agentes no ACS-R: (a) passos dos agentes; (b) topologia encontrada.

Neste exemplo, 3 agentes são colocados na barra 4 no início do ciclo. A seguinte lista de barras a serem visitadas é criada: $J=\left[\begin{array}{llll}1 & 2 & 3 & 5\end{array}\right]$. Partindo da barra 4, existe a possibilidade dos agentes visitarem as barras 2, 3 ou 5. Supondo que a primeira transição dos agentes ocorreu da seguinte maneira: 
$1^{\circ}$ Passo $\left\{\begin{array}{l}\text { agente I }- \text { barra } 4 \underset{\text { para }}{\longrightarrow} \text { barra } 3 \\ \text { agente II }- \text { barra } 4 \underset{\text { para }}{\longrightarrow} \text { barra } 2 \\ \text { agente III }- \text { barra } 4 \underset{\text { para }}{\longrightarrow} \text { barra } 5\end{array} \quad \Rightarrow \quad \therefore \quad J=[1]\right.$

Nota-se que cada agente escolheu uma barra diferente para a primeira transição, restando apenas a barra 1 a ser visitada no próximo passo. Pela topologia da rede, sabe-se que as barras 2 e 3 estão conectadas com a barra 1; tanto o agente I como o agente II podem se deslocar para lá. Por ordem de transição, o agente I tem preferência na escolha da barra em relação ao agente II. Assim, o agente I passa da barra 3 para a barra 1, mas o agente II não, pois esta transição criaria um laço na rede. Os agentes II e III não realizam transições de barras neste passo. Após o agente I se deslocar, tem-se o final do ciclo e uma topologia radial foi criada. Resumindo os passos, tem-se:

$$
\begin{aligned}
& 1^{\circ} \text { Passo }\left\{\begin{array} { l } 
{ \text { agente I } - \text { barra } 4 \stackrel { \text { para } } { \longrightarrow } \text { barra } 3 } \\
{ \text { agente II } - \text { barra } 4 \stackrel { \text { para } } { \longrightarrow } \text { barra } 2 } \\
{ \text { agente III } - \text { barra } 4 \stackrel { \text { para } } { \longrightarrow } \text { barra } 5 }
\end{array} 2 ^ { \circ } \text { Passo } \left\{\begin{array}{l}
\text { agente I }- \text { barra } 3 \stackrel{\text { para }}{\longrightarrow} \text { barra } 1 \\
\text { agente II }- \text { barra } 2 \rightarrow \text { não se desloca } \\
\text { agente III }- \text { barra } 5 \rightarrow \text { não se desloca }
\end{array} \Rightarrow \therefore J=[\varnothing]\right.\right.
\end{aligned}
$$

Outra vantagem do ACS-R sobre o ACS é o número de passos por ciclos. No ACS clássico, cada agente deveria dar 4 passos para gerar uma topologia para o sistema de 5 barras. Um exemplo com três agentes significaria 12 passos no total. Já no ACS-R, o número de passos pode ser menor, como visto no exemplo descrito anteriormente. Foram necessários apenas 4 passos para gerar uma topologia radial. Nota-se também que a topologia encontrada não faz parte do conjunto de topologias que os agentes encontrariam no algoritmo ACS clássico. Isto mostra que o conjunto de soluções possíveis aumentou. Outra vantagem é que não existem ciclos perdidos. Neste exemplo, os agentes que se isolaram em algum ponto do sistema, contribuíram para gerar a topologia, uma vez que seus passos não foram desconsiderados. A seguir é apresentado o pseudocódigo do algoritmo ACS-R seguido de dois exemplos do ACS-R aplicado ao sistema de 5 barras. O primeiro exemplo considera um único agente para gerar as topologias, enquanto o segundo utiliza um número variável de agentes. 


\section{Algoritmo 4.2 Pseudocódigo ACS-R \\ /* Inicialização*/}

PARA cada linha $(i, j)$ FAZER

$\tau_{i j}(0)=\tau_{0}$

\section{FIM}

Seja $T^{+}$a melhor topologia encontrada no início e $P^{+}$o valor de perdas ativas desta.

Escolher aleatoriamente uma barra do sistema da qual todos os agentes partem

/*Laço principal*/

PARA $t=1$ até $N_{c}$ FAZER

Construir a topologia $T(t)$ aplicando $n-1$ vezes os seguintes passos:

PARA $k=1$ até $N_{a}$ FAZER

Escolha a próxima barra $j, j \in J_{i}$, como segue

$$
j=\left\{\begin{array}{cc}
\arg \max _{u \in J_{i}}\left\{\left[\tau_{i u}(t)\right] \cdot\left[\eta_{i u}\right]^{\beta}\right\} & \text { se } q \leq q_{0} \\
j & \text { se } q>q_{0}
\end{array}\right.
$$

onde $j$ é escolhida de acordo com a probabilidade:

SE $j$ não foi visitada OU SE $j$ foi visitada no ciclo $t$ pelo agente $k_{j} \mathbf{E}$ o agente $k_{j}$ estava na barra $i$ com o agente $k_{i}$ no ciclo $t-1$ ENTÃo

$$
p_{i j}(t)=\frac{\left[\tau_{i j}(t)\right] \cdot\left[\eta_{i j}\right]^{\beta}}{\sum_{l \in J_{i}}\left[\tau_{i l}(t)\right] \cdot\left[\eta_{i l}\right]^{\beta}}
$$

e onde $i$ é a barra atual onde se encontra o agente $k_{i}$

\section{SENÃO}

Sortear novo $q$

\section{FIM}

\section{FIM}

Aplicar a atualização local do feromônio sobre as linhas escolhidas pelos agentes:

$$
\tau_{i j}(t) \leftarrow(1-\rho) \cdot \tau_{i j}(t)+\rho \cdot \tau_{0}
$$

Calcular as perdas ativas $D(t)$ produzidas pela topologia $T(t)$ encontrada pelos agentes

SE uma topologia com um valor menor de perdas ativas foi encontrada ENTÃO

$$
\text { Atualizar } T^{+} \text {e } D^{+} \text {. }
$$

\section{FIM}

PARA cada linha $(i, j) \in T^{+}$FAZER

$$
\tau_{i j}(t) \leftarrow(1-\rho) \cdot \tau_{i j}(t)+\rho \cdot \Delta \tau_{i j}(t) \text { onde } \Delta \tau_{i j}(t)=1 / D^{+}
$$

FIM 


\subsubsection{Exemplo 3: ACS-R - Variando o número de agentes}

Abaixo, na Tabela 4.2, são apresentados os resultados de 5 experimentos feitos com o ACS-R com o objetivo de analisar o seu comportamento para um número $N_{a}$ de agentes diferente em cada experimento. O número de ciclos $N_{c}$ em todos os experimentos foi igual a 100 e os parâmetros utilizados foram os mesmos dos exemplos anteriores (Tabela 4.1).

Pela Tabela 4.2, pode-se observar que, ao utilizar apenas 1 agente, o método ACS-R é idêntico ao método ACS clássico, onde um determinado agente constrói sua própria topologia.

Utilizando 2 agentes, a topologia com o menor valor de perdas foi encontrada. O espaço de busca aumenta consideravelmente, ficando apenas uma topologia sem ser encontrada (topologia 6), por ter o maior número de ramificações dentre todas as topologias.

Tabela 4.2: Resultados dos experimentos para diferentes números de agentes

\begin{tabular}{cccc}
\hline Experimento & $\begin{array}{c}\text { Número de } \\
\text { Agentes }\end{array}$ & Topologias encontradas & $\begin{array}{c}\text { Menor valor de } \\
\text { perdas (pu) }\end{array}$ \\
\hline 1 & 1 & $1,7,9,11,12,13,17,18,20 \mathrm{e} 21$ & 0,0383 \\
2 & 2 & $1,2,3,4,5,7,8,9,10,11,12,13,14,15$, & 0,0362 \\
3 & 3 & $16,17,18,19,20 \mathrm{e} 21$ & 0,0362 \\
4 & 4 & Todas & 0,0362 \\
5 & 5 & $1,2,3,4,5,7,8,9,10,14,15,16,18,19 \mathrm{e}$ & 0,0362 \\
\hline
\end{tabular}

Com 3 e 4 agentes, todo o espaço de busca é explorado e, assim como com 2 agentes, também foi encontrada a melhor topologia. O experimento 5 também encontra a melhor topologia, mas neste, o espaço de busca diminuiu. Isto se deve ao fato de que, quanto mais agentes, maior a probabilidade de se encontrar topologias que possuem um número de ramificações elevado. E inversamente, quanto menor o número de agentes, maior a probabilidade de se encontrar topologias com um número menor de ramos.

Assim, o número "ótimo" de agentes, necessário para encontrar a melhor topologia em um determinado sistema de distribuição, pode variar entre um número mínimo e um máximo. 
A topologia radial com menor perda ativa encontrada nos experimentos com 2,3 , 4 e 5 agentes é apresentada na figura 4.7. A evolução do método ao longo dos ciclos para o experimento com 2 agentes é apresentada na figura 4.8 .

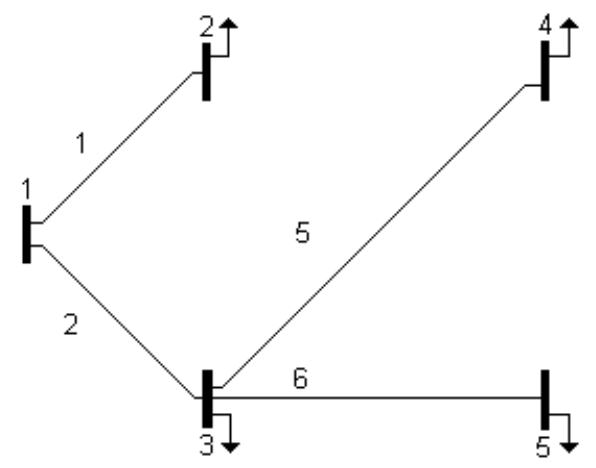

Figura 4.7 - Sistema de distribuição radial de 5 barras

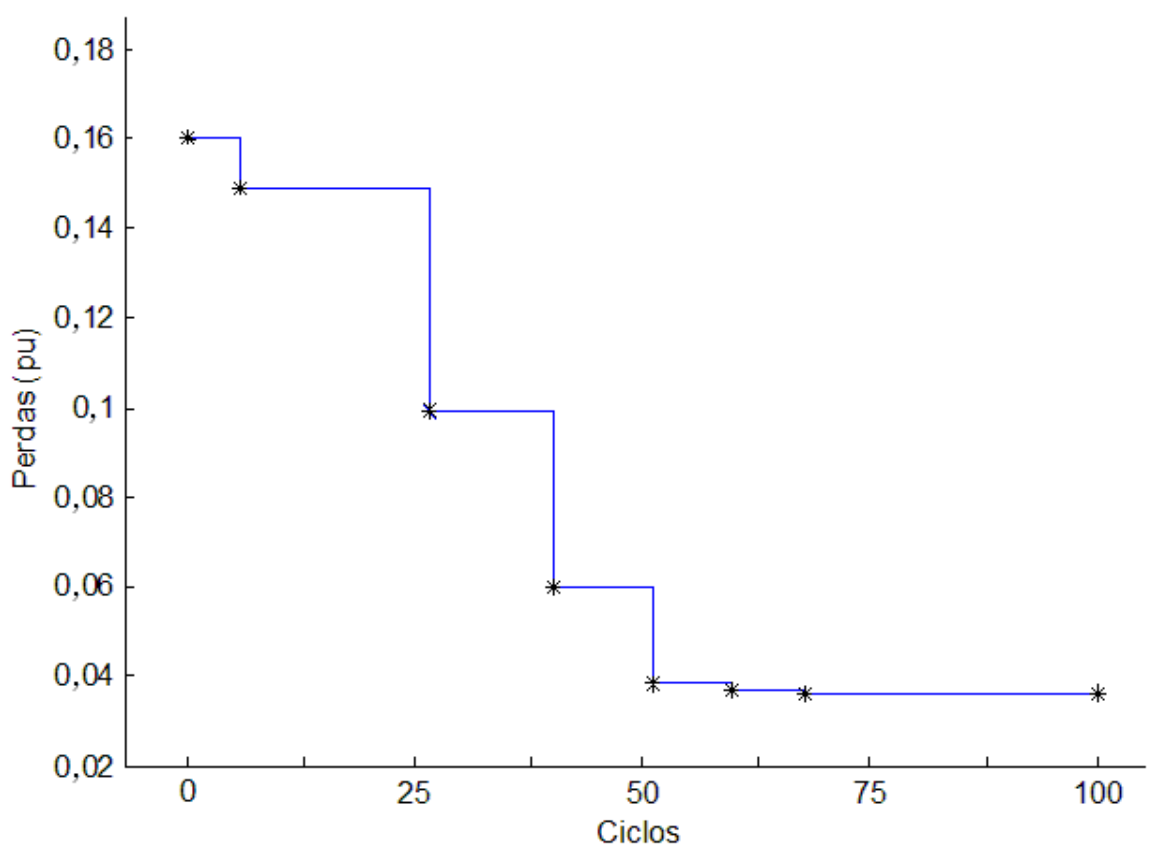

Figura 4.8 - Evolução do método ACS-R

Um ponto a ser ressaltado é que, apesar do espaço de busca ter aumentado, por se tratar de um método metaheurístico o ACS-R está sujeito a não encontrar uma solução que seja o ótimo global. Alguns testes realizados com o número de ciclos inferior a 50 não encontraram a melhor topologia. Isto é um indicativo de que a quantidade de ciclos pode influenciar o desempenho do método. 


\subsection{CONCLUSÕES}

Neste capítulo, foi apresentado um algoritmo ACS para reconfiguração de redes de distribuição. O método difere do ACS clássico na forma como os agentes interagem uns com os outros para construir uma topologia. Esta diferença possibilitou que o espaço de soluções possíveis aumentasse. Conseqüentemente, aumentou-se a probabilidade de encontrar a topologia que apresenta o menor valor de perdas ativas.

Além disso, o algoritmo manteve a característica do ACS clássico de encontrar apenas topologias radiais, o que dispensa a necessidade de uma rotina de verificação de radialidade, muitas vezes comum em métodos aplicados em reconfiguração de redes de distribuição.

Outra melhora aparece na geração de topologias. No ACS clássico, existia um número elevado de configurações inválidas, fazendo com que os ciclos de alguns agentes, ao longo da execução do algoritmo, fossem descartados por não gerar topologias completas. No ACS-R, isto não ocorre, pois os agentes trabalham em conjunto para gerar topologias radiais.

Analisando os resultados dos exemplos, verificou-se que o ACS-R apresentou um desempenho melhor que o ACS clássico para o problema de reconfiguração. Verificou-se também que tanto o número de agentes como o número de ciclos podem influenciar na descoberta da melhor topologia. Cabe ao programador, através de testes, verificar o "melhor" valor destes parâmetros para cada sistema de distribuição.

A modificação na forma como os agentes constroem suas rotas trouxe alguns benefícios para o método em termos de desempenho. Como os agentes cooperam entre si para construir uma mesma topologia, apenas um fluxo de carga é executado ao final de cada ciclo e o número de agentes e o número de passos para se encontrar esta topologia pode ser reduzido.

O próximo capítulo apresenta uma nova abordagem para resolução do problema de fluxo de potência (FP) em sistemas de distribuição radial. A abordagem consiste na associação dos métodos da função penalidade e de Newton. O mal-condicionamento da matriz Jacobiana de Newton é resolvido pela associação com o método da função penalidade. 


\section{CAPÍTULO 5}

\section{FLUXO DE CARGA}

\subsection{INTRODUÇÃO}

Na medida em que os sistemas de distribuição tornam-se maiores e mais complexos, aumenta a preocupação por uma operação eficiente e confiável desses sistemas. O fluxo de potência é uma ferramenta básica utilizada pelos centros de controle para determinar os estados e condições operacionais dos sistemas de potência. Basicamente, as metodologias empregadas para o cálculo do fluxo de potência são baseadas nos métodos clássicos de Newton ou Gauss (DENIS; PADILHA, 2000). Mas em sistemas de distribuição de energia, devido a particularidades inerentes a estes, como a alta relação entre a resistência e a reatância da linha $(r / x)$ e a operação radial, estes métodos podem apresentar problemas de convergência e se tornam ineficientes em alguns casos.

Alguns pesquisadores contornaram estes problemas sugerindo versões modificadas dos métodos clássicos. Em Rajičić e Bose (1988), foi proposta uma modificação no método de Newton desacoplado rápido utilizando técnicas de compensação para resolver problemas com alta relação $r / x$. Estes mesmos problemas foram resolvidos por Zhang e Cheng (1997) através da mudança na representação da matriz Jacobiana do método de Newton convencional para evitar o mau condicionamento da mesma. Em 2002, Teng (2002), apresenta um algoritmo modificado de Gauss-Seidel para análise trifásica de sistemas de distribuição. O método, baseado na ordenação ótima da matriz $Y$-bus, pode ser aplicado tanto às redes radiais como a redes malhadas e fracamente malhadas.

Outros autores desenvolveram formulações específicas para aplicação em sistemas de distribuição radiais. Dentre estes, o método o Backward/Forward Sweep (BFS) proposto por Shirmohammadi et al. (1988) é um dos mais conhecidos. Aplicado à sistemas radiais ou fracamente malhados, é dividido em duas fases. Na primeira, calculam-se as correntes dos ramos, partindo das barras extremas em direção à subestação (backward sweep). Na segunda fase, fazendo-se o caminho inverso (forward sweep), são calculadas as tensões nas barras. 
Cheng e Shirmohammadi (1995) e Chang et al. (2007) entenderam este método para sistemas trifásicos desequilibrados.

Baran e Wu (1989b) propuseram uma solução iterativa, pelo método de NewtonRaphson, de um novo modelo de equações de potência ativa, reativa e magnitude de tensão para resolver o fluxo de potência. Estas equações são denominadas pelos autores de "equações de fluxo nos ramos" ou DistFlow e diferem das equações de fluxo de potência para sistemas de transmissão. Outra proposta dos autores é a utilização de uma matriz de sensibilidade (Jacobiana) modificada para atender a característica radial dos sistemas de distribuição tornando este método exclusivo para sistemas radiais.

Em 1990, Cespedes (1990) apresentou uma modelagem simples de fluxo de carga que elimina a necessidade de se trabalhar com tensões complexas e permite incluir na formulação cargas dependentes da tensão. Mais recentemente, Bijwe e Raju (2006) apresentaram um método baseado em lógica fuzzy que pode ser aplicado a sistemas fracamente malhados e desequilibrados.

Embora estes métodos específicos sejam mais eficientes para sistemas de distribuição radiais que os outros baseados em Newton ou Gauss, sua estrutura não permite seu uso em redes malhadas. E para problemas de fluxo de potência ótimo ou mesmo estimação de estados, as metodologias baseadas no método de Newton ainda são mais apropriadas (Patra e Goswani, 2007).

Este capítulo apresenta uma nova abordagem para resolução do problema de fluxo de potência (FP) em sistemas de distribuição radial. A abordagem consiste na associação dos métodos da função penalidade e de Newton. O mal condicionamento da matriz Jacobiana de Newton é resolvido pela associação com o método da função penalidade. Para ilustrar o funcionamento do método, um sistema de 2 barras é utilizado como exemplo. Testes com sistemas maiores foram realizados para verificar a eficiência da abordagem proposta. 


\subsection{MÉTODO DA FUNÇÃO PENALIDADE-NEWTON}

Nesta seção, as principais características do método da função penalidade, na sua forma básica, são apresentadas. Para essa finalidade, considere um problema de programação não-linear com restrições de igualdade e desigualdade, da forma:

$$
\begin{array}{ll}
\text { Minimizar } & f(x) \\
\text { sujeito a } & g(x)=0 \\
& x_{\min } \leq x \leq x_{\max }
\end{array}
$$

onde $x \in R^{n}, g(x) \in R^{m}$, as funções são de classe $C_{2}, x_{\min }$ e $x_{\max }$ são os seus limites inferiores e superiores, respectivamente.

O método da função penalidade (MFP) utiliza uma função auxiliar, na qual as restrições de desigualdade violadas são introduzidas na função objetivo através de um fator de penalidade. Esse método gera uma seqüência de pontos infactíveis, cujo limite é a solução ótima do problema original. O problema penalizado consiste em:

$$
\begin{array}{ll}
\text { Minimizar } & F(x)=f(x)+\sum_{l} \gamma_{l} \\
\text { sujeito a } & g(x)=0
\end{array}
$$

onde $\sum_{l} \gamma_{i}$ é a função auxiliar que representa o conjunto de restrições de desigualdade violadas associadas com os fatores de penalidades, isto é:

$$
\gamma=\frac{c}{2}\left(y_{\min }-y\right)^{2} \text { ou } \gamma=\frac{c}{2}\left(y-y_{\max }\right)^{2}
$$

onde que $\gamma$ representa a variável cujo limite está violado e $c$ é o fator de penalidade.

A função Lagrangiana associada ao problema (equação 5.2) é dada por:

$$
L(x, \lambda)=F(x)+\sum_{k=1}^{m} \lambda_{k} g(x)
$$

sendo $\lambda$ o multiplicador de Lagrange.

A solução consiste em encontrar os valores de $x$ e $\lambda$ que satisfazem as condições necessárias de primeira ordem: 


$$
\begin{aligned}
& \frac{\partial L}{\partial x}=0 \\
& \frac{\partial L}{\partial \lambda}=0
\end{aligned}
$$

A solução da equação 5.5 pode ser obtida pelo método de Newton, e é dada por:

$$
\left[\begin{array}{cc}
H & J^{T} \\
J & 0
\end{array}\right]\left[\begin{array}{l}
\Delta x \\
\Delta \lambda
\end{array}\right]=-\left[\begin{array}{c}
\nabla_{x} L \\
\nabla_{\lambda} L
\end{array}\right]
$$

A matriz Hessiana da função Lagrangiana é simétrica, onde:

$$
H=\nabla_{x x}^{2} L
$$

$$
J=\nabla_{x \lambda}^{2} L=\nabla_{x} g(x)
$$

A solução de (5.6) é utilizada para atualizar $x$ e $\lambda$.

$$
\begin{aligned}
& x^{k+1}=x^{k}+\Delta x \\
& \lambda^{k+1}=\lambda^{k}+\Delta \lambda
\end{aligned}
$$

O fator de penalidade $c$ é atualizado por:

$$
c^{k+1}=\rho c^{k}
$$

em que $\rho>1$ é o fator de correção da penalidade.

A solução será encontrada quando os valores de $x$ e $\lambda$ satisfizerem as restrições de igualdade dentro de uma tolerância e as condições de Karush-Kuhn-Turcker (KKT), minimizando a função objetivo. 


\subsection{MÉTODO DA FUNÇÃO PENALIDADE-NEWTON (FPN) APLICADO AO FLUXO DE POTÊNCIA RADIAL}

Em geral, um sistema de distribuição é alimentado por uma barra de tensão controlada, a qual se adota como a barra de referência angular (barra slack) e todos os outros nós são assumidos como sendo barras de carga (barra $P Q$ ). Para o cálculo dos estados do sistema (tensões nodais e ângulos de fase), o problema de fluxo de carga pode ser formulado de forma simples como:

$$
\begin{array}{ll}
\text { Minimizar } & f(V, \theta) \\
\text { sujeito a } & \Delta P(V, \theta)=0 \\
& \Delta Q(V, \theta)=0 \\
& V_{\min } \leq V \leq V_{\max }
\end{array}
$$

sendo: $\Delta P \in R^{m}, \Delta Q \in R^{m}, \theta \in R^{m}$ e $V \in R^{m}$, onde $m=1,2 \ldots, n b c$ (número de barras de carga); $f(V, \theta)$ as perdas de potência ativa na transmissão, $V$ a magnitude da tensão; $\theta$ o ângulo de fase da tensão; $\Delta P(V, \theta)$ e $\Delta Q(V, \theta)$ os resíduos de potência ativa e reativa, respectivamente.

No problema apresentado na equação (5.11), o número de variáveis é igual ao número de equações $(n=2 \cdot m)$, sendo um problema de fluxo de potência. Portanto, ele possui uma única solução. Assim, o problema (5.11) não é um problema de otimização.

Aplicando o MFP ao problema (5.11), tem-se:

$$
\begin{array}{cl}
\text { Minimizar } & F(V, \theta)=f(V, \theta)+\sum_{i} \gamma_{i} \\
\text { sujeito a } & \Delta P(V, \theta)=0 \\
\Delta Q(V, \theta)=0
\end{array}
$$

sendo $\gamma$ o conjunto de restrições de magnitudes de tensão violadas associadas com os fatores de penalidades, isto é:

$$
\left\{\begin{array}{l}
\gamma=\frac{c}{2}\left(V_{\min }-V\right)^{2} \quad \text { ou } \\
\gamma=\frac{c}{2}\left(V-V_{\max }\right)^{2}
\end{array}\right.
$$


A função Lagrangiana associada ao problema (equação 5.12) é dada por:

$$
L(x, \lambda)=F(x)+\sum_{k=1}^{m} \lambda_{p_{k}} \Delta P(x)+\sum_{k=1}^{m} \lambda_{q_{k}} \Delta Q(x)
$$

sendo $x=(V, \theta), \lambda_{p}$ e $\lambda_{q}$ os multiplicadores de Lagrange.

As condições necessárias de primeira ordem são aplicadas sobre a função Lagrangiana, gerando um sistema de equações não lineares, como segue:

$$
\left\{\begin{array}{l}
\nabla_{x} F(x)+J_{p}(x)^{T} \lambda_{p}+J_{q}(x)^{T} \lambda_{q}=0 \\
\Delta P(x)=0 \\
\Delta Q(x)=0
\end{array}\right.
$$

em que: $J_{p}(x)^{T}=\left(\nabla_{x} \Delta P_{1}(x), \ldots, \nabla_{x} \Delta P_{m}(x)\right)$, e $J_{q}(x)^{T}=\left(\nabla_{x} \Delta Q_{1}(x), \ldots, \nabla_{x} \Delta Q_{m}(x)\right)$.

O sistema de equações não lineares (5.15) é resolvido utilizando-se o método de Newton. A aplicação do método de Newton gera as direções de busca $\left(\Delta V, \Delta \theta, \Delta \lambda_{p}\right.$ e $\left.\Delta \lambda_{q}\right)$, as quais serão utilizadas para a atualização das variáveis do problema, e resulta num sistema matricial, que pode ser representado de forma simplificada como:

$$
W \Delta d=-\nabla L
$$

em que:

$$
W=\left(\begin{array}{ccc}
\nabla_{x x} L & J_{p}(x)^{T} & J_{q}(x)^{T} \\
J_{p}(x) & 0 & 0 \\
J_{q}(x) & 0 & 0
\end{array}\right)
$$

é a matriz Hessiana da Lagrangiana com:

$$
\Delta d^{T}=\left(\Delta x, \Delta \lambda_{p}, \Delta \lambda_{q}\right)
$$

e

$$
\nabla L=\left[\begin{array}{l}
\nabla_{x x} F(x)+J_{p}(x)^{T} \lambda_{p}+J_{q}(x)^{T} \lambda_{q} \\
\Delta P(x) \\
\Delta Q(x)
\end{array}\right]
$$

é o vetor gradiente. 
Os vetores das variáveis $x, \lambda_{p}$, e $\lambda_{q}$ são atualizados da seguinte forma:

$$
\begin{aligned}
& x^{k+1}=x^{k}+\Delta x^{k} \\
& \lambda_{p}^{k+1}=\lambda_{p}^{k}+\Delta \lambda_{p}^{k} \\
& \lambda_{q}^{k+1}=\pi_{q}^{k}+\Delta \pi_{q}^{k}
\end{aligned}
$$

O fator de penalidade $c$ é atualizado por:

$$
c^{k+1}=\rho c^{k}
$$

em que $\rho>1$ é o fator de correção da penalidade.

\subsection{ALGORITMO FPN}

O problema de fluxo de potência mostrado na Equação (5.11) pode ser resolvido iterativamente, através do algoritmo apresentado a seguir:

a) Passo 1: Faça $k=0$, dê uma estimativa inicial para $d^{k}=\left(x^{k}, \lambda_{p}^{k}, \lambda_{q}^{k}\right)$ e $c^{k}>1$;

b) Passo 2: Verifique quais restrições de tensão estão violadas e construa $\gamma$;

c) Passo 3: Determine o gradiente e a matriz Hessiana da Lagrangiana, e resolva o sistema da Equação (5.16);

d) Passo 4: Atualize as variáveis do problema. Faça $k=k+1$;

e) Passo 5: Atualize o fator de penalidade $c$;

f) Passo 6: Se o critério de parada for satisfeito, então pare; caso contrário, vá para o passo 2 .

O critério de parada utilizado consiste em verificar se as equações do fluxo de potência são menores que uma precisão $\varepsilon$ e se todas as magnitudes de tensão estão dentro dos seus limites.

Em Sousa, Pereira e da Costa (2008), o método FPN foi aplicado em 4 sistemas de distribuição (10, 33, 34 e 69 barras) conhecidos da literatura. Seu desempenho foi comparado com o dos métodos BFS (Shirmohammadi et al. 1988) e Baran-Wu (Baran e Wu 1989), que são métodos clássicos utilizados para solução do problema de fluxo de potência em sistemas 
de distribuição radiais. Segundo os autores, o FPN teve desempenho superior em todos os testes realizados.

\subsection{EXEMPLO: SISTEMA DE 2 BARRAS}

Para mostrar o funcionamento do método, a seguir é apresentado um sistema de 2 barras utilizado em Monticelli (1983).

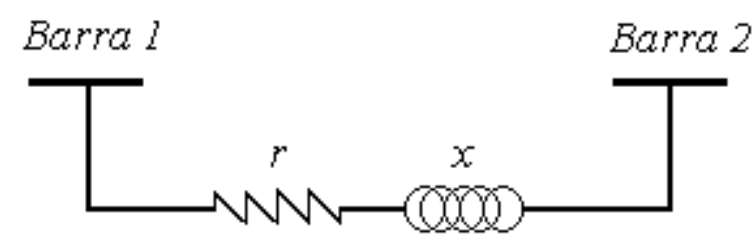

Figura 5.1: Sistema de 2 barras.

Os dados referentes a este sistema são os seguintes:

$\left\{\begin{array}{l}r=0,2 \mathrm{pu} \\ x=1,0 \mathrm{pu} \\ \theta_{1}=0 \mathrm{rad}\end{array}\right.$

O problema:

$$
\begin{cases}\min & g_{21} \cdot\left(V_{1}^{2}+V_{2}^{2}-2 V_{1} \cdot V_{2} \cdot \cos \theta_{2}\right) \\ \text { s.a. } & P_{2}^{e s p}-\left[g_{22} \cdot V_{2}^{2}+V_{1} \cdot V_{2} \cdot\left(g_{21} \cdot \cos \theta_{2}\right)+b_{21} \cdot \operatorname{sen} \theta_{2}\right]=0 \\ & 0,9 \leq \mathrm{V}_{1} \leq 1,0 \\ & 0,9 \leq \mathrm{V}_{2} \leq 1,0\end{cases}
$$


Montagem da função penalidade:

$$
\begin{aligned}
P\left(V_{1}, V_{2}, \theta_{2}\right) & =g_{21} \cdot\left(V_{1}^{2}+V_{2}^{2}-2 \cdot V_{1} \cdot V_{2} \cdot \cos \theta_{2}\right)+ \\
& +\lambda_{1} \cdot\left\{P_{2}^{e s p}-\left[g_{22} \cdot V_{2}^{2}+V_{1} \cdot V_{2} \cdot\left(g_{21} \cdot \cos \theta_{2}\right)+b_{21} \cdot \operatorname{sen} \theta_{2}\right]\right\}+ \\
& +\frac{1}{2} \lambda_{2}\left\{\begin{array}{cl}
\left(V_{1}-1,0\right)^{2} & \text { se } \mathrm{V}_{1}>1,0 \\
\left(0,9-V_{1}\right)^{2} & \text { se } \mathrm{V}_{1}<0,9 \\
0 & \text { se } 0,9 \leq \mathrm{V}_{1} \leq 1,0
\end{array}+\right. \\
& +\frac{1}{2} \lambda_{3}\left\{\begin{array}{cl}
\left(V_{2}-1,0\right)^{2} & \text { se } \mathrm{V}_{2}>1,0 \\
\left(0,9-V_{2}\right)^{2} & \text { se } \mathrm{V}_{2}<0,9 \\
0 & \text { se } 0,9 \leq \mathrm{V}_{2} \leq 1,0
\end{array}\right.
\end{aligned}
$$

Aplicando o algoritmo, tem-se:

Tabela 5.1: Resultados

\begin{tabular}{cccc}
\hline Iteração & $V_{1}$ & $V_{2}$ & $\theta_{2}$ \\
\hline 1 & 1,0 & 0,999 & $-0,2065$ \\
2 & 1,0 & 0,999 & $-0,2294$ \\
\hline
\end{tabular}

Resposta:

$\left\{\begin{array}{l}V_{1}=1,0 \mathrm{pu} \\ V_{2}=0,999 \mathrm{pu} \\ \theta_{2}=-0,2294 \text { graus } \\ \text { perdas na linha }=32,052 \mathrm{~kW}\end{array}\right.$ 


\subsection{TESTES}

Testes foram realizados para verificar a eficiência da abordagem proposta. Os programas foram desenvolvidos em linguagem de programação FORTRAN no ambiente integrado de desenvolvimento (Integrated Development Environment - IDE) COMPAQ VISUAL FORTRAN 6 em um computador pessoal com o sistema operacional Microsoft Windows XP e processador Intel Pentium 4 de 3,4 GHz com 2 GB de memória RAM. As características principais dos sistemas elétricos de distribuição estudados são resumidas na Tabela 5.2.

Tabela 5.2: Características elétricas dos sistemas.

\begin{tabular}{ccccc}
\hline Sistemas & Barra de subestação & Barras de Carga & Linhas & Laterais \\
\hline 10 & 1 & 9 & 9 & 0 \\
33 & 1 & 32 & 32 & 4 \\
34 & 1 & 33 & 33 & 4 \\
69 & 1 & 68 & 68 & 7 \\
\hline
\end{tabular}

Em todos os testes, os valores dos multiplicadores de Lagrange iniciais foram $\lambda_{p}=$ $\lambda_{\mathrm{q}}=0$, o fator de penalidade e o fator de correção da penalidade foram definidos como $\mathrm{c}=100 \mathrm{e}$ $\rho=5$, respectivamente. Os valores iniciais do vetor das magnitudes da tensão foram $V=1$ e do vetor dos ângulos de fase da tensão $\theta=0^{\circ}$.

\subsubsection{Sistema de 10 barras}

Para o sistema de 10 barras utilizado em (Grainger et al. 1982) o método convergiu em 3 iterações e o valores das perdas de potência ativa e reativa nas linhas foram de 783,77 kW e 1036,47 Kvar, respectivamente. O processo de convergência está resumido na Tabela 5.3, a qual apresenta por iteração a perda de potência ativa $(P)$, a perda de potência reativa $(Q)$, o maior erro de potência ativa $(\Delta P)$ e de potência reativa $(\Delta Q)$. 
Tabela 5.3. Processo de convergência do sistema 10 barras pelo método FP.

\begin{tabular}{ccccc}
\hline Iteração & $\mathbf{P}(\mathbf{k W})$ & $\mathbf{Q}($ Kvar $)$ & $\Delta \mathbf{P}(\mathbf{M W})$ & $\Delta \mathbf{Q}$ (Mvar) \\
\hline 0 & 0 & 0 & 1,84000 & 1,84000 \\
1 & 592,26 & 810,28 & 0,65103 & 1,09528 \\
2 & 778,39 & 1030,75 & 0,00952 & 0,00439 \\
3 & 783,77 & 1036,47 & 0,00002 & 0,00007 \\
\hline
\end{tabular}

\subsubsection{Sistema de 33 barras}

Para o sistema de 33 barras utilizado em (Baran e Wu, 1989a) o método convergiu em 2 iterações e os valores das perdas de potência ativa e reativa nas linhas foram de 123,28 kW e 87,91 Kvar, respectivamente. O processo de convergência está resumido na tabela 5.4.

Tabela 5.4. Processo de convergência do sistema 33 barras pelo método FP.

\begin{tabular}{ccccc}
\hline Iteração & $\boldsymbol{P}(\mathbf{k W})$ & $\boldsymbol{Q}($ Kvar $)$ & $\boldsymbol{\Delta P}(\mathbf{M W})$ & $\boldsymbol{\Delta} \boldsymbol{Q}($ Mvar $)$ \\
\hline 0 & 0 & 0 & 0,42000 & 0,60000 \\
1 & 117,08 & 82,81 & 0,49474 & 0,21350 \\
2 & 123,28 & 87,91 & 0,00006 & 0,00011 \\
\hline
\end{tabular}

\subsubsection{Sistema de 34 barras}

Para o sistema de 34 barras utilizado em (Chis et al., 1997) o método convergiu em 3 iterações e os valores das perdas de potência ativa e reativa nas linhas foram de 222,29 kW e 65,20 Kvar, respectivamente. O processo de convergência está resumido na Tabela 5.5.

Tabela 5.5: Processo de convergência do sistema 34 barras pelo método FP.

\begin{tabular}{ccccc}
\hline Iteração & $\boldsymbol{P}(\mathbf{k W})$ & $\boldsymbol{Q}($ Kvar $)$ & $\boldsymbol{\Delta P}(\mathbf{M W})$ & $\boldsymbol{\Delta Q}($ Mvar $)$ \\
\hline 0 & 0 & 0 & 0,23000 & 0,14250 \\
1 & 209,20 & 62,36 & 0,64368 & 0,17655 \\
2 & 222,24 & 65,18 & 0,00030 & 0,0001 \\
3 & 222,29 & 65,20 & 0,00009 & 0,00003 \\
\hline
\end{tabular}




\subsubsection{Sistema de 69 barras}

Para o sistema utilizado em (Baran e Wu, 1989b) o método convergiu em 3 iterações e os valores das perdas de potência ativa e reativa nas linhas foram de $225,02 \mathrm{~kW}$ e 102,18 Kvar, respectivamente. O processo de convergência está resumido na Tabela 5.6.

Tabela 5.6: Processo de convergência do sistema 69 barras pelo método FP.

\begin{tabular}{lllll}
\hline Iteração & $\boldsymbol{P}(\mathbf{k W})$ & $\boldsymbol{Q}($ Kvar $)$ & $\boldsymbol{\Delta P}(\mathbf{M W})$ & $\boldsymbol{\Delta} \boldsymbol{Q}($ Mvar $)$ \\
\hline 0 & 0 & 0 & 1,24400 & 0,88800 \\
1 & 190,65 & 87,51 & 0,09317 & 0,42638 \\
2 & 224,70 & 102,05 & 0,01473 & 0,01451 \\
3 & 225,02 & 102,18 & 0,01417 & 0,01472 \\
\hline
\end{tabular}

\subsubsection{Teste Comparativo}

Os resultados obtidos com a implementação do método FPN, adaptado para sistemas de distribuição radiais, foram comparados com os métodos BFS (Shirmohammadi et al. 1988), Baran-Wu (Baran e Wu 1989). Os resultados apresentados são referentes às simulações de três sistemas radias de distribuição, com 10, 34 e 69 barras.

A Tabela 5.7 mostra um resumo dos resultados obtidos no teste comparativo utilizando o sistema de 10 barras.

Tabela 5.7: Teste comparativo sistema de 10 barras.

\begin{tabular}{llll}
\hline Método & Iteração & $\mathbf{P}(\mathbf{k W})$ & $\mathbf{Q}($ Kvar $)$ \\
\hline FPN & 3 & 783,77 & 1036,47 \\
Baran-Wu & 4 & 783,77 & 1036,50 \\
BFS & 9 & 783,77 & 1036,50 \\
\hline
\end{tabular}

Na Tabela 5.8 apresenta-se um resumo dos resultados obtidos no teste comparativo com o sistema de 34 barras. 
Tabela 5.8. Teste comparativo sistema de 34 barras.

\begin{tabular}{cccc}
\hline Método & Iteração & $\mathbf{P}(\mathbf{k W})$ & $\mathbf{Q}$ (Kvar) \\
\hline FPN & 3 & 222,29 & 65,20 \\
Baran-Wu & 4 & 222,29 & 65,27 \\
BFS & 6 & 222,29 & 65,27 \\
\hline
\end{tabular}

A Tabela 5.9 mostra um resumo do teste comparativo com o sistema de 69 barras.

Tabela 5.9. Teste comparativo sistema de 69 barras.

\begin{tabular}{lccl}
\hline Método & Iteração & $\mathbf{P}(\mathbf{k W})$ & $\mathbf{Q}($ Kvar $)$ \\
\hline FPN & 3 & 225,02 & 102,18 \\
Baran-Wu & 4 & 225,04 & 102,26 \\
BFS & 7 & 225,05 & 102,26 \\
\hline
\end{tabular}

Observa-se das Tabelas 5.7, 5.8 e 5.9 que o método da FPN teve um melhor desempenho que os métodos clássicos, pois convergiu com um número menor de iterações.

\subsection{CONCLUSÕES}

Este capítulo apresentou uma nova abordagem para resolução do problema de fluxo de potência (FP) em sistemas de distribuição radial associando os métodos da função penalidade e de Newton. Uma das vantagens do método é a capacidade de lidar com o mau condicionamento da matriz Jacobiana de Newton, causado pela alta relação $r / x$. A outra vantagem reside na possibilidade deste método ser aplicado tanto a sistemas radiais como malhados. Uma importante contribuição da aplicação do método da FPN ao problema de fluxo de carga radial é a obtenção dos multiplicadores de Lagrange, os quais podem ser usados para estudos de alocação de reativos, geração distribuída, entre outros. 


\section{CAPÍTULO 6}

\section{RESULTADOS NUMÉRICOS}

Para verificar o comportamento dos algoritmos que incorporam as idéias apresentadas neste trabalho, neste capítulo são apresentados os resultados dos testes realizados em quatro sistemas de distribuição conhecidos da literatura, a saber: 16 barras (CIVANLAR et. al., 1988), 33 barras (BARAN; WU, 1989a), 69 barras (CHIANG; JEAN-JUMEAU, 1990) e 136 barras (MANTOVANI; CASARI; ROMERO, 2000). Em todos os testes, os resultados obtidos pelo ACS-R foram comparados com os resultados obtidos em alguns trabalhos que, utilizando metodologias heurísticas ou metaheurísticas, fizeram uso destes quatro sistemas.

$\mathrm{O}$ algoritmo ACS-R e o fluxo de potência foram implementados em linguagem de programação FORTRAN no ambiente integrado de desenvolvimento (Integrated Development Environment - IDE) COMPAQ VISUAL FORTRAN 6 em um computador pessoal com o sistema operacional Microsoft Windows XP e processador Intel Pentium 4 de 3,4 GHz com 2 GB de memória RAM.

Em todos os testes, os valores dos parâmetros utilizados pelo ACS-R são os apresentados na Tabela 6.1, sendo os mesmos valores sugeridos por Bonabeau, Dorigo e Theraulaz (1999). Nestes testes, para o fluxo de potência, foi limitado em 10 o número máximo de iterações para o mesmo atingir a convergência com erro de $10^{-3}$ p.u.. O menor valor de tensão nas barras foi fixado em $10 \%$ do valor nominal. Qualquer topologia gerada pelos agentes que não respeitou estas duas restrições durante a execução do ACS-R foi descartada. Nestes casos, não houve atualização de feromônio sobre as linhas dos sistemas, para o referido ciclo, e o algoritmo ACS-R seguiu para o próximo ciclo. 
Tabela 6.1- Parâmetros iniciais

\begin{tabular}{cc}
\hline Parâmetros & Valores \\
\hline Feromônio inicial $\left(\tau_{0}\right)$ & 1,0 \\
Número de ciclos $(t)$ & 1.000 \\
Peso $\beta$ & 2 \\
Decaimento $(\rho)$ & 0,1 \\
Parâmetro de escolha $\left(q_{0}\right)$ & 0,9 \\
\hline
\end{tabular}

\subsection{SISTEMA DE 16 BARRAS}

O primeiro sistema de teste é um sistema hipotético de $23 \mathrm{kV}$ e potência base de 100 MVA apresentado em Civanlar et. al. (1988). Este sistema possui 16 barras (barras 1, 2 e 3 são subestações), 3 laços e 16 chaves seccionadoras, sendo originalmente 13 chaves fechadas e 3 chaves abertas. A topologia inicial deste sistema apresenta perdas ativas iguais a 511,4 KW. Os dados de barra e de linha deste sistema podem vistos no apêndice A. É comum este sistema ser descrito como sendo de 14 barras, já que as três barras que são subestações podem ser consideradas como sendo uma única barra. Tanto a configuração inicial como a configuração com as subestações agrupadas (14 barras), podem ser vistas na Figura 6.1.

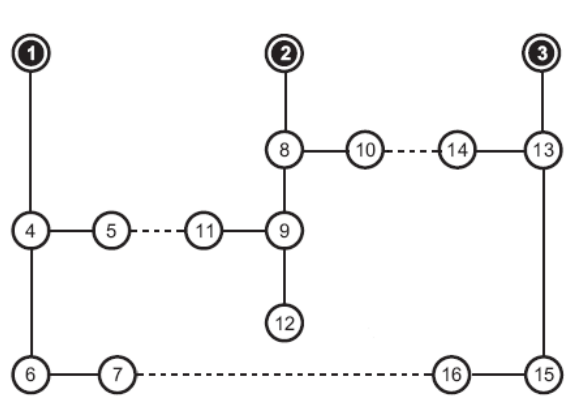

(a)

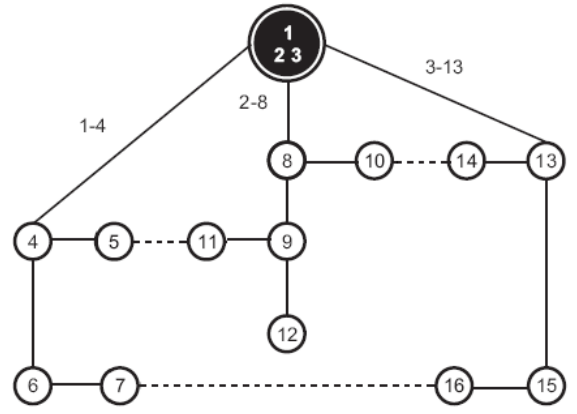

(b)

Figura 6.1 - (a) Sistema original de 16 barras. (b) Sistema com as subestações agrupadas (14 barras) ${ }^{1}$.

\footnotetext{
${ }^{1}$ Figura retirada de Fontan (2008).
} 
A Tabela 6.2 abaixo exibe a comparação entre o ACS-R e as melhores topologias encontradas por Civanlar et. al. (1988), Mantovani, Casari e Romero (2000), Lorenzeti (2004), Gomes et. al. (2005) e Guimarães (2005).

Tabela 6.2 - Resultados obtidos para o sistema de 16 barras.

\begin{tabular}{cccc}
\hline Experimentos & $\begin{array}{c}\text { Perdas Finais } \\
(\mathbf{k W})\end{array}$ & $\begin{array}{c}\text { Redução } \\
(\%)\end{array}$ & $\begin{array}{c}\text { Chaves abertas } \\
\text { (número da linha) }\end{array}$ \\
\hline ACS-R & 466,13 & 8,86 & $7-8-16$ \\
\cline { 2 - 4 } Civanlar & 483,88 & 5,38 & $7-14-16$ \\
Guimarães & 466,13 & 8,86 & $7-8-16$ \\
Gomes & 466,13 & 8,86 & $7-8-16$ \\
Lorenzeti & 466,13 & 8,86 & $7-8-16$ \\
Mantovani & 466,13 & 8,86 & $7-8-16$ \\
\hline
\end{tabular}

$\mathrm{Na}$ Tabela 6.2, verifica-se que apenas Civanlar et. al. (1988) não encontra a melhor topologia. O ACS-R, juntamente com os outros métodos, encontraram a topologia com menor valor de perdas ativas. Esta topologia, segundo Gomes et. al. (2005) representa a solução ótima do problema.

A diferença entre as perdas da configuração original e a melhor encontrada no teste é de aproximadamente 8,86\%. A topologia correspondente ao menor valor de perdas encontrado no teste pode ser vista na Figura 6.2 a seguir:

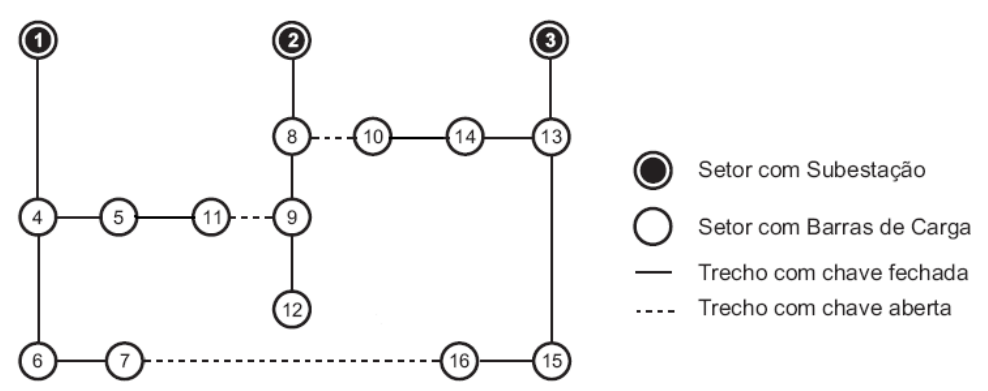

Figura 6.2 - Topologia encontrada pelo ACS-R - 16 barras. 


\subsection{SISTEMA DE 33 BARRAS}

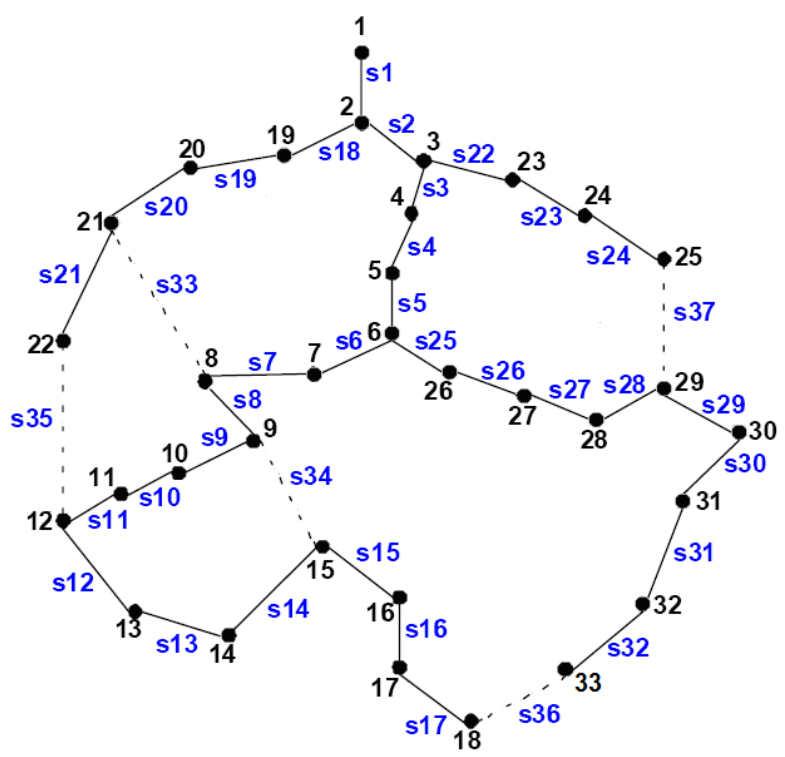

Figura 6.3 - Sistema de 33 Barras $^{2}$.

O segundo sistema de teste é um sistema hipotético de 12,66 kV apresentado por Baran e Wu (1989a). Este sistema possui 33 barras (barra 1 é a subestação), 5 laços e 37 chaves seccionadoras, sendo originalmente 32 chaves fechadas (chaves de 1 a 32) e 5 chaves abertas (chaves de 33 a 37). A topologia inicial deste sistema é apresentada na Figura 6.3 acima e, para esta configuração a perdas ativas iniciais são de 202,68 KW. Os dados de barra e de linha deste sistema podem vistos no apêndice A. Para este sistema foram realizados dois testes. O primeiro teste é feito com o sistema original e o segundo é feito modificando o carregamento de duas barras do sistema. Estes testes são os mesmos realizados por Gomes et. al. (2005) e são mostrados a seguir.

\footnotetext{
${ }^{2}$ Figura retirada de Gomes et. al. (2005).
} 


\subsubsection{Sistema de 33 barras - teste 1}

A Tabela 6.3 exibe a comparação entre o ACS-R e a melhor topologia encontrada por Baran e Wu (1989), Mantovani, Casari e Romero (2000), Lorenzeti (2004), Gomes et. al. (2005) e Guimarães (2005).

Tabela 6.3 - Resultados obtidos para o sistema de 33 barras - teste 1

\begin{tabular}{cccc}
\hline Experimentos & $\begin{array}{c}\text { Perdas finais } \\
(\mathbf{K W})\end{array}$ & $\begin{array}{c}\text { Redução } \\
(\boldsymbol{\%})\end{array}$ & $\begin{array}{c}\text { Chaves abertas } \\
\text { (número da linha) }\end{array}$ \\
\hline \hline ACS-R & 139,98 & 31 & $7-9-14-28-32$ \\
\cline { 2 - 4 } $\begin{array}{c}\text { Baran-Wu } \\
\text { Lorenzeti }\end{array}$ & 160,99 & 20 & $7-10-14-27-30$ \\
\cline { 2 - 4 } \begin{tabular}{c} 
Guimarães \\
\cline { 2 - 4 } Mantovani
\end{tabular} & 140,71 & 30 & $7-10-14-28-32$ \\
\cline { 2 - 4 } Gomes & 136,57 & 32,6 & $7-9-14-32-37$ \\
\cline { 2 - 4 } & 136,57 & 32,6 & $7-9-14-32-37$ \\
\hline
\end{tabular}

* Ótimo global

Na Tabela 6.3, verifica-se que o ACS-R encontra a segunda melhor topologia dentre as topologias encontradas pelos outros métodos. Mesmo sendo o segundo menor valor de perdas ativas, este difere muito pouco do valor das perdas da melhor topologia para este sistema, que é o ótimo global segundo Gomes (2005).

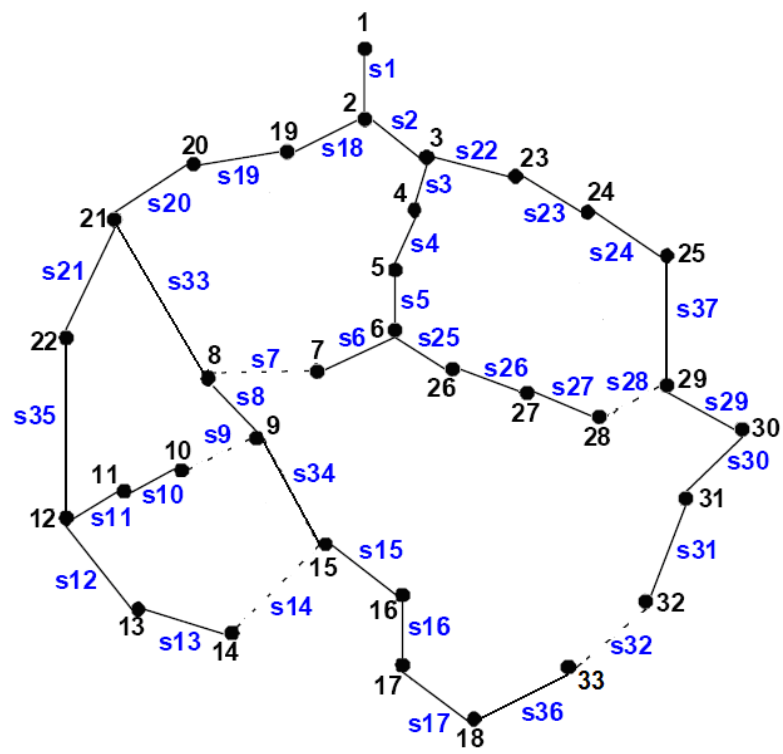

Figura 6.4 - Topologia encontrada pelo ACS-R - 33 barras - teste 1. 
A diferença entre as perdas da configuração original e as perdas da topologia encontrada pelo ACS-R é de 31\%. A topologia encontrada pelo ACS-R correspondente ao menor valor de perdas ativas pode ser vista na Figura 6.4.

\subsubsection{Sistema 33 barras modificado - teste 2}

Para este teste, foram feitas modificações nas cargas das barras 10 (60 kW e $20 \mathrm{kVAr})$ e $14(120 \mathrm{~kW}$ e $80 \mathrm{kVAr})$ que passaram a ter, em ambas, o mesmo valor (420 kW e 200 kVAr) - mesma modificação apresentada em Gomes et. al. (2005). Para este carregamento, o valor das perdas ativas para a topologia inicial é de 299,97 kW. A Tabela 6.4 mostra a comparação entre estes experimentos e a melhor topologia encontrada por Gomes et. al. (2005) e a solução ótima ${ }^{3}$.

Tabela 6.4 - Resultados obtidos para o sistema de 33 barras - teste 2

\begin{tabular}{cccc}
\hline Experimentos & Perdas finais (kW) & Redução $(\%)$ & $\begin{array}{c}\text { Chaves abertas } \\
\text { (número da linha) }\end{array}$ \\
\hline ACS-R & 200,19 & 33 & $9-14-28-33-36$ \\
Gomes & 199,56 & 33,5 & $7-10-14-28-36$ \\
Ótimo & 198,11 & 34 & $9-14-28-32-33$ \\
\hline
\end{tabular}

$\mathrm{Na}$ Tabela 6.4, verifica-se que o ACS-R encontra uma topologia com valor maior de perdas ativas que a dos outros experimentos. Mas a diferença entre estas perdas para esta topologia, em relação às das outras, é pequena (apenas 1,9\% em relação à de Gomes et. al. (2005) e 2,6\% em relação à solução ótima).

A diferença entre as perdas da melhor topologia encontrada pelos agentes em relação à configuração original é de 33\%. A topologia correspondente à encontrada pelo ACS-R pode ser vista na Figura 6.5.

\footnotetext{
${ }^{3}$ Solução ótima obtida em Gomes et. al. (2005) através de um algoritmo de busca exaustiva.
} 


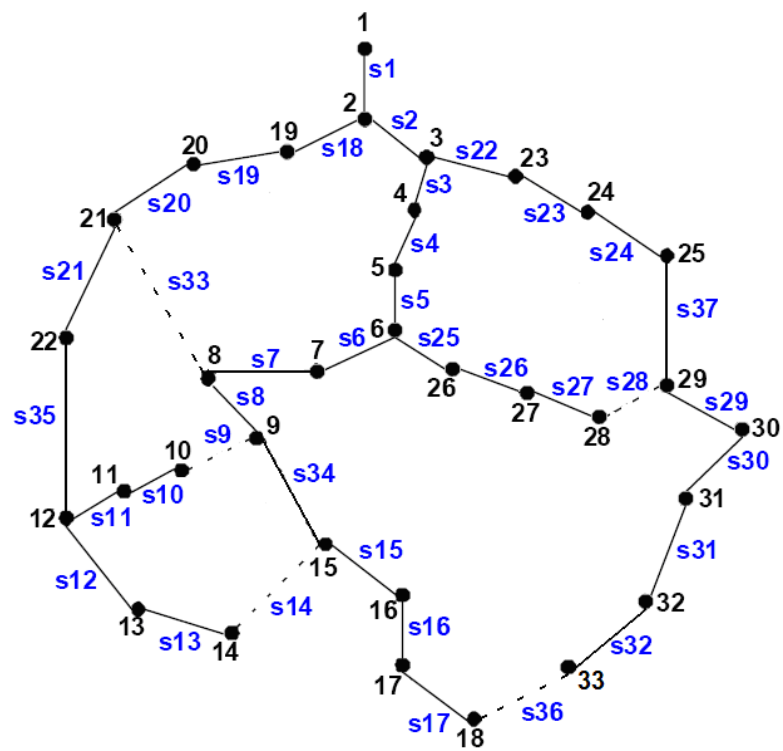

Figura 6.5 - Topologia encontrada pelo ACS-R - 33 barras - teste 2.

Apesar de não ter encontrado, em ambos os testes para o sistema de 33 barras, a melhor topologia ou uma topologia com perdas menores que a encontrada por Gomes et. al. (2005), o método foi capaz de encontrar uma topologia com um valor de perdas ativas muito próximo daquelas, o que demonstra a sua capacidade de encontrar boas soluções em ambos os testes.

\subsection{SISTEMA DE 69 BARRAS}

O terceiro sistema de teste é um sistema hipotético de $12,66 \mathrm{kV}$ e potência base de 10 MVA apresentado em Chiang e Jean-Jumeau (1990). Este sistema possui 69 barras (a barra 1 é a subestação) e 73 chaves seccionadoras, sendo originalmente 68 chaves fechadas e 5 chaves abertas como mostra a Figura 6.6. A topologia inicial deste sistema apresenta perdas ativas iguais a $20,91 \mathrm{KW}$. Os dados de barra e de linha deste sistema podem vistos no apêndice A. As metodologias, as quais o método ACS-R foi comparado, são as apresentadas em Chiang e Jean-Jumeau (1990), Mantovani, Casari e Romero (2000), e Guimarães (2005). 


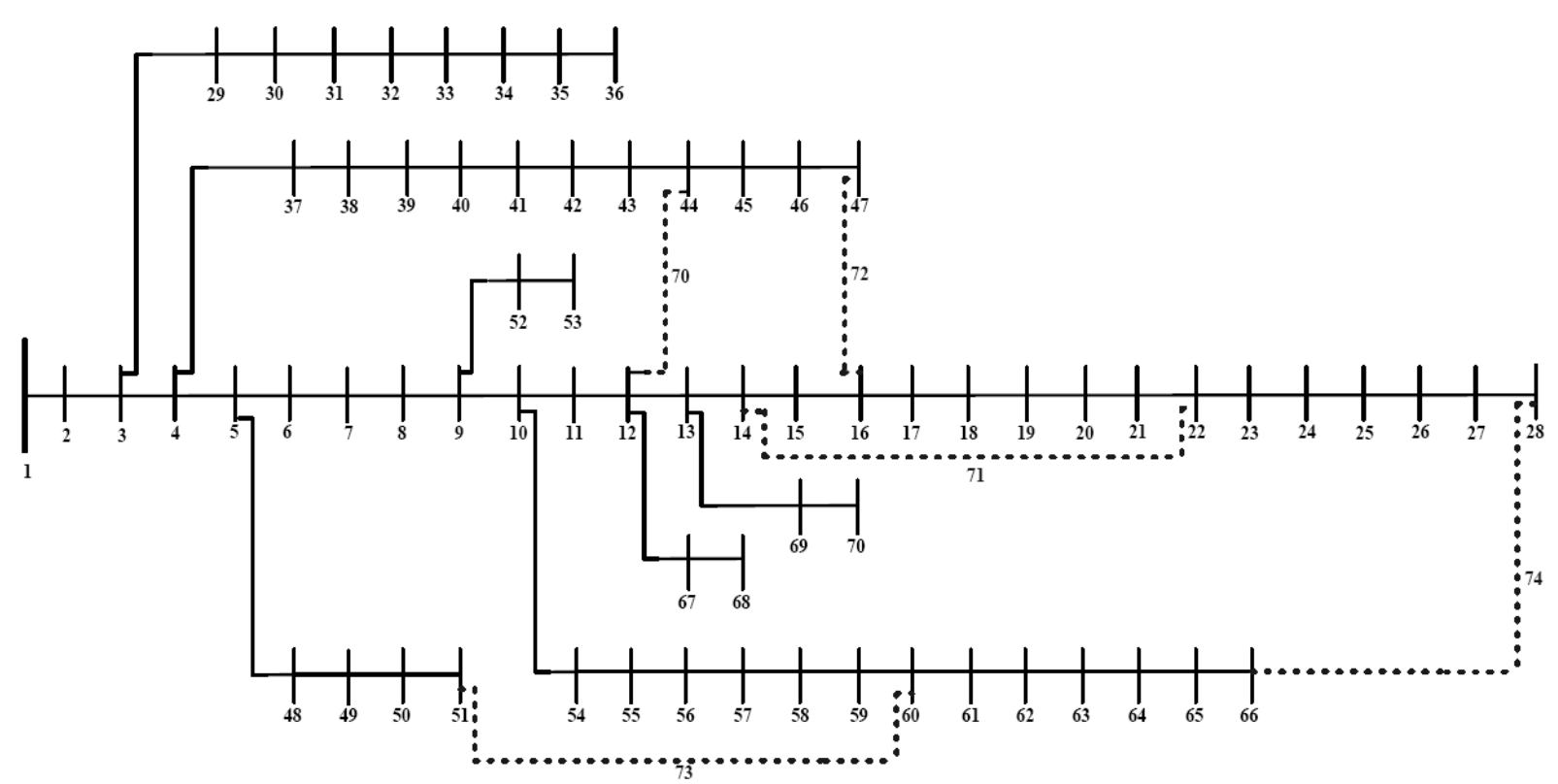

Figura 6.6 - Sistema de 69 barras $^{4}$.

Os resultados obtidos pelo ACS-R e a comparação de seu desempenho com outras metodologias podem ser vistos na Tabela 6.5 e a topologia correspondente à encontrada pelo ACS-R pode ser vista na Figura 6.7.

Tabela 6.5 - Resultados obtidos para o sistema de 69 barras.

\begin{tabular}{cccc}
\hline Experimentos & Perdas finais $(\mathbf{k W})$ & Redução $(\%)$ & $\begin{array}{c}\text { Chaves abertas } \\
\text { (número da linha) }\end{array}$ \\
\hline ACS-R & 9,34 & 55,33 & $15-57-62-70-71$ \\
Chiang & 9,34 & 55,33 & $15-57-62-70-71$ \\
Lorenzeti & 9,42 & 54,95 & $14-58-62-70-71$ \\
Mantovani & 9,34 & 55,33 & $15-57-62-70-71$ \\
Guimarães & 9,41 & 54,98 & $15-59-62-70-71$ \\
\hline
\end{tabular}

Verifica-se que o método ACS-R encontra, juntamente com os métodos de Chiang e Jean-Jumeau (1990) e Mantovani, Casari e Romero (2005), a topologia com menor valor de perdas ativas para o sistema de 69 barras. Estas perdas representam uma diminuição de pouco mais de $55 \%$ das perdas ativas para a configuração inicial.

\footnotetext{
${ }^{4}$ Figura retirada de Guimarães (2005).
} 


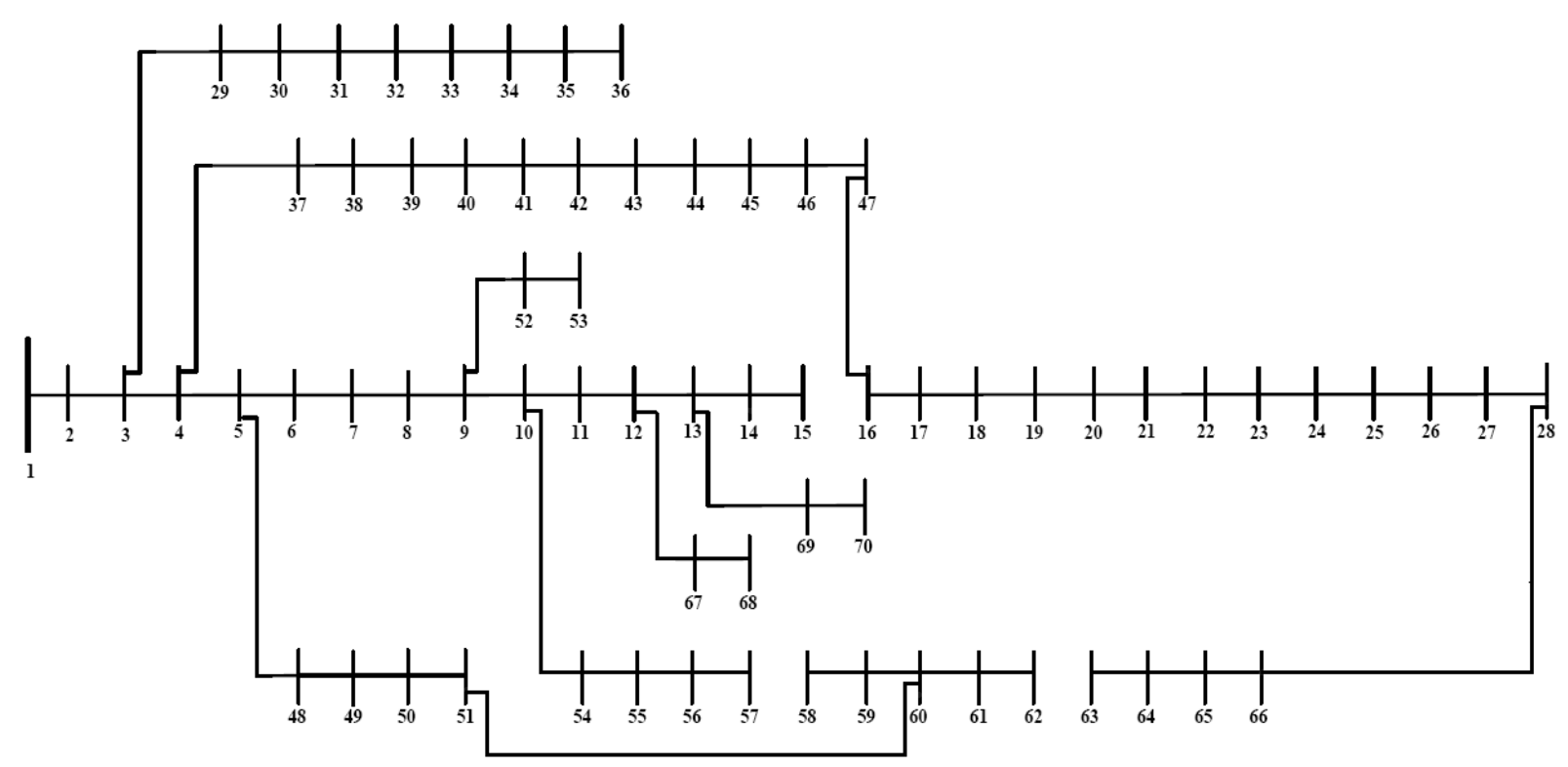

Figura 6.7 - Topologia encontrada pelo ACS-R - sistema de 69 barras.

\subsection{SISTEMA DE 136 BARRAS}

O quarto sistema de teste é um sistema real da cidade de Três Lagoas (MS) apresentado em Mantovani, Casari e Romero (2000). A tensão base é de 13,8 kV e potência base de 100 MVA. Este sistema possui 136 barras (a barra 1 é a subestação) e 156 chaves seccionadoras, sendo originalmente 135 chaves fechadas e 21 chaves abertas como mostra a Figura 6.8. A topologia inicial deste sistema apresenta perdas ativas iguais a $320,30 \mathrm{KW}$. Os dados de barra e de linha deste sistema podem vistos no apêndice A. As metodologias, as quais o método ACS-R foi comparado, são as apresentadas em Mantovani, Casari e Romero (2000), Lorenzeti (2004) e Guimarães (2005).

Os resultados obtidos pelo ACS-R e a comparação de seu desempenho com o destas metodologias podem ser vistos na Tabela 6.6. Nesta verifica-se que o método ACS-R encontra a topologia com maior valor perdas ativas para o sistema de 136 barras em relação às topologias encontradas pelos outros métodos. As perdas, para esta topologia, representam uma diminuição de quase $11 \%$ das perdas ativas para a configuração inicial.

Apesar de não ter encontrado a topologia que apresente o menor valor de perdas ativas, o método foi capaz de encontrar uma topologia com um valor muito próximo desta. A diferença entre a melhor topologia encontrada (GUIMARÃES, 2005) e a encontrada pelo 
ACS-R é de aproximadamente 2,03\%., o que demonstra a sua capacidade de encontrar boas soluções. A topologia correspondente à encontrada pelo ACS-R pode ser vista na Figura 6.9:

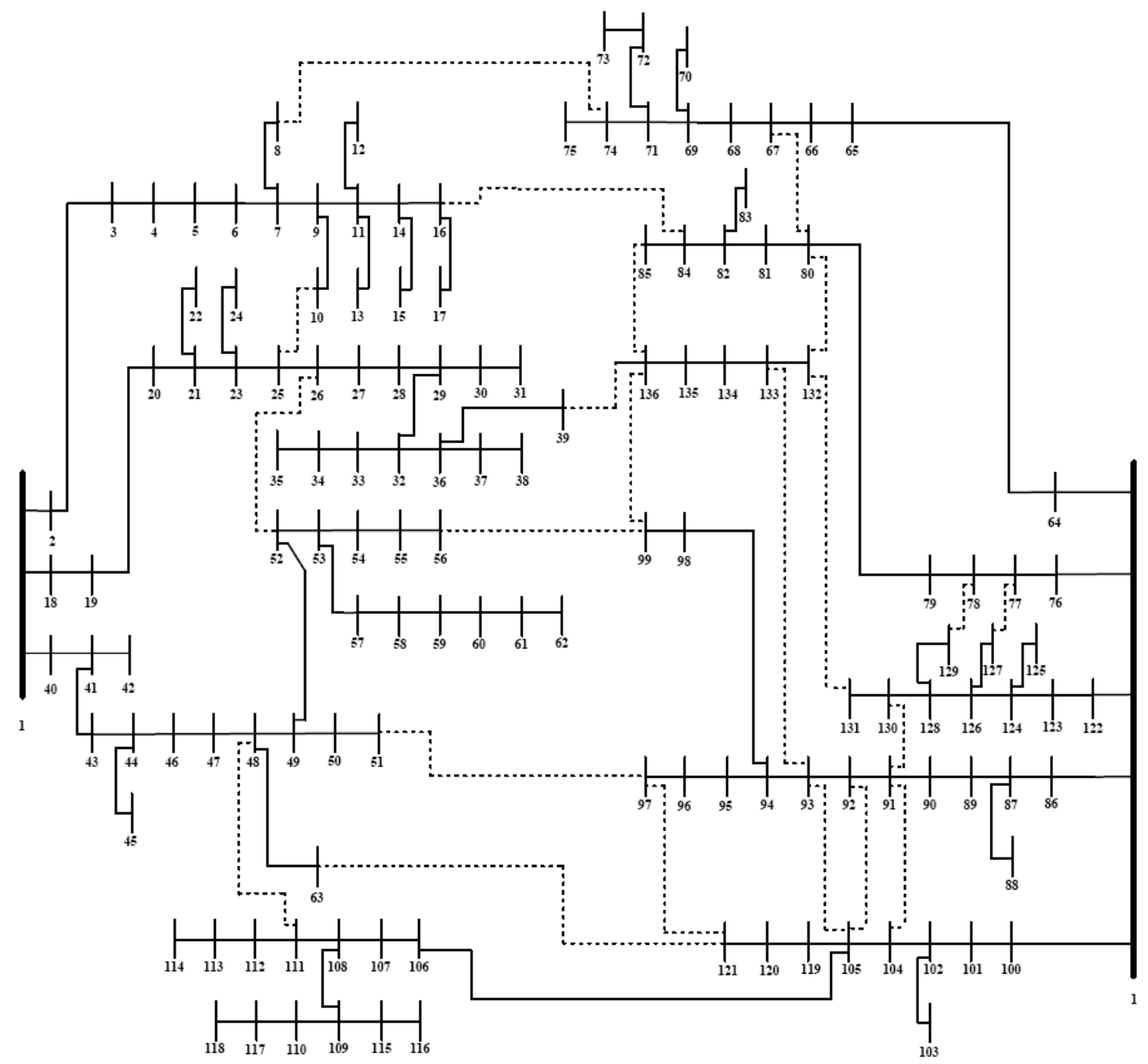

Figura 6.8 - Sistema de 136 barras $^{5}$

Tabela 6.6 - Resultados obtidos para o sistema de 136 barras.

\begin{tabular}{|c|c|c|c|}
\hline Método & $\begin{array}{c}\text { Perdas } \\
(\mathbf{k W})\end{array}$ & $\begin{array}{c}\text { Redução } \\
(\%)\end{array}$ & $\begin{array}{l}\text { Chaves abertas } \\
\text { (número da linha) }\end{array}$ \\
\hline ACS-R & 285,91 & 10,74 & $\begin{array}{l}7-106-137-138-139-140-141-142-143-144-145 \\
\quad-146-147-148149-150-151-152-154-155-156\end{array}$ \\
\hline Guimarães & 280,23 & 12,51 & $\begin{array}{c}7-38-51-53-90-96-106-118-126-137-138-141 \\
\quad-144-145-146147-148-150-151-155-156\end{array}$ \\
\hline Lorenzeti & 284,46 & 11,19 & $\begin{array}{c}38-51-53-106-119-136-137-138-141-144-145- \\
\quad 146-147-148149-150-151-152-154-155-156\end{array}$ \\
\hline Mantovani & 285,50 & 10,95 & $\begin{array}{c}51-136-137-138-139-141-142-143-144-145- \\
146-147-148-149150-151-152-106-154-155- \\
156\end{array}$ \\
\hline
\end{tabular}

\footnotetext{
${ }^{5}$ Figura retirada de Lorenzeti (2004).
} 


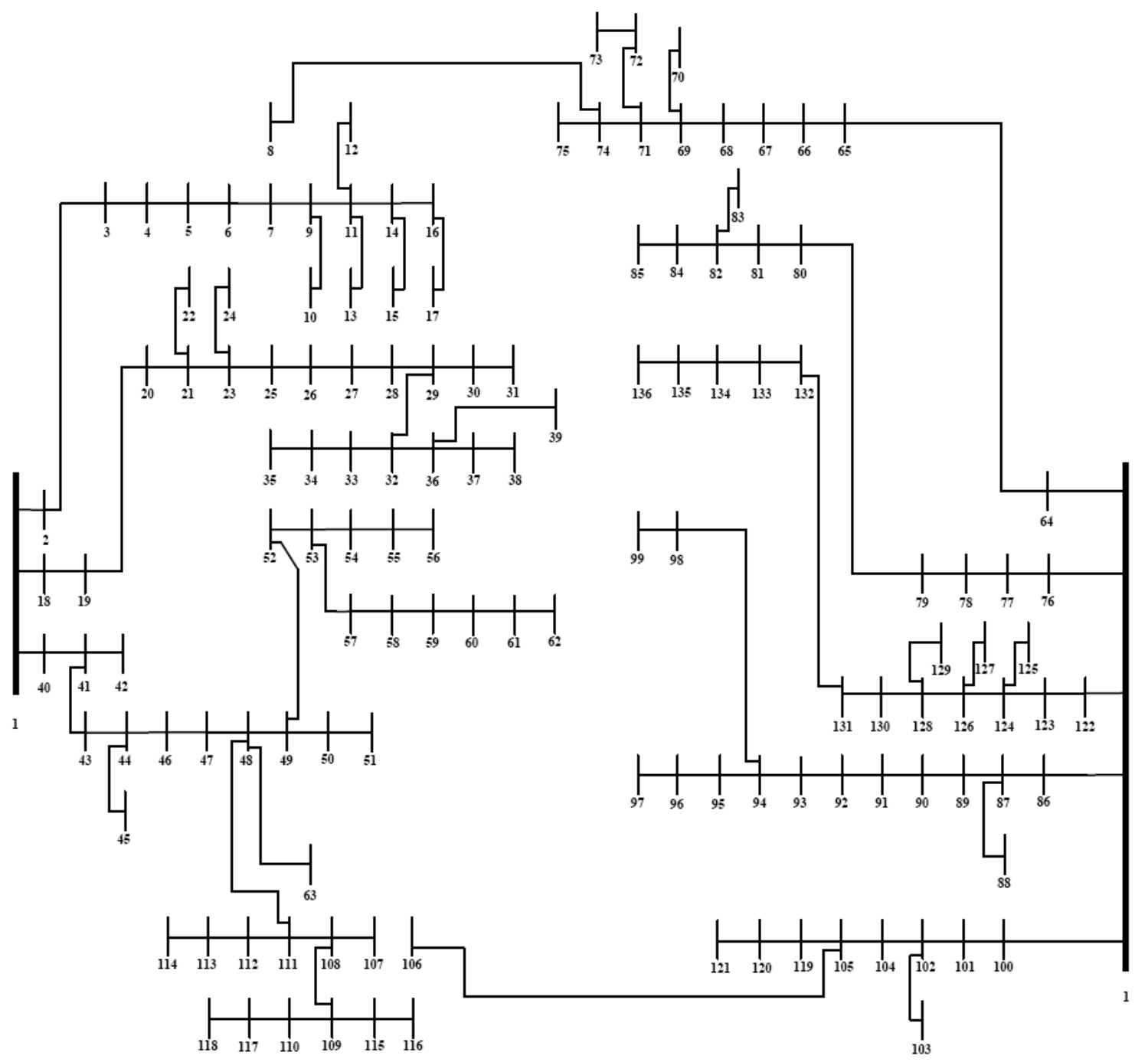

Figura 6.9 - Topologia encontrada pelo ACS-R - sistema de 136 barras.

\subsection{CONCLUSÕES}

Neste capítulo foram apresentados os testes realizados com quatro sistemas de distribuição conhecidos da literatura para a redução de perdas ativas através da reconfiguração. Em todos os testes foram feitas comparações com outras metodologias que também fizeram uso destes sistemas. Os resultados mostram que o ACS-R foi eficaz ao encontrar configurações de ótima qualidade em todos os testes, tanto para sistemas pequenos como de grande porte. Os resultados, ainda que não representem a melhor solução, o que é aceitável por ser tratar de uma metaheurística, apresentaram níveis de redução de perdas em relação às configurações iniciais coerentes com os encontrados na literatura.

No próximo capítulo são apresentadas conclusões e propostas para trabalhos futuros. 


\section{CAPÍTULO 7}

\section{CONCLUSÕES}

A proposta deste trabalho foi resolver o problema de reconfiguração de sistemas de distribuição de energia elétrica para redução de perdas ativas através de uma nova metodologia baseada no comportamento de colônias de formigas em busca de alimentos na natureza. Nesta metodologia, denominada de otimização por colônias de formigas (Ant Colony Optimization - ACO), formigas artificiais (agentes), exploram o meio ambiente (sistema de distribuição) e trocam informações para tentar encontrar a topologia que apresente o menor valor de perdas ativas.

Inicialmente, demonstrou-se como o método ACO foi idealizado e o primeiro algoritmo, denominado Sistema de Formigas (Ant System - AS), foi estruturado e aplicado ao problema do caixeiro viajante (Travelling Salesman Problem - TSP) no início da década de 90. Nos anos que se seguiram, o algoritmo AS foi sendo modificado para incorporar características que melhorassem seu desempenho para o TSP. As variações do AS que tiveram mais sucesso foram o Max-Min Ant System (MMAS) e o Ant Colony System (ACS), sendo que esta última é a mais utilizada por ter um desempenho melhor que o de seus antecessores.

A adaptação do ACS ao problema de reconfiguração foi possível devido ao fato que, tanto o problema do caixeiro viajante como o de reconfiguração de redes de distribuição apresentarem, em sua natureza, a mesma estrutura. Porém, ao se aplicar o ACS-TSP ao problema de reconfiguração, verificou-se que ele atuava em uma sub-região do espaço total de configurações possíveis - o que limitou o método para este tipo de problema.

Verificou-se que este fato estava diretamente associado ao modo como os agentes geravam as topologias no ACS-TSP. Ao fazer a busca por novas topologias, cada agente construía sua própria topologia a cada novo ciclo. Estas topologias eram representadas por uma linha que interligava todas as barras do sistema, não possuindo ramificações, o que não condiz com os sistemas de distribuição, que possuem um número significativo de ramos. Portanto, para contornar esta limitação, propôs-se uma modificação na forma de os agentes gerarem novas topologias. 
O algoritmo ACS-TSP tradicional foi então adaptado para incorporar esta modificação. Nesta modificação, os agentes atuam em conjunto para construir apenas uma única topologia por ciclo, ao invés de cada um construir a sua própria. Ao mesmo tempo em que esta simples modificação fez com que o espaço de busca aumentasse, tornou os ciclos mais rápidos, uma vez que diminuiu o número de passos necessários para gerar uma topologia radial e apenas um fluxo de carga é executado por ciclo. A este algoritmo adaptado foi dado o nome de ACS-R.

Os testes iniciais realizados para a análise do comportamento do ACS-R na reconfiguração de redes de distribuição de diferentes tamanhos, foram considerados ótimos uma vez que, mesmo quando não encontrada a melhor topologia, o método foi capaz de encontrar topologias com o valor de perdas resistivas muito próximo desta.

O ACS-R, além de ser independente da configuração inicial do sistema, tem a vantagem de não precisar de uma subrotina para verificar se as topologias geradas pelos agentes são radiais. A forma como as topologias são geradas a cada ciclo, garante que todas são factíveis do ponto de vista da radialidade. Uma vez que a subrotina de verificação de radialidade não é executada - e, por ciclo, apenas um fluxo de carga é executado -, o ACS-R torna-se um método simples e muito atraente para o problema de reconfiguração de redes de distribuição. Assim, todo o processo de reconfiguração fica restrito à geração de topologias pelo ACS-R e ao cálculo das perdas ativas pelo fluxo de potência.

Para o cálculo das perdas ativas, este trabalho também apresentou uma nova abordagem para resolução do problema de fluxo de potência (FP) adaptada às características dos sistemas de distribuição radiais. A abordagem consiste na associação dos métodos da função Penalidade-Newton (FPN). Um estudo comparativo entre o método da FPN e os métodos clássicos, BFS e Baran-Wu, de cálculo de FP para redes de distribuição de energia elétrica foi analisado em diferentes sistemas radiais. Em todos os testes realizados, o método da FPN teve um desempenho superior aos métodos clássicos.

Uma importante contribuição da aplicação do método da FPN ao problema de FP radial é a obtenção dos multiplicadores de Lagrange, os quais podem ser usados para estudos de alocação de reativos, geração distribuída, entre outros. 


\subsection{TRABALHOS FUTUROS}

Com a intenção de aumentar a eficácia do método ACS-R na busca pela topologia que represente o menor valor de perdas ativas, pretende-se estudar outras formas de os agentes escolherem os nós a serem visitados. Também será realizada uma análise dos parâmetros que guiam a busca dos agentes, para verificar como eles afetam a convergência do método.

Com base nestas informações, mais testes serão realizados, com o intuito de verificar o comportamento do ACS-R quando aplicado a sistemas de distribuição reais e maiores, e também de testar sua eficiência no problema de restabelecimento de energia em sistemas de distribuição.

Ainda como trabalhos futuros, pretende-se calcular e analisar o problema de fluxo de potência radial considerando as barras de controle de reativos. O objetivo é proporcionar as empresas de distribuição de energia elétrica uma ferramenta computacional capaz de auxiliar os operadores do sistema de distribuição com eficácia. 


\section{REFERENCIAS $^{1}$}

ABUR, A. A modified linear programming method for distribution system reconfiguration. International Journal of Electrical Power \& Energy Systems, vol. 18, no. 7, p. 469-474, Oct. 1996a

Determining the optimal radial network topology within the line flow constrains. In: IEEE International Symposium on Circuits and Systems, 1996 - ISCAS '96, 'Connecting the World', vol. 1, p. 673-676, May 12-15 1996b.

AHUJA, A.; PAHWA, A. Using ant colony optimization for loss minimization in distribution networks. In: Proceedings of the 37th Annual North American Power Symposium, p. 470-474, Oct. 2005.

AHUJA, A.; DAS, S.; PAHWA, A. An AIS-ACO hybrid approach for multi-objective distribution system reconfiguration. IEEE Transactions on Power System, vol. 22, no. 3, p. 1101-1111, Aug. 2007.

AMASIFEN, J. C. C.; ROMERO R. A.; MANTOVANI, J. R. S. Algoritmo evolutivo dedicado a reconfiguração de redes radiais de distribuição de energia elétrica sob demandas variáveis. In: Anais do XV Congresso Brasileiro de Automática - CBA 2004, Gramado RS, vol. 1, p. 1-6, 2004.

AOKI, K. et al.. New approximate optimization method for distribution systems planning. IEEE Transactions on Power System, vol. 5, no. 1, p. 126-132, Feb. 1990.

BARAN, M. E.; WU, F. F. Network reconfiguration in distribution systems for loss reduction and load balancing. IEEE Transactions on Power Delivery, vol. 4, no. 2, p. 1401-1407, Apr. 1989a.

Optimal capacitor placement on radial distribution systems. IEEE Transactions on Power Delivery, vol. 4, no. 1, p. 725-734, Jan. 1989b.

BARROS, J. R. P.; MELO, A. C. G. Usando a meta-heurística colônias de formigas para alocar dispositivos de manobra e proteção em redes de distribuição. In: Simpósio de Especialistas em Planejamento da Operação e Expansão Elétrica - X SEPOPE, Florianópolis - SC, 21-25 de maio de 2006.

\footnotetext{
${ }^{1}$ De acordo com ASSOCIAÇÃO BRASILEIRA DE NORMAS TÉCNICAS. NBR 6023.
} 
BAZARAA, M. S., SHETY, C. M. Nonlinear programming: theory and algorithms. New York: John Wiley, 1979, p. 560.

BENEMAR, A. S. et al. Configuração de redes de distribuição via algoritmo de formigas. In: Anais do IX Simpósio Brasileiro de Automação Inteligente - IX SBAI, Brasília - DF, 2023, set. 2009.

BIJWE, P. R.; RAJU, V. Fuzzy distribution power flow for weakly meshed systems. IEEE Transactions on Power System, vol. 21, no. 4, p. 1645-1652, Nov. 2006.

BLUM, C; DORIGO, M. The hyper-cube framework for ant colony optimization. IEEE Transactions on systems, man, and cybernetics, vol. 34, no. 2, p. 1161-1172, Apr. 2004.

BONABEAU, E; DORIGO, M.; THERAULAZ, G. Swarm intelligence: from natural to artificial systems. New York: Oxford University Press, 1999, pp. 307.

BUENO, E. A. Redução de perdas técnicas através de reconfigurações de redes de distribuição de energia elétrica sob demandas variáveis. 2005. 148 f. Tese (Doutorado em Engenharia Elétrica) - Faculdade de Engenharia Elétrica e Computação da Universidade de Campinas, Campinas - SP, 2005.

CARPANETO, E.; CHICCO, G. Ant colony search-based minimum losses reconfiguration of distribution systems. In: Proceedings of the 12th IEEE Mediterranean Electrotechnical Conference, 2004 - MELECON 2004, vol. 3, p. 12-15, May 2004.

Distribution system minimum loss reconfiguration in the hyper-cube ant colony optimization framework. Electric Power Systems Research, vol. 78, no. 12, p. 2037-2045, Dec. 2008.

CASTRO JR., C. A.; WATANABE, A. A. An efficient reconfiguration algorithm for loss reduction of distribution systems. Electric Power Systems Research, vol. 19, no. 2, p. 137144, Aug. 1990.

CAVELLUCI, C. Buscas Informadas baseadas em grafos para a minimização das perdas em sistemas de distribuição de energia elétrica. 1998. 139 f. Tese (Doutorado em Engenharia Elétrica) - Faculdade de Engenharia Elétrica e Computação da Universidade de Campinas, Campinas - SP, 1998.

CESPEDES, R. G. New method for the analysis of distribution networks. IEEE Transactions on Power Deliver, vol. 5, no. 1, p. 391-396, Jan. 1990. 
CHANG, C-F. Reconfiguration and capacitor placement for loss reduction of distribution systems by ant colony search algorithm. IEEE Transactions on Power Systems, vol. 23, no. 4, p. $1747-1755$, Nov. 2008

CHANG, G. W.; CHU, S. Y.; WANG, H. L. An improved backward-forward sweep load flow algorithm for radial distribution systems. IEEE Transactions on Power Systems, vol. 22, no. 2, p. 882-284, May 2007.

CHARLES D. L.; KHAN, I.H; RAVICHANDRAN, S. Distribution network reconfiguration for loss reduction using ant colony system algorithm. In: Annual IEEE India Conference, 2005 - INDICON 2005, p. 619 - 622, Dec. 2005.

CHENG, C. S.; SHIRMOHAMMADI, D. A three-phase power flow method for real-time distribution system analysis. IEEE Transactions on Power Systems, vol. 10, no. 2, p. 671679, May 1995.

CHIANG, H-D; JEAN-JUMEAU, R. Optimal network reconfigurations in distribution systems: Part 2: Solution algorithms and numerical results. IEEE Transactions on Power Delivery, vol 5, no.3, July 1990.

CHIOU, J-P; CHANG, C-F; SU, C-T. Ant direction hybrid differential evolution for solving large capacitor placement problems. IEEE Transactions on Power Systems, vol. 19, no. 4, p. 1794- 1800, Nov. 2004.

CHIS, M.; SALAMA, M. M. A.; JAYARAM, S. Capacitor placement in distribution systems using heuristic search strategies, IEE Proceedings - Generation, Transmission and Distribution, vol. 144, no. 3, p. 225-230, May 1997.

CIVANLAR, S. et al. Distribution reconfiguration for loss reduction. IEEE Transactions on Power Delivery, vol. 3, no. 3, p. 1217-1223, Jul. 1988.

DELBEM, A. C. B. Restabelecimento de energia em sistemas de distribuição por algoritmo evolucionário associado a cadeias de grafos. 2002. $114 \mathrm{f}$. Tese (Doutorado em Engenharia elétrica) - Escola de engenharia de São Carlos - USP, São Carlos - SP, 2002.

DENIS, I. F. E. D.; PADILHA, A. Fluxo de potência trifásico para redes de distribuição. Anais do XIII Congresso brasileiro de Automática, 2000 - CBA 2000, Florianópolis - SC - Brasil, p. 1598-1603, set. 2000. 
DORIGO, M.; DI CARO, G. Colony optimization: a new meta-heuristic. In: Proceedings of the 1999 Congress on Evolutionary Computation, 1999 - CEC 99, vol. 2, p. 1470-1477, July 1999.

DORIGO, M.; GAMBARDELLA, L. M. Ant colony system: a cooperative learning approach to the traveling salesman problem. IEEE Transactions on Evolutionary Computation, vol. 1, no. 1, p. 53-66, Apr. 1997.

DORIGO, M. ; BIRATTARI, M. ; STÜTZLE, T. Ant colony optimization. IEEE Computational Intelligence Magazine, vol. 1, no. 4, p. 28-39, Nov. 2006.

DORIGO, M.; DI CARO, G.; GAMBARDELLA, L. M. Ant algorithms for discrete optimization. Artificial Life, v. 5, no. 2 p. 172-176, 1999.

DORIGO, M.; MANIEZZO, V.; COLORNI, A. Ant system: optimization by a colony of cooperating agents. IEEE Transactions on Systems, Man and Cybernetics, Part B, vol. 26, no. 1, p. 29-41, Feb. 1996.

DORIGO, M.; STÜTZLE, T. Ant colony optimization. Cambridge, Massachusetts: The MIT Press, 2004, p. 305.

FONTAN, D. M. S. Reconfiguração de Sistemas de Distribuição Utilizando um Algoritmo Evolutivo. 2008. 65 f. Dissertação (Mestrado em Engenharia Elétrica) - Centro de Ciências e Tecnologia da Universidade Federal de Campina Grande - UFCG, Campina Grande - Paraíba, 2008.

GAMBARDELLA, L. M.; DORIGO, M. Solving symmetric and asymmetric TSPs by ant colonies. In: Proceedings of IEEE International Conference on Evolutionary Computation, p. 622-627, May 1996.

GHORBANI, M.A.; HOSSEINIAN, S.H.; VAHIDI, B. Application of Ant Colony System algorithm to distribution networks reconfiguration for loss reduction. In: 11th International Conference on Optimization of Electrical and Electronic Equipment, 2008 - OPTIM 2008, p. 269-273, May 2008.

GLAMOCANIN, V. Optimal loss reduction of distribution networks. IEEE Transactions on Power System, vol. 5, no. 3, p. 774-782, Aug. 1990.

GOMES, F. V. et al. A new heuristic reconfiguration algorithm for large distribution system. IEEE Transactions on Power System, vol. 20, no. 3, p. 1373-1378, Aug. 2005. 
GOMEZ J. F. et. al. Ant colony system algorithm for the planning of primary distribution circuits. IEEE Transactions on Power System, vol. 19, no. 2, p. 996-1004, May 2004.

GOSWAMI, S. K.; BASU, S. K. A new algorithm for the reconfiguration of distribution feeders for loss minimization. IEEE Transactions on Power Delivery, vol. 7, no. 3, p. 1484-1491, July 1992.

GRAINGER, J. J.; LEE, S. H. Capacity Release by Shunt Capacitor Placement on Distribution Feeders: A New Voltage-Dependent Model, IEEE Transactions on Power Apparatus and Systems, vol. 101, no. 5, p. 1236-1244, May 1982.

GUIMARÃES, M. A. N. Reconfiguração de redes de distribuição de energia elétrica utilizando algoritmos de busca tabu. 2005. 108 f. Dissertação (Mestrado em Engenharia Elétrica) - Faculdade de Engenharia Elétrica e Computação da Universidade Estadual de Campinas - UNICAMP, Campinas - SP, 2005.

HAYASHI, Y. et al. Efficient determination of optimal radial power system structure using Hopfield neural network with constrained noise. IEEE Transactions on Power Delivery, vol. 11, no. 3, p. 1529-1535, July 1996.

HÖLLDOBLER. B.; WILSON, E. O. The ants. Cambridge, MA: Belknap Press of Harvard University Press, 1990, 732 p.

HOU, Y-H et al. Generalized ant colony optimization for economic dispatch of power systems. In: Proceedings of International Conference on Power System Technology, PowerCon 2002, vol. 1, p. 225-229, Oct 13-17 2002.

HSU, Y.-Y. et al. Distribution system service restoration using a heuristic search approach. IEEE Transactions on Power Delivery, vol. 7, no. 2, p. 734-740, Apr. 1992.

HU, Z. et. al. Distribution network reconfiguration based on ant colony system algorithm. IEEE Transactions on Power Delivery, vol. 23, no. 3, p. 1288 - 1295, July 2008.

IPPOLITO, M. G.; SANSEVERINO, E. R.; VUINOVICH, F. Multiobjective ant colony search algorithm optimal electrical distribution system planning. In: Congress on Evolutionary Computation. CEC 2004, vol. 2, p. 1924- 1931, June 19-23 2004.

JASMON, G. B.; LEE, L. H. C. C. A modified technique for minimization of distribution system losses. Electric Power Systems Research, vol. 20, no. 2, p. 81- 88, Feb. 1991. 
KASHEM, M. A.; JASMON, G. B., GANAPATHY, V. A new approach of distribution system reconfiguration for loss minimization. International Journal of Electrical Power \& Energy Systems, vol. 22, no. 4, p. 269-276, May 2000.

KHOA, T.Q.D., BINH, P.T.T. A hybrid ant colony search based reconfiguration of distribution network for loss reduction. In: IEEE/PES Transmission \& Distribution Conference and Exposition: Latin America. T\&D 2006, p. 1-7, Aug. 2006.

KIM, H.; KO, Y.; JUNG, K.-H. Artificial neural-network based feeder reconfiguration for loss reduction in distribution systems. IEEE Transaction on Power Delivery, vol. 8, no. 3, p. 1356-1366, July 1993.

LAI, L. L.; MA, J. T. Application of evolutionary programming to reactive power planningcomparison with nonlinear programming approach. IEEE Transactions on Power System, vol. 12, no. 1, p. 198-206, Feb. 1997.

LIN, W.-M.; CHENG, F.-S.; TSAY, M.-T. Distribution feeder reconfiguration with refined genetic algorithm. In: IEE Proceedings - Generation, Transmission and Distribution, vol. 147, no. 6, p. 349-354, Nov. 2000.

LORENZETI, J. F. C. Reconfiguração de sistemas de distribuição de energia elétrica para a melhoria das condições de operação com relação à estabilidade de tensão. 2004. 99f. Dissertação (Mestrado em Engenharia Elétrica) - Faculdade de Engenharia Elétrica e Computação da Universidade Estadual de Campinas - UNICAMP, Campinas - SP, 2004.

MANTOVANI, J. R. S.; CASARI, F.; ROMERO, R. A. Reconfiguração de sistemas de distribuição radiais utilizando o critério da queda de tensão. Revista SBA: Controle \& Automação, vol. 11, no. 3, set., out., nov., dez. 2000.

MCDERMOTT, T. E.; DREZGA, I.; BROADWATER, R. P. A heuristic nonlinear constructive method for distribution system reconfiguration. IEEE Transactions on Power System, vol. 14, no. 2, p. 478 - 483, May 1999.

MENDONZA, J. et al. Minimal loss reconfiguration using genetic algorithms with restricted population and address. IEEE Transactions on Power System, vol. 21, no. 2, p. 948 - 954, may 2006.

MERLIN, A.; BACK, H. Search for a minimal-loss operation spanning tree configuration in a urban power distribution system. In: Proceedings of $5^{\text {th }}$ Power System Computation Conference - PSCC, Cambridge, UK, v.1, p. 1-18, 1975. 
MONTICELLI, A. J. Fluxo de carga em redes de energia elétrica. São Paulo: Editora Edgard Blücher Ltda., 1983, 164 p.

NARA, K. An improved genetic algorithm for large scale distribution systems loss minimum problem. In: IEEE International Conference on Evolutionary Computation, vol. 1, p. 120-125, Nov 29 - Dec. 11995.

NARA, K. et al. Implementation of genetic algorithm for distribution systems loss minimum reconfiguration. IEEE Transactions on Power Systems, vol. 7, no. 3, p. 1044-1051, Aug. 1992.

PACHECO, M. A. C. Algoritmos genéticos: princípios e aplicações. 1999. Disponível em: <http://www.ica.ele.puc-rio.br/Downloads/38/CE-Apostila-Comp-Evol.pdf > Acesso em: 14 de junho de 2009.

PATRA, S.; GOSWAMI, S. K. Optimum power flow solution using a non-interior point method. Electrical Power and Energy Systems, vol. 29, no. 2, p. 138-146, Feb. 2007.

QUEIROZ, L. M. O.; FILHO, C. L. Redução de perdas por reconfiguração de redes radiais de distribuição de energia elétrica sob demandas variadas por um algoritmo genético adaptativo. In: Anais do XVI Congresso Brasileiro de Automática - CBA 2006, Salvador - BA Brasil, p. 2903-2908, 3-6 out. 2006.

RAJIČIĆ, D.; BOSE, A. A modification to the fast decoupled power flow for networks with high R/X ratios. IEEE Transactions on Power Systems, vol. 3, no. 2, p. 743-746, May 1988.

SALAZAR H.; GALLEGO R.; ROMERO R. Artificial neural networks and clustering techniques applied in the reconfiguration of distribution systems. IEEE Transactions on Power Delivery, vol. 21, no. 3, p. 1735-1742, Jul. 2006.

SALUME, G. N. et al. Reconfiguração de sistemas de distribuição desbalanceados utilizando metodologia heurística e fluxo de potência trifásico. In: Anais do XVI Congresso Brasileiro de Automática - CBA 2006, Salvador - BA - Brasil, p. 2263-2268, 3-6 out. 2006.

SARFI, R. J.; SALAMA, M. M. A.; CHIKHANI, A. Y. A survey of the state of the art in distribution system reconfiguration for system loss reduction. Electric Power System Research, vol. 30, no. 1, p. 61-70, Oct. 1994. 
SHIRMOHAMMADI, D.; HONG, H. W. Reconfiguration of electric distribution networks for resistive line losses reduction. IEEE Transactions on Power Delivery, vol. 4, no. 2, p. 1492-1498, Apr. 1989.

SHIRMOHAMMADI, D. et al. A compensation-based power flow method for weakly meshed distribution and transmission networks. IEEE Transactions on Power Systems, vol. 3, no. 2, p. 753-762, May 1988.

SISHAJ P. S.; PADHY, N. P.; ANAND, R. S. An ant colony system approach for unit commitment problem. International Journal of Electrical Power \& Energy Systems, vol. 28 , no. 5, p. 293-358, June 2006a.

Ant colony system based unit commitment problem with gaussian load distribution. IEEE Power Engineering Society General Meeting, p.1-8, June 18-22 2006b.

SOUSA, V. A.; PEREIRA, F. S.; DA COSTA, G. R. M. Fluxo de carga em sistemas de distribuição: método da função penalidade. In: Anais do XVII Congresso Brasileiro de Automática - CBA 2008, Juiz de Fora - MG - Brasil, p. 1-6, 14-17 set. 2008.

SU, C-T.; CHANG, C-F.; CHIOU, J-P. Distribution network reconfiguration for loss reduction by ant colony search algorithm. Electric Power Systems Research, vol. 75, no. 23, p. 190-199, Aug. 2005.

SUM-IM, T. Economic dispatch by ant colony search algorithm. In: IEEE Conference on cybernetics and intelligent systems, 2004, vol. 1, p. 416- 421, Dec. 1-3 2004.

TENG, J-H. A modified Gauss-Seidel algorithm of three-phase power flow analysis in distribution networks. International Journal of Electrical Power \& Energy Systems, vol. 24, no. 2, p. 97-102, feb. 2002.

TENG, J-H; LIU, Y-H; Application of the ant colony system for optimum switch adjustment. In: IEEE/PES Transmission and Distribution Conference and Exhibition: Asia Pacific, 2002, vol. 2, p. 751 - 756, Oct. 6-10 2002.

VITTORI, K. Estudo experimental, modelagem e implementação do comportamento de colônias de formigas em um ambiente dinâmico. 2005. Tese (Doutorado em Engenharia Elétrica) - Escola de Engenharia de São Carlos - USP, São Carlos - SP, 2005. 
VLACHOGIANNIS, J. G.; HATZIARGYRIOU, N. D.; LEE, K. Y. Ant colony system-based algorithm for constrained load flow problem. IEEE Transactions on Power Systems, vol. 20, no. 3, p. 1241- 1249, Aug. 2005.

WAGNER, T. P., CHIKHANI, A. Y., HACKAM, R. Feeder reconfiguration for loss reduction: an application of distribution automation. IEEE Transactions on Power Delivery, vol. 6, no. 4, p. 1922-1933, Oct. 1991.

ZHANG, F.; CHENG, C. S. A modified Newton method for radial distribution system power flow analysis. IEEE Transactions on Power Systems, vol. 12, no. 1, p. 389-397, Feb. 1997.

ZHIJIAN HU; XIXIONG HE; YANG GAO; DONG LIU. Distribution network reconfiguration based on ant colony system algorithm. In: $3^{\text {rd }}$ IEEE Conference on Industrial Electronics and Applications, 2008 - ICIEA 2008, p. 2470 - 2474, June 2008. 


\section{APÊNDICE A}

\section{DADOS DOS SISTEMAS DE DISTRIBUIÇÃO}

\section{A1 - Sistema de 5 barras:}

Tabela A1 - Dados de barra do sistema de 5 barras

\begin{tabular}{ccc}
\hline Barra & $\begin{array}{c}\text { Potência } \\
\text { ativa }(\mathbf{p u})\end{array}$ & $\begin{array}{c}\text { Potência } \\
\text { reativa }(\mathbf{p u})\end{array}$ \\
\hline 1 & 0 & 0 \\
2 & 1,28 & 1,28 \\
3 & 0,32 & 0,16 \\
4 & 1,60 & 0,80 \\
5 & 0,74 & 0,37 \\
\hline
\end{tabular}

A barra 1é subestação e o valor da tensão de referência é $V_{0}=1,05+j 0,0 p u$.

Tabela A1.1 - Dados de linha do sistema de 5 barras

\begin{tabular}{ccccc}
\hline Linha & Barra inicial & Barra final & $\mathbf{R}(\mathbf{p u})$ & $\mathbf{X}(\mathbf{p u})$ \\
\hline 1 & 1 & 2 & 0,0066 & 0,0033 \\
2 & 1 & 3 & 0,0016 & 0,0006 \\
3 & 2 & 3 & 0,0003 & 0,0002 \\
4 & 2 & 4 & 0,0051 & 0,0005 \\
5 & 3 & 4 & 0,0005 & 0,0005 \\
6 & 3 & 5 & 0,0027 & 0,0012 \\
7 & 4 & 5 & 0,0033 & 0,0015 \\
\hline
\end{tabular}


A2 - Sistema de 16 barras

Tabela A2 - Dados do sistema de 16 barras

\begin{tabular}{cccccccc}
\hline Linha & $\begin{array}{c}\text { Barra } \\
\text { inicial }\end{array}$ & Barra final & $\begin{array}{c}\text { Resistência } \\
\text { da linha } \\
\text { (p.u.) }\end{array}$ & $\begin{array}{c}\text { Reatância } \\
\text { da linha } \\
\text { (p.u.) }\end{array}$ & $\begin{array}{c}\text { Potência } \\
\text { ativa barra } \\
\text { final (MW) }\end{array}$ & $\begin{array}{c}\text { Potência } \\
\text { reativa } \\
\text { barra final } \\
\text { (kVAr) }\end{array}$ & $\begin{array}{c}\text { Capacitor } \\
\text { barra final } \\
\text { (MVAr) }\end{array}$ \\
\hline 1 & 1 & 4 & 0.0750 & 0.1000 & 2.000 & 1.600 & 0.000 \\
2 & 4 & 5 & 0.0800 & 0.1100 & 3.000 & 1.500 & 1.100 \\
3 & 4 & 6 & 0.0900 & 0.1800 & 2.000 & 0.800 & 1.200 \\
4 & 6 & 7 & 0.0400 & 0.0400 & 1.500 & 1.200 & 0.000 \\
5 & 2 & 8 & 0.1100 & 0.1100 & 4.000 & 2.700 & 0.000 \\
6 & 8 & 9 & 0.0800 & 0.1100 & 5.000 & 3.000 & 1.200 \\
7 & 8 & 10 & 0.1100 & 0.1100 & 1.000 & 0.900 & 0.000 \\
8 & 9 & 11 & 0.1100 & 0.1100 & 0.600 & 0.100 & 0.600 \\
9 & 2 & 12 & 0.0800 & 0.1100 & 4.500 & 2.000 & 3.700 \\
10 & 3 & 13 & 0.1100 & 0.1100 & 1.000 & 0.900 & 0.000 \\
11 & 13 & 14 & 0.0900 & 0.1200 & 1.000 & 0.700 & 1.800 \\
12 & 13 & 15 & 0.0800 & 0.1100 & 1.000 & 0.900 & 0.000 \\
13 & 15 & 16 & 0.0400 & 0.0400 & 2.100 & 1.000 & 1.800 \\
14 & 5 & 11 & 0.0400 & 0.0400 & & & \\
15 & 10 & 14 & 0.0400 & 0.0400 & & & \\
16 & 7 & 16 & 0.0900 & 0.1200 & & & \\
\hline
\end{tabular}


A3 - Sistema de 33 barras:

Tabela A3 - Dados do sistema de 33 barras

\begin{tabular}{|c|c|c|c|c|c|c|}
\hline Linha & Barra inicial & Barra final & $\begin{array}{c}\text { Resistência } \\
\text { da linha }(\Omega)\end{array}$ & $\begin{array}{c}\text { Reatância } \\
\text { da linha }(\Omega)\end{array}$ & $\begin{array}{c}\text { Potência ativa } \\
\text { barra final } \\
\text { (MW) }\end{array}$ & $\begin{array}{c}\text { Potência reativa } \\
\text { barra final } \\
\text { (kVAr) }\end{array}$ \\
\hline 1 & 1 & 2 & 0,0922 & 0,0470 & 100 & 60 \\
\hline 2 & 2 & 3 & 0,4930 & 0,2511 & 90 & 40 \\
\hline 3 & 3 & 4 & 0,3660 & 0,1864 & 120 & 80 \\
\hline 4 & 4 & 5 & 0,3811 & 0,1941 & 60 & 30 \\
\hline 5 & 5 & 6 & 0,8190 & 0,7070 & 60 & 20 \\
\hline 6 & 6 & 7 & 0,1872 & 0,6188 & 200 & 100 \\
\hline 7 & 7 & 8 & 0,7114 & 0,2351 & 200 & 100 \\
\hline 8 & 8 & 9 & 10,300 & 0,7400 & 60 & 20 \\
\hline 9 & 9 & 10 & 10,440 & 0,7400 & 60 & 20 \\
\hline 10 & 10 & 11 & 0,1966 & 0,0650 & 45 & 30 \\
\hline 11 & 11 & 12 & 0,3744 & 0,1238 & 60 & 35 \\
\hline 12 & 12 & 13 & 14,680 & 11,550 & 60 & 35 \\
\hline 13 & 13 & 14 & 0,5416 & 0,7129 & 120 & 80 \\
\hline 14 & 14 & 15 & 0,5910 & 0,5260 & 60 & 10 \\
\hline 15 & 15 & 16 & 0,7463 & 0,5450 & 60 & 20 \\
\hline 16 & 16 & 17 & 12,890 & 17,210 & 60 & 20 \\
\hline 17 & 17 & 18 & 0,7320 & 0,5740 & 90 & 40 \\
\hline 18 & 2 & 19 & 0,1640 & 0,1565 & 90 & 40 \\
\hline 19 & 19 & 20 & 15,042 & 13,554 & 90 & 40 \\
\hline 20 & 20 & 21 & 0,4095 & 0,4784 & 90 & 40 \\
\hline 21 & 21 & 22 & 0,7089 & 0,9373 & 90 & 40 \\
\hline 22 & 3 & 23 & 0,4512 & 0,3083 & 90 & 50 \\
\hline 23 & 23 & 24 & 0,8980 & 0,7091 & 420 & 200 \\
\hline 24 & 24 & 25 & 0,8960 & 0,7011 & 420 & 200 \\
\hline 25 & 6 & 26 & 0,2030 & 0,1034 & 60 & 25 \\
\hline 26 & 26 & 27 & 0,2842 & 0,1447 & 60 & 25 \\
\hline 27 & 27 & 28 & 10,590 & 0,9337 & 60 & 20 \\
\hline 28 & 28 & 29 & 0,8042 & 0,7006 & 120 & 70 \\
\hline 29 & 29 & 30 & 0,5075 & 0,2585 & 200 & 600 \\
\hline 30 & 30 & 31 & 0,9744 & 0,9630 & 150 & 70 \\
\hline 31 & 31 & 32 & 0,3105 & 0,3619 & 210 & 100 \\
\hline 32 & 32 & 33 & 0,3410 & 0,5302 & 60 & 40 \\
\hline 33 & 8 & 21 & 20,000 & 20,000 & & \\
\hline 34 & 9 & 15 & 20,000 & 20,000 & & \\
\hline 35 & 12 & 22 & 20,000 & 20,000 & & \\
\hline 36 & 18 & 33 & 0,5000 & 0,5000 & & \\
\hline 37 & 25 & 29 & 0,5000 & 0,5000 & & \\
\hline
\end{tabular}


A5 - Sistema de 69 barras

Tabela A5 - Dados do sistema de 69 barras

\begin{tabular}{|c|c|c|c|c|c|c|}
\hline Linha & $\begin{array}{l}\text { Barra } \\
\text { inicial }\end{array}$ & $\begin{array}{c}\text { Barra } \\
\text { final }\end{array}$ & $\begin{array}{c}\text { Resistência } \\
\text { da linha } \\
\text { (p.u.) }\end{array}$ & $\begin{array}{c}\text { Reatância } \\
\text { da linha } \\
\text { (p.u.) }\end{array}$ & $\begin{array}{c}\text { Potência ativa } \\
\text { barra final } \\
\text { (KW) }\end{array}$ & $\begin{array}{c}\text { Potência reativa } \\
\text { barra final } \\
\text { (kVAr) }\end{array}$ \\
\hline 1 & 1 & 2 & 0.0005 & 0.0012 & 0.0 & 0.0 \\
\hline 2 & 2 & 3 & 0.0005 & 0.0012 & 0.0 & 0.0 \\
\hline 3 & 3 & 4 & 0.0015 & 0.0036 & 0.0 & 0.0 \\
\hline 4 & 4 & 5 & 0.0251 & 0.0294 & 0.0 & 0.0 \\
\hline 5 & 5 & 6 & 0.3660 & 0.1864 & 0.8780 & 0.7200 \\
\hline 6 & 6 & 7 & 0.3811 & 0.1941 & 13.4550 & 0.7200 \\
\hline 7 & 7 & 8 & 0.0922 & 0.0470 & 24.8870 & 17.8100 \\
\hline 8 & 8 & 9 & 0.0493 & 0.0251 & 10.0000 & 7.2080 \\
\hline 9 & 9 & 10 & 0.8190 & 0.2707 & 9.3330 & 6.6660 \\
\hline 10 & 10 & 11 & 0.1872 & 0.0619 & 48.5000 & 34.6090 \\
\hline 11 & 11 & 12 & 0.7114 & 0.2351 & 48.5000 & 34.6090 \\
\hline 12 & 12 & 13 & 1.0300 & 0.3400 & 2.7100 & 1.8210 \\
\hline 13 & 13 & 14 & 1.0440 & 0.3450 & 2.7100 & 1.5210 \\
\hline 14 & 14 & 15 & 1.0580 & 0.3496 & 0.0 & 0.0 \\
\hline 15 & 15 & 16 & 0.1966 & 0.0650 & 15.1760 & 10.1980 \\
\hline 16 & 16 & 17 & 0.3744 & 0.1238 & 16.5000 & 11.7750 \\
\hline 17 & 17 & 18 & 0.0047 & 0.0016 & 16.5000 & 11.7750 \\
\hline 18 & 18 & 19 & 0.3276 & 0.1083 & 0.0 & 0.0 \\
\hline 19 & 19 & 20 & 0.2106 & 0.0696 & 0.3160 & 0.2120 \\
\hline 20 & 20 & 21 & 0.3416 & 0.1129 & 37.9830 & 27.1000 \\
\hline 21 & 21 & 22 & 0.0140 & 0.0046 & 1.7620 & 1.1840 \\
\hline 22 & 22 & 23 & 0.1591 & 0.0526 & 0.0 & 0.0 \\
\hline 23 & 23 & 24 & 0.3463 & 0.1145 & 9.3900 & 6.6700 \\
\hline 24 & 24 & 25 & 0.7488 & 0.2475 & 0.0 & 0.0 \\
\hline 25 & 25 & 26 & 0.3089 & 0.1021 & 4.6670 & 3.3300 \\
\hline 26 & 26 & 27 & 0.1732 & 0.0572 & 4.6670 & 3.3300 \\
\hline 27 & 3 & 28 & 0.0044 & 0.0108 & 8.6670 & 6.1850 \\
\hline 28 & 28 & 29 & 0.0640 & 0.1565 & 8.6670 & 6.1850 \\
\hline 29 & 29 & 30 & 0.3978 & 0.1315 & 0.0 & 0.0 \\
\hline 30 & 30 & 31 & 0.0702 & 0.0232 & 0.0 & 0.0 \\
\hline 31 & 31 & 32 & 0.3510 & 0.1160 & 0.0 & 0.0 \\
\hline 32 & 32 & 33 & 0.8390 & 0.2816 & 4.5820 & 3.2600 \\
\hline 33 & 33 & 34 & 1.7080 & 0.5646 & 6.5010 & 5.5490 \\
\hline 34 & 34 & 35 & 1.4740 & 0.4873 & 1.9200 & 1.2900 \\
\hline 35 & 3 & 36 & 0.0044 & 0.0108 & 8.6670 & 6.1850 \\
\hline 36 & 36 & 37 & 0.0640 & 0.1565 & 8.6670 & 6.1850 \\
\hline 37 & 37 & 38 & 0.1053 & 0.1230 & 0.0 & 0.0 \\
\hline 38 & 38 & 39 & 0.0304 & 0.0355 & 8.0 & 5.7090 \\
\hline 39 & 39 & 40 & 0.0018 & 0.0021 & 8.0 & 5.7090 \\
\hline 40 & 40 & 41 & 0.7283 & 0.8509 & 0.3920 & 0.3250 \\
\hline 41 & 41 & 42 & 0.3100 & 0.3623 & 0.0 & 0.0 \\
\hline 42 & 42 & 43 & 0.0410 & 0.0478 & 2.0 & 1.4270 \\
\hline
\end{tabular}


Tabela A5 - Continuação - Dados do sistema de 69 barras

\begin{tabular}{|c|c|c|c|c|c|c|}
\hline Linha & $\begin{array}{l}\text { Barra } \\
\text { inicial }\end{array}$ & $\begin{array}{l}\text { Barra } \\
\text { final }\end{array}$ & $\begin{array}{l}\text { Resistência } \\
\text { da linha } \\
\text { (p.u.) }\end{array}$ & $\begin{array}{c}\text { Reatância } \\
\text { da linha } \\
\text { (p.u.) }\end{array}$ & $\begin{array}{c}\text { Potência ativa } \\
\text { barra final } \\
\text { (KW) }\end{array}$ & $\begin{array}{c}\text { Potência reativa } \\
\text { barra final } \\
\text { (kVAr) }\end{array}$ \\
\hline 43 & 43 & 44 & 0.0092 & 0.0116 & 0.0 & 0.0 \\
\hline 44 & 44 & 45 & 0.1089 & 0.1373 & 3.0760 & 8.7870 \\
\hline 45 & 45 & 46 & 0.0009 & 0.0012 & 3.0760 & 8.7870 \\
\hline 46 & 4 & 47 & 0.0034 & 0.0084 & 0.0 & 0.0 \\
\hline 47 & 47 & 48 & 0.0851 & 0.2083 & 26.3500 & 18.8000 \\
\hline 48 & 48 & 49 & 0.2898 & 0.7091 & 28.2260 & 91.4920 \\
\hline 49 & 49 & 50 & 0.0822 & 0.2011 & 128.226 & 91.4920 \\
\hline 50 & 8 & 51 & 0.0928 & 0.0473 & 13.5120 & 9.4420 \\
\hline 51 & 51 & 52 & 0.3319 & 0.1114 & 1.2020 & 0.8940 \\
\hline 52 & 9 & 53 & 0.1740 & 0.0886 & 1.4490 & 1.1620 \\
\hline 53 & 53 & 54 & 0.2030 & 0.1034 & 8.7870 & 6.3220 \\
\hline 54 & 54 & 55 & 0.2842 & 0.1447 & 8.0000 & 5.7080 \\
\hline 55 & 55 & 56 & 0.2813 & 0.1433 & 0.0 & 0.0 \\
\hline 56 & 56 & 57 & 1.5900 & 0.5337 & 0.0 & 0.0 \\
\hline 57 & 57 & 58 & 0.7837 & 0.2630 & 0.0 & 0.0 \\
\hline 58 & 58 & 59 & 0.3042 & 0.1006 & 0.6670 & 24.0250 \\
\hline 59 & 59 & 60 & 0.3861 & 0.1172 & 0.0 & 0.0 \\
\hline 60 & 60 & 61 & 0.5075 & 0.2585 & 414.667 & 295.9100 \\
\hline 61 & 61 & 62 & 0.9740 & 0.0496 & 10.6670 & 7.6120 \\
\hline 62 & 62 & 63 & 0.1450 & 0.0738 & 0.0 & 0.0 \\
\hline 63 & 63 & 64 & 0.7105 & 0.3619 & 75.6700 & 53.8730 \\
\hline 64 & 64 & 65 & 1.0410 & 0.5302 & 19.6700 & 13.9120 \\
\hline 65 & 11 & 66 & 0.2012 & 0.0611 & 6.0000 & 4.2820 \\
\hline 66 & 66 & 67 & 0.0047 & 0.0014 & 6.0000 & 4.2820 \\
\hline 67 & 12 & 68 & 0.7394 & 0.2444 & 9.3330 & 6.6600 \\
\hline 68 & 68 & 69 & 0.0047 & 0.0016 & 9.3330 & 6.6600 \\
\hline 69 & 11 & 43 & 0.5000 & 0.5000 & & \\
\hline 70 & 13 & 21 & 0.5000 & 0.5000 & & \\
\hline 71 & 15 & 46 & 1.0000 & 1.0000 & & \\
\hline 72 & 50 & 59 & 2.0000 & 2.0000 & & \\
\hline 73 & 27 & 65 & 1.0000 & 1.0000 & & \\
\hline
\end{tabular}




\section{A6 - Sistema de 136 barras}

Tabela A6 - Dados do sistema de 136 barras

\begin{tabular}{|c|c|c|c|c|c|c|}
\hline Linha & $\begin{array}{l}\text { Barra } \\
\text { inicial }\end{array}$ & $\begin{array}{c}\text { Barra } \\
\text { final }\end{array}$ & $\begin{array}{c}\text { Resistência } \\
\text { da linha } \\
(\Omega)\end{array}$ & $\begin{array}{c}\text { Reatância } \\
\text { da linha } \\
(\Omega)\end{array}$ & $\begin{array}{c}\text { Potência ativa } \\
\text { barra final } \\
(\mathrm{KW})\end{array}$ & $\begin{array}{c}\text { Potência reativa } \\
\text { barra final } \\
\text { (kVAr) }\end{array}$ \\
\hline 1 & 1 & 2 & 0.33205 & 0.76653 & 0.000 & 0.000 \\
\hline 2 & 2 & 3 & 0.00188 & 0.00433 & 47.780 & 19.009 \\
\hline 3 & 3 & 4 & 0.22340 & 0.5153 & 42.551 & 16.929 \\
\hline 4 & 4 & 5 & 0.09943 & 0.22953 & 87.022 & 34.622 \\
\hline 5 & 5 & 6 & 0.15571 & 0.35945 & 311.310 & 23.855 \\
\hline 6 & 6 & 7 & 0.16321 & 0.37677 & 148.869 & 59.228 \\
\hline 7 & 7 & 8 & 0.11444 & 0.26417 & 238.672 & 94.956 \\
\hline 8 & 7 & 9 & 0.05675 & 0.05666 & 62.299 & 24.786 \\
\hline 9 & 9 & 10 & 0.52124 & 0.27418 & 124.598 & 49.571 \\
\hline 10 & 9 & 11 & 0.10877 & 0.10860 & 140.175 & 55.768 \\
\hline 11 & 11 & 12 & 0.39803 & 0.20937 & 116.813 & 46.474 \\
\hline 12 & 11 & 13 & 0.91744 & 0.31469 & 249.203 & 99.145 \\
\hline 13 & 11 & 14 & 0.11823 & 0.11805 & 291.447 & 115.592 \\
\hline 14 & 14 & 15 & 0.50228 & 0.26421 & 303.720 & 120.835 \\
\hline 15 & 14 & 16 & 0.05675 & 0.05666 & 215.396 & 85.695 \\
\hline 16 & 16 & 17 & 0.29379 & 0.15454 & 198.586 & 79.007 \\
\hline 17 & 1 & 18 & 0.33205 & 0.76653 & 0.000 & 0.000 \\
\hline 18 & 18 & 19 & 0.00188 & 0.00433 & 0.000 & 0.000 \\
\hline 19 & 19 & 20 & 0.22324 & 0.51535 & 0.000 & 0.000 \\
\hline 20 & 20 & 21 & 0.10881 & 0.25118 & 30.127 & 14.729 \\
\hline 21 & 21 & 22 & 0.71078 & 0.37388 & 230.972 & 112.920 \\
\hline 22 & 21 & 23 & 0.18197 & 0.42008 & 60.256 & 29.459 \\
\hline 23 & 23 & 24 & 0.30326 & 0.15952 & 230.972 & 112.920 \\
\hline 24 & 23 & 25 & 0.02439 & 0.05630 & 120.507 & 58.915 \\
\hline 25 & 25 & 26 & 0.04502 & 0.10394 & 0.000 & 0.000 \\
\hline 26 & 26 & 27 & 0.01876 & 0.04331 & 56.981 & 27.857 \\
\hline 27 & 27 & 28 & 0.11823 & 0.11230 & 364.665 & 178.281 \\
\hline 28 & 28 & 29 & 0.02365 & 0.02361 & 0.000 & 0.000 \\
\hline 29 & 29 & 30 & 0.18954 & 0.09970 & 124.647 & 60.939 \\
\hline 30 & 30 & 31 & 0.39803 & 0.20937 & 56.981 & 27.857 \\
\hline 31 & 29 & 32 & 0.05675 & 0.05666 & 0.000 & 0.000 \\
\hline 32 & 32 & 33 & 0.09477 & 0.04985 & 85.473 & 41.787 \\
\hline 33 & 33 & 34 & 0.41699 & 0.21934 & 0.000 & 0.000 \\
\hline 34 & 34 & 35 & 0.11372 & 0.05982 & 396.735 & 193.960 \\
\hline 35 & 32 & 36 & 0.07566 & 0.07555 & 0.000 & 0.000 \\
\hline 36 & 36 & 37 & 0.36960 & 0.19442 & 181.152 & 88.563 \\
\hline 37 & 37 & 38 & 0.26536 & 0.13958 & 242.172 & 118.395 \\
\hline 38 & 36 & 39 & 0.05675 & 0.05660 & 75.316 & 36.821 \\
\hline 39 & 1 & 40 & 0.33205 & 0.76653 & 0.000 & 0.000 \\
\hline 40 & 40 & 41 & 0.11819 & 0.27283 & 1.254 & 0.531 \\
\hline 41 & 41 & 42 & 296.288 & 101.628 & 6.274 & 2.660 \\
\hline 42 & 41 & 43 & 0.00188 & 0.00433 & 0.000 & 0.000 \\
\hline
\end{tabular}


Tabela A6 - Continuação - Dados do sistema de 136 barras

\begin{tabular}{|c|c|c|c|c|c|c|}
\hline Linha & $\begin{array}{l}\text { Barra } \\
\text { inicial }\end{array}$ & $\begin{array}{c}\text { Barra } \\
\text { final }\end{array}$ & $\begin{array}{c}\text { Resistência } \\
\text { da linha } \\
(\Omega) \\
\end{array}$ & $\begin{array}{c}\text { Reatância } \\
\text { da linha } \\
(\Omega)\end{array}$ & $\begin{array}{c}\text { Potência ativa } \\
\text { barra final } \\
\text { (KW) }\end{array}$ & $\begin{array}{c}\text { Potência reativa } \\
\text { barra final } \\
(\mathrm{kVAr})\end{array}$ \\
\hline 43 & 43 & 44 & 0.06941 & 0.16024 & 117.880 & 49.971 \\
\hline 44 & 44 & 45 & 0.81502 & 0.42872 & 62.668 & 25.566 \\
\hline 45 & 44 & 46 & 0.06378 & 0.14724 & 172.285 & 73.034 \\
\hline 46 & 46 & 47 & 0.13132 & 0.30315 & 458.556 & 194.388 \\
\hline 47 & 47 & 48 & 0.06191 & 0.14291 & 262.962 & 111.473 \\
\hline 48 & 48 & 49 & 0.11444 & 0.26417 & 235.761 & 99.942 \\
\hline 49 & 49 & 50 & 0.28374 & 0.28331 & 0.000 & 0.000 \\
\hline 50 & 50 & 51 & 0.28374 & 0.28331 & 109.215 & 46.298 \\
\hline 51 & 49 & 52 & 0.04502 & 0.10394 & 0.000 & 0.000 \\
\hline 52 & 52 & 53 & 0.02626 & 0.06063 & 72.809 & 30.865 \\
\hline 53 & 53 & 54 & 0.06003 & 0.13858 & 258.473 & 109.570 \\
\hline 54 & 54 & 55 & 0.03002 & 0.06929 & 69.169 & 29.322 \\
\hline 55 & 55 & 56 & 0.02064 & 0.04764 & 21.843 & 9.260 \\
\hline 56 & 53 & 57 & 0.10881 & 0.25118 & 0.000 & 0.000 \\
\hline 57 & 57 & 58 & 0.25588 & 0.13460 & 20.527 & 8.702 \\
\hline 58 & 58 & 59 & 0.41699 & 0.21934 & 150.548 & 63.819 \\
\hline 59 & 59 & 60 & 0.50228 & 0.26421 & 220.687 & 93.552 \\
\hline 60 & 60 & 61 & 0.33170 & 0.17448 & 92.384 & 39.163 \\
\hline 61 & 61 & 62 & 0.20849 & 0.10967 & 0.000 & 0.000 \\
\hline 62 & 48 & 63 & 0.13882 & 0.32047 & 226.693 & 96.098 \\
\hline 63 & 1 & 64 & 0.00750 & 0.01732 & 0.000 & 0.000 \\
\hline 64 & 64 & 65 & 0.27014 & 0.62362 & 294.016 & 116.974 \\
\hline 65 & 65 & 66 & 0.38270 & 0.88346 & 83.015 & 33.028 \\
\hline 66 & 66 & 67 & 0.33018 & 0.76220 & 83.015 & 33.028 \\
\hline 67 & 67 & 68 & 0.32830 & 0.75787 & 103.770 & 41.285 \\
\hline 68 & 68 & 69 & 0.17072 & 0.39409 & 176.408 & 70.184 \\
\hline 69 & 69 & 70 & 0.55914 & 0.29412 & 83.015 & 33.028 \\
\hline 70 & 69 & 71 & 0.05816 & 0.13425 & 217.917 & 86.698 \\
\hline 71 & 71 & 72 & 0.70130 & 0.36890 & 23.294 & 9.267 \\
\hline 72 & 72 & 73 & 102.352 & 0.53839 & 5.075 & 2.019 \\
\hline 73 & 71 & 74 & 0.06754 & 0.15591 & 72.638 & 28.899 \\
\hline 74 & 74 & 75 & 132.352 & 0.45397 & 405.990 & 161.523 \\
\hline 75 & 1 & 76 & 0.01126 & 0.02598 & 0.000 & 0.000 \\
\hline 76 & 76 & 77 & 0.72976 & 168.464 & 100.182 & 42.468 \\
\hline 77 & 77 & 78 & 0.22512 & 0.51968 & 142.523 & 60.417 \\
\hline 78 & 78 & 79 & 0.20824 & 0.48071 & 96.042 & 40.713 \\
\hline 79 & 79 & 80 & 0.04690 & 0.10827 & 300.454 & 127.366 \\
\hline 80 & 80 & 81 & 0.61950 & 0.61857 & 141.238 & 59.873 \\
\hline 81 & 81 & 82 & 0.34049 & 0.33998 & 279.847 & 118.631 \\
\hline 82 & 82 & 83 & 0.56862 & 0.29911 & 87.312 & 37.013 \\
\hline 83 & 82 & 84 & 0.10877 & 0.10860 & 243.849 & 103.371 \\
\hline 84 & 84 & 85 & 0.56862 & 0.29911 & 247.750 & 105.025 \\
\hline 85 & 1 & 86 & 0.01126 & 0.02598 & 0.000 & 0.000 \\
\hline
\end{tabular}


Tabela A6 - Continuação - Dados do sistema de 136 barras

\begin{tabular}{|c|c|c|c|c|c|c|}
\hline Linha & $\begin{array}{l}\text { Barra } \\
\text { inicial }\end{array}$ & $\begin{array}{c}\text { Barra } \\
\text { final }\end{array}$ & $\begin{array}{c}\text { Resistência } \\
\text { da linha } \\
(\Omega)\end{array}$ & $\begin{array}{c}\text { Reatância } \\
\text { da linha } \\
(\Omega)\end{array}$ & $\begin{array}{c}\text { Potência ativa } \\
\text { barra final } \\
\text { (KW) }\end{array}$ & $\begin{array}{c}\text { Potência reativa } \\
\text { barra final } \\
\text { (kVAr) }\end{array}$ \\
\hline 86 & 86 & 87 & 0.41835 & 0.96575 & 89.878 & 38.101 \\
\hline 87 & 87 & 88 & 0.10499 & 0.13641 & 1137.28 & 482.108 \\
\hline 88 & 87 & 89 & 0.43898 & 101.338 & 458.339 & 194.296 \\
\hline 89 & 89 & 90 & 0.07520 & 0.12579 & 385.197 & 163.290 \\
\hline 90 & 90 & 91 & 0.07692 & 0.17756 & 0.000 & 0.000 \\
\hline 91 & 91 & 92 & 0.33205 & 0.76653 & 79.608 & 33.747 \\
\hline 92 & 92 & 93 & 0.08442 & 0.19488 & 87.312 & 37.013 \\
\hline 93 & 93 & 94 & 0.13320 & 0.30748 & 0.000 & 0.000 \\
\hline 94 & 94 & 95 & 0.29320 & 0.29276 & 74.001 & 31.370 \\
\hline 95 & 95 & 96 & 0.21753 & 0.21721 & 232.050 & 98.369 \\
\hline 96 & 96 & 97 & 0.26482 & 0.26443 & 141.819 & 60.119 \\
\hline 97 & 94 & 98 & 0.10318 & 0.23819 & 0.000 & 0.000 \\
\hline 98 & 98 & 99 & 0.13507 & 0.31181 & 76.449 & 32.408 \\
\hline 99 & 1 & 100 & 0.00938 & 0.02165 & 0.000 & 0.000 \\
\hline 100 & 100 & 101 & 0.16884 & 0.38976 & 51.322 & 21.756 \\
\hline 101 & 101 & 102 & 0.11819 & 0.27283 & 59.874 & 25.381 \\
\hline 102 & 102 & 103 & 228.608 & 0.78414 & 9.065 & 3.843 \\
\hline 103 & 102 & 104 & 0.45587 & 105.236 & 2.092 & 0.887 \\
\hline 104 & 104 & 105 & 0.69600 & 160.669 & 16.735 & 7.094 \\
\hline 105 & 105 & 106 & 0.45774 & 105.669 & 1.506 .522 & 638.634 \\
\hline 106 & 106 & 107 & 0.20298 & 0.26373 & 313.023 & 132.694 \\
\hline 107 & 107 & 108 & 0.21348 & 0.27737 & 79.831 & 33.842 \\
\hline 108 & 108 & 109 & 0.54967 & 0.28914 & 51.322 & 21.756 \\
\hline 109 & 109 & 110 & 0.54019 & 0.28415 & 0.000 & 0.000 \\
\hline 110 & 108 & 111 & 0.04550 & 0.05911 & 202.435 & 85.815 \\
\hline 111 & 111 & 112 & 0.47385 & 0.24926 & 60.823 & 25.874 \\
\hline 112 & 112 & 113 & 0.86241 & 0.45364 & 45.618 & 19.338 \\
\hline 113 & 113 & 114 & 0.56862 & 0.29911 & 0.000 & 0.000 \\
\hline 114 & 109 & 115 & 0.77711 & 0.40878 & 157.070 & 66.584 \\
\hline 115 & 115 & 116 & 108.038 & 0.56830 & 0.000 & 0.000 \\
\hline 116 & 116 & 117 & 106.633 & 0.57827 & 250.148 & 106.041 \\
\hline 117 & 117 & 118 & 0.47385 & 0.24926 & 0.000 & 0.000 \\
\hline 118 & 105 & 119 & 0.32267 & 0.74488 & 68.809 & 28.593 \\
\hline 119 & 119 & 120 & 0.14633 & 0.33779 & 32.072 & 13.596 \\
\hline 120 & 120 & 121 & 0.12382 & 0.28583 & 61.084 & 25.894 \\
\hline 121 & 1 & 122 & 0.01126 & 0.02598 & 0.000 & 0.000 \\
\hline 122 & 122 & 123 & 0.64910 & 149.842 & 94.622 & 46.260 \\
\hline 123 & 123 & 124 & 0.04502 & 0.10394 & 49.858 & 24.375 \\
\hline 124 & 124 & 125 & 0.52640 & 0.18056 & 123.164 & 60.214 \\
\hline 125 & 124 & 126 & 0.02064 & 0.04764 & 78.350 & 38.304 \\
\hline 126 & 126 & 127 & 0.53071 & 0.27917 & 145.575 & 71.121 \\
\hline 127 & 126 & 128 & 0.09755 & 0.22520 & 21.369 & 10.447 \\
\hline 128 & 128 & 129 & 0.11819 & 0.27283 & 74.789 & 36.564 \\
\hline
\end{tabular}


Tabela A6 - Continuação - Dados do sistema de 136 barras

\begin{tabular}{ccccccc}
\hline Linha & $\begin{array}{c}\text { Barra } \\
\text { inicial }\end{array}$ & $\begin{array}{c}\text { Barra } \\
\text { final }\end{array}$ & $\begin{array}{c}\text { Resistência } \\
\text { da linha } \\
(\boldsymbol{\Omega})\end{array}$ & $\begin{array}{c}\text { Reatância } \\
\text { da linha } \\
(\boldsymbol{\Omega})\end{array}$ & $\begin{array}{c}\text { Potência ativa } \\
\text { barra final } \\
(\mathbf{K W})\end{array}$ & $\begin{array}{c}\text { Potência reativa } \\
\text { barra final } \\
\text { (kVAr) }\end{array}$ \\
\hline 129 & 128 & 130 & 0.13882 & 0.32047 & 227.926 & 11.431 \\
130 & 130 & 131 & 0.04315 & 0.09961 & 35.614 & 17.411 \\
131 & 131 & 132 & 0.09192 & 0.21220 & 249.295 & 121.877 \\
132 & 132 & 133 & 0.16134 & 0.37244 & 316.722 & 154.842 \\
133 & 133 & 134 & 0.37832 & 0.37775 & 333.817 & 163.199 \\
134 & 134 & 135 & 0.39724 & 0.39664 & 249.295 & 121.877 \\
135 & 135 & 136 & 0.29320 & 0.29276 & 0.000 & \\
136 & 8 & 74 & 0.13132 & 0.30315 & & \\
137 & 10 & 25 & 0.26536 & 0.13958 & & \\
138 & 16 & 84 & 0.14187 & 0.14166 & & \\
139 & 39 & 136 & 0.08512 & 0.08499 & & \\
140 & 26 & 52 & 0.04502 & 0.10394 & & \\
141 & 51 & 97 & 0.14187 & 0.14166 & & \\
142 & 56 & 99 & 0.14187 & 0.14166 & & \\
143 & 63 & 121 & 0.03940 & 0.09094 & & \\
144 & 67 & 80 & 0.12944 & 0.29882 & & \\
145 & 80 & 132 & 0.01688 & 0.03898 & & \\
146 & 85 & 136 & 0.33170 & 0.17448 & & \\
147 & 92 & 105 & 0.14187 & 0.17166 & & \\
148 & 91 & 130 & 0.07692 & 0.17756 & & \\
149 & 91 & 104 & 0.07692 & 0.17756 & & \\
150 & 93 & 105 & 0.07692 & 0.17756 & & \\
151 & 93 & 133 & 0.07692 & 0.17756 & & \\
152 & 97 & 121 & 0.26482 & 0.26443 & & \\
153 & 111 & 48 & 0.49696 & 0.64567 & & \\
154 & 127 & 77 & 0.17059 & 0.08973 & & \\
155 & 129 & 78 & 0.05253 & 0.12126 & & \\
156 & 136 & 99 & 0.29320 & 0.29276 & & \\
\hline & & & & & \\
\end{tabular}

